


\section{A Reef Manager's Guide to Fostering Community Stewardship}
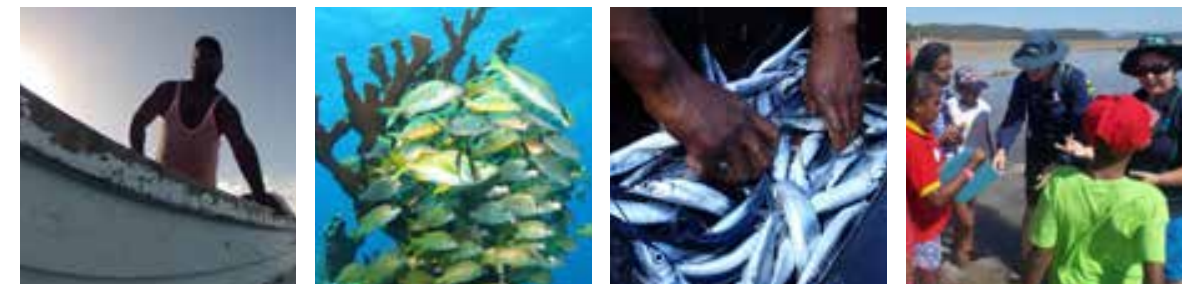

HELPING PEOPLE WORK TOGETHER TO IMPROVE THE OUTLOOK FOR CORAL REEFS AND COMMUNITIES

Coordinating authors: Paul Marshall, Anna Lyons, Carolyn Luder, Jeffrey Maynard, Roger Beeden

Contributing authors: Karen Vohland, Sarah Strutt, Randall Owens, Christabelle Andrews, Megan Connell, Jeremy Goldberg, Nadine Marshall, Adam Smith, Ameer Abdulla 

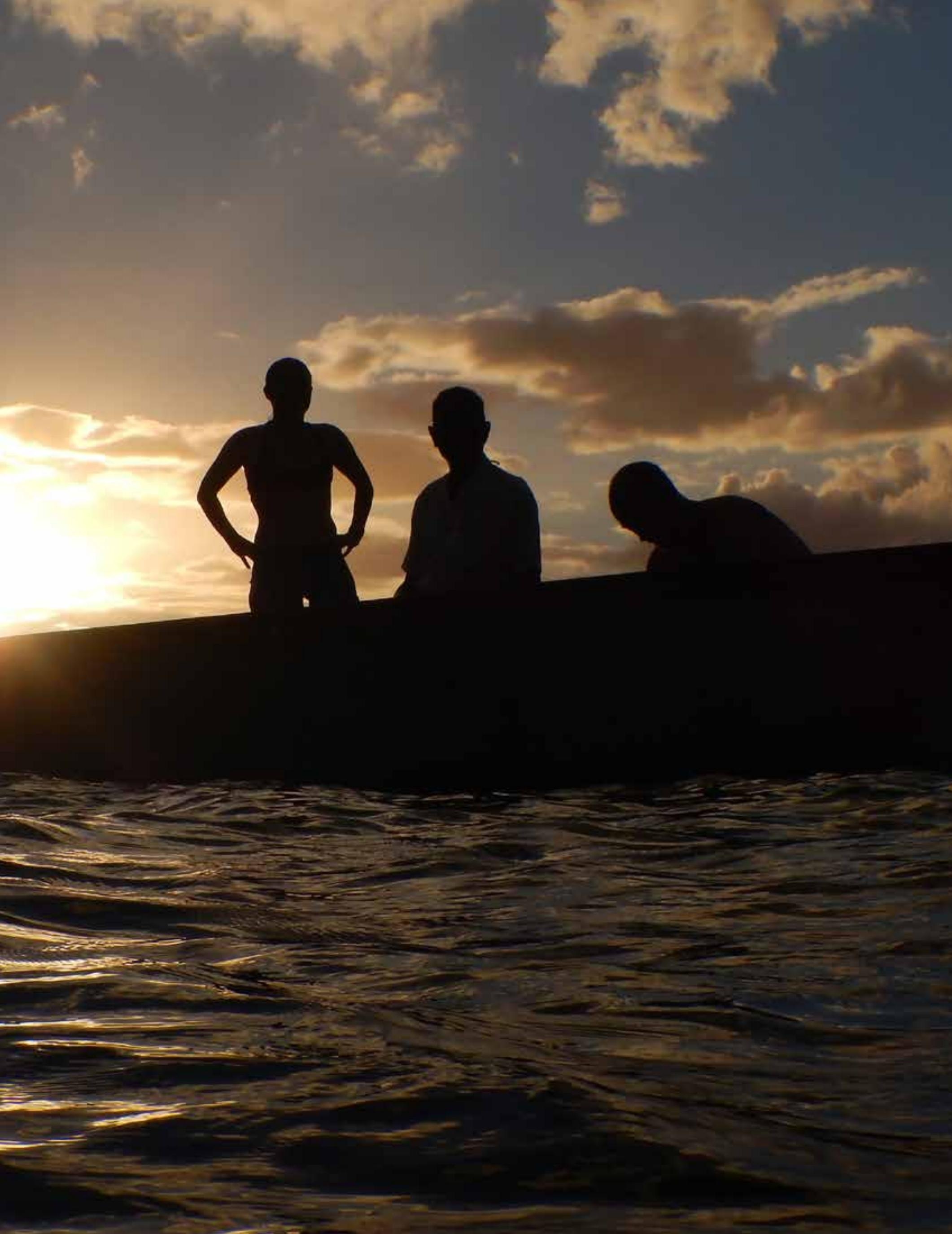
(C) 2015 International Union for Conservation of Nature and Natural Resources

Published by IUCN, Gland, Switzerland, Cambridge, UK, and Arlington, USA

This publication is licensed under a Creative Commons Attribution 4.0 International License with the exception of content supplied by third parties, logos, the Commonwealth Coat of Arms and any material protected by a trademark.

(c) (i) Creative Commons Attribution 4.0 International Licence is a standard form licence agreement that allows you to copy, distribute, transmit and adapt this publication provided you attribute the work. A summary of the licence terms is available from creativecommons.org/licenses/by/4.0. The full licence terms are available from creativecommons.org/licenses/by/4.0/legalcode.

\section{This publication should be cited as:}

Marshall, P.A., Dowd, A.M., Luder, C., Maynard, J.A., Beeden, R. (2015). A Reef Manager's Guide to Fostering Community Stewardship. Gland, Switzerland: IUCN.

\section{Cataloguing-in-Publication entry}

A reef manager's guide to fostering community stewardship / P.A. Marshall et al.

ISBN (ebook): 978-2-8317-1771-5

DOI (ebook): http://dx.doi.org/10.2305/IUCN.CH.2016.01e.en

Coral reef management-Handbooks, manuals, etc.

Coral reef management-Citizen participation.

Great Barrier Reef Marine Park (Qld.)

Caribbean Area.

Marshall, P.A.

Dowd, A.M.

Luder, C.

Maynard, J.A.

Beeden, R.

Comments and inquiries on this document should be addressed to:

Reef Ecologic

14 Cleveland Terrace

North Ward, Townsville

Queensland Australia 4810

Contact: reefecologic@gmail.com

Available online at www.reefecologic.org and www.climateandreefs.org, www.iucn.org and www.gbrmpa.gov.au.

Coordinating authors: Paul Marshall, Anna Dowd, Carolyn Luder, Jeffrey Maynard, Roger Beeden

Contributing authors: Karen Vohland, Sarah Strutt, Randall Owens, Christabelle Andrews, Megan Connell, Jeremy Goldberg, Nadine Marshall, Adam Smith, Ameer Abdulla

Production: DieterTracey (dieter@sciencegraphics.com.au)

The publication was produced through a partnership between the Australian Department of Foreign Affairs and Trade (Caribbean Development Assistance Program), US National Fish and Wildlife Foundation (Coral Reef Conservation Fund), IUCN International Union for Conservation of Nature, Great Barrier Reef Marine Park Authority, US National Oceanic and Atmospheric Administration, and University of Queensland.

Project coordination and implementation by Reef Ecologic (www.reefecologic.org) and SymbioSeas (www.symbioseas.org).

This publication is a contribution of the IUCN Marine Biodiversity and Conservation Science Group.

The designation of geographical entities in this book, and the presentation of the material, do not imply the expression of any opinion whatsoever on the part of IUCN [** or other participating organizations] concerning the legal status of any country, territory, or area, or of its authorities, or concerning the delimitation of its frontiers or boundaries.

The views expressed in this publication do not necessarily reflect those of IUCN [** or other participating organizations].

Photograph credits: iStock.com/Tammy616 (front cover); James Byrne (first inset on front cover); Mito Paz/Marine Photobank (second inset on front cover); Great Barrier Reef Marine Park Authority (fourth inset on front cover; second and third inset on back cover; pages 4, 9, 10, 11, 16, 29, 32, 36, 40, 41, 50); Peter McGinnity (facing page i); XL Catlin Seaview Survey (banner on pages 7, 9) Jeffrey Maynard (banner in Part A; page 43); Christobel Andrews (page 19, 54, 55); Roger Beeden (page 21); Anna Dowd (page 26). All other images by Paul Marshall. 


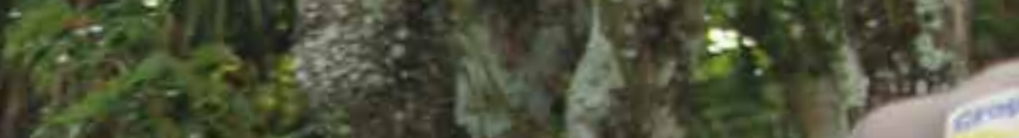



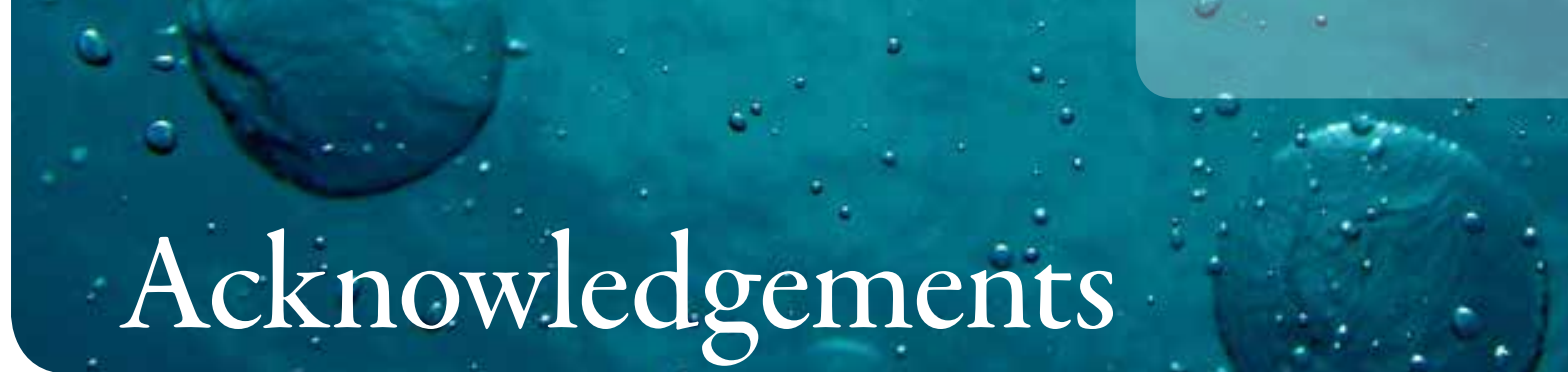

This guide has been a labour of love driven by our dedication to helping the world's coral reefs. Like all such endeavours, it has only been possible thanks to the generosity and sense of shared purpose among a much larger group of experts. We would like to thank, firstly, the contributing authors who provided text and substantive technical review. Our authoring team represent some of the most knowledgeable and experienced people working on coral reef stewardship programs today.

The inspiration for this guide, and many of the ideas and experiences within, come from our involvement and exposure to the Reef Guardians program of the Great Barrier Reef Marine Park Authority. The authors and all of those who benefit from this Guide owe a great debt to the founders of the GBRMPA Reef Guardians program, the thousands of energetic and dedicated Reef Guardian Program participants, and the Reef Guardian team members who have nurtured their vision into a model for reef stewardship programs worldwide. At the time of writing, the GBRMPA Reef Guardians team included: Roger Beeden, Vicki Bonanno, Bonnie Boyce, Megan Connell, Julie Cook, Jen Dryden, Katie Finch, Sandra Garvin, Samantha Gibbs, Angela Greer, Chris Jones, Phil Laycock, Doon McColl, Fiona Merida, Randall Owens, Rhianna Rickard, Nicole Robbins, Renee Rosse, Sarah Strutt, Carolyn Thompson, Antoinette Woods and Margaret Johnson.

We would also like to acknowledge the instrumental role of the Australian High Commissioner to the Caribbean region during the production of this publication, Mr Ross Tysoe. His vision and support has enabled us to work with countries in the Caribbean to adapt and implement reef stewardship programs. Ms Lucrecia Birch and Mr Brian Borgonha, also from the Australian Department of Foreign Affairs and Trade, have played instrumental roles in administering and planning the projects in the Caribbean. Their help and the generous funding from DFAT has greatly expanded the community of coral reef managers running stewardship programs over the last five years.

Our friends and colleagues in Grenada, Belize, Jamaica, St Vincent \& the Grenadines, Indonesia and the Maldives have helped shape our ideas and ambitions, provided inspiration and kept us honest and relevant as we have shaped our collective experiences into guidance for coral reef managers everywhere. A special thanks goes to Roland Baldeo and Christabelle Andrews from Grenada who had the vision and energy to lead the first Reef Guardians pilot program outside Australia.

This guide is a contribution of the Reef Resilience Network, which is a partnership of leading organisations and individuals dedicated to helping resource managers share ideas, experiences, and expertise to effectively manage our coral reefs and reef fisheries. The ten-year legacy of this effort underpins the guide, which reflects the ongoing commitment of key partners including The Nature Conservancy, NOAA's Coral Reef Conservation Program, International Union for Conservation of Nature and the Great Barrier Reef Marine Park Authority. Reef Ecologic and SymbioSeas are more recent institutional partners that have provided the organizational platform for this latest contribution to the Network.

Finally, we would like to express our gratitude to the US National Fish and Wildlife Foundation (Coral Reef Conservation Fund), AusAID and IUCN for funding the production of this guide; without their support this guide would not exist.

Yours in people-powered coral reef conservation,

Paul, Anna, Carolyn, Jeffrey, Roger. 


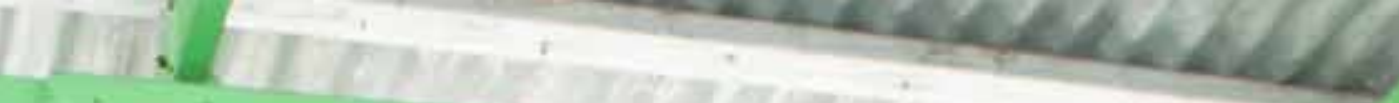

2.46

The

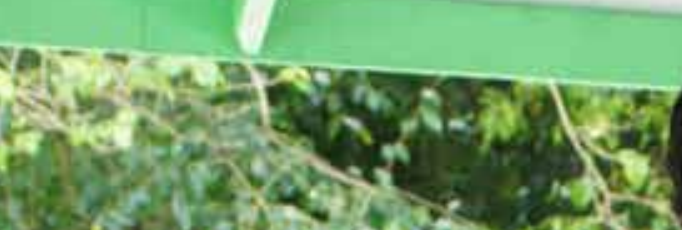
$(2)^{2}+2 x+2$

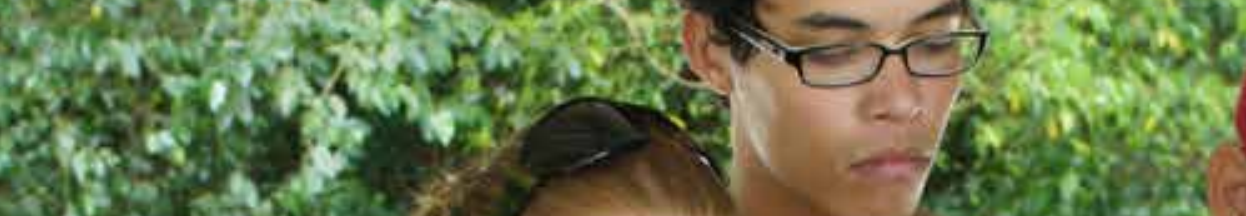

ix 250
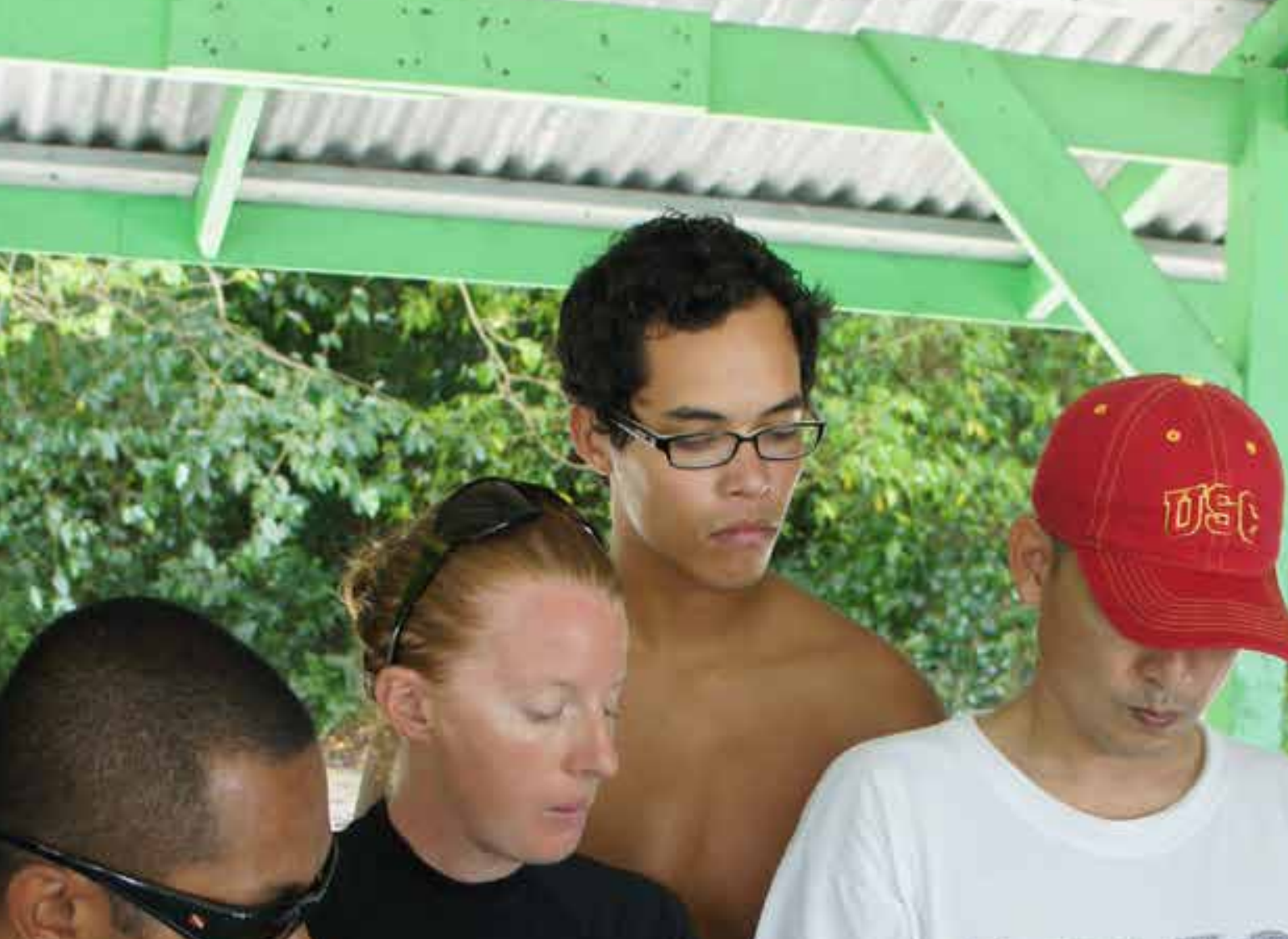
x. E

2. 7 . (tive

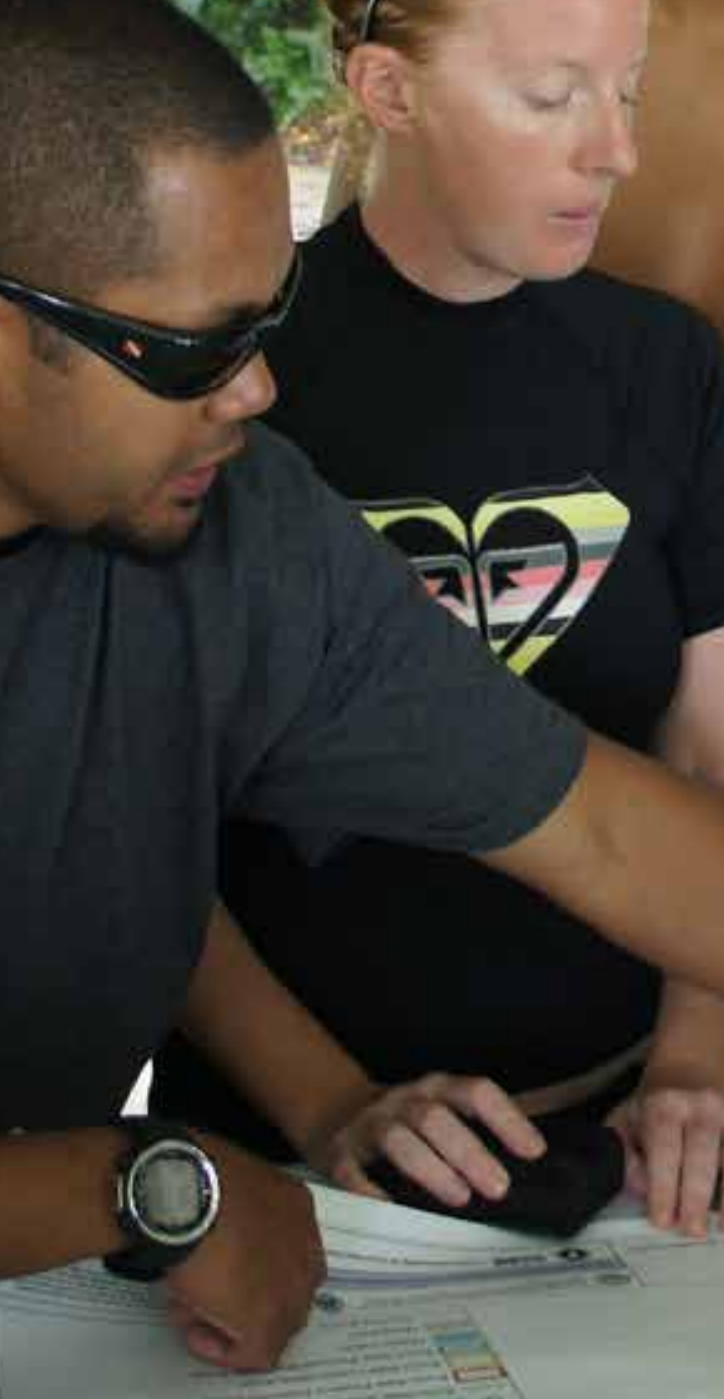

1
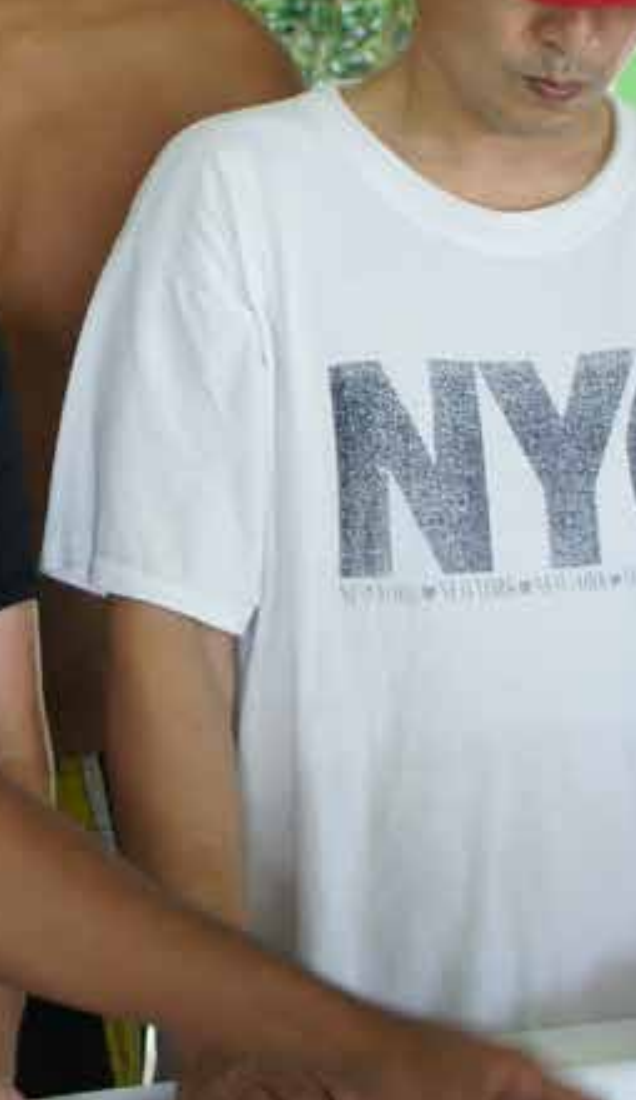

(⿹丁口)

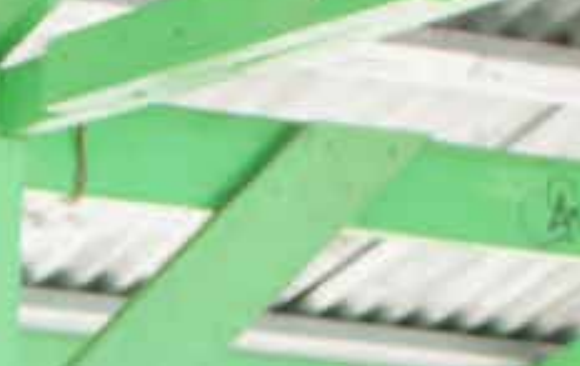




\section{Contents}

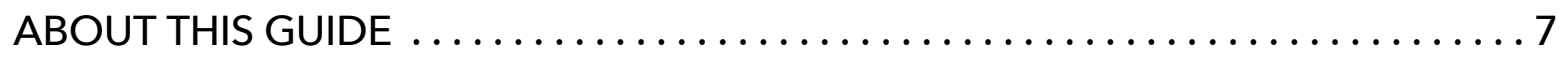

PART A: A FRAMEWORK FOR STEWARDSHIP $\ldots \ldots \ldots \ldots \ldots \ldots \ldots \ldots \ldots \ldots$

1. The logic behind stewardship recognition programs $\ldots \ldots \ldots \ldots \ldots \ldots \ldots$

2. Design considerations: building blocks of a program . . . . . . . . . . . . 14

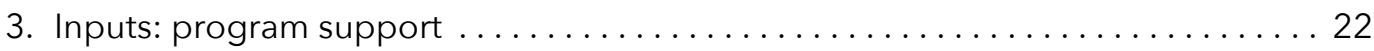

4. Stewardship capacity: attitudes, knowledge and skills ................. 23

5. Indicators of success . . . . . . . . . . . . . . . . . . . . . . . . . 24

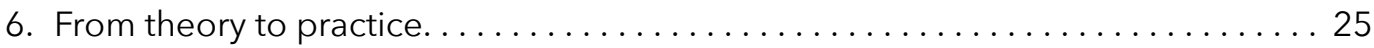

PART B: STEP-BY-STEP GUIDE. . . . . . . . . . . . . . . . . . . 27

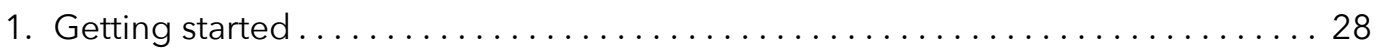

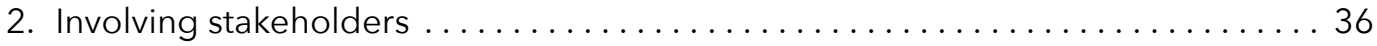

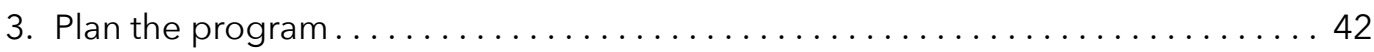

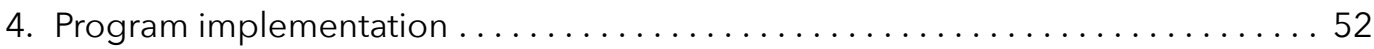

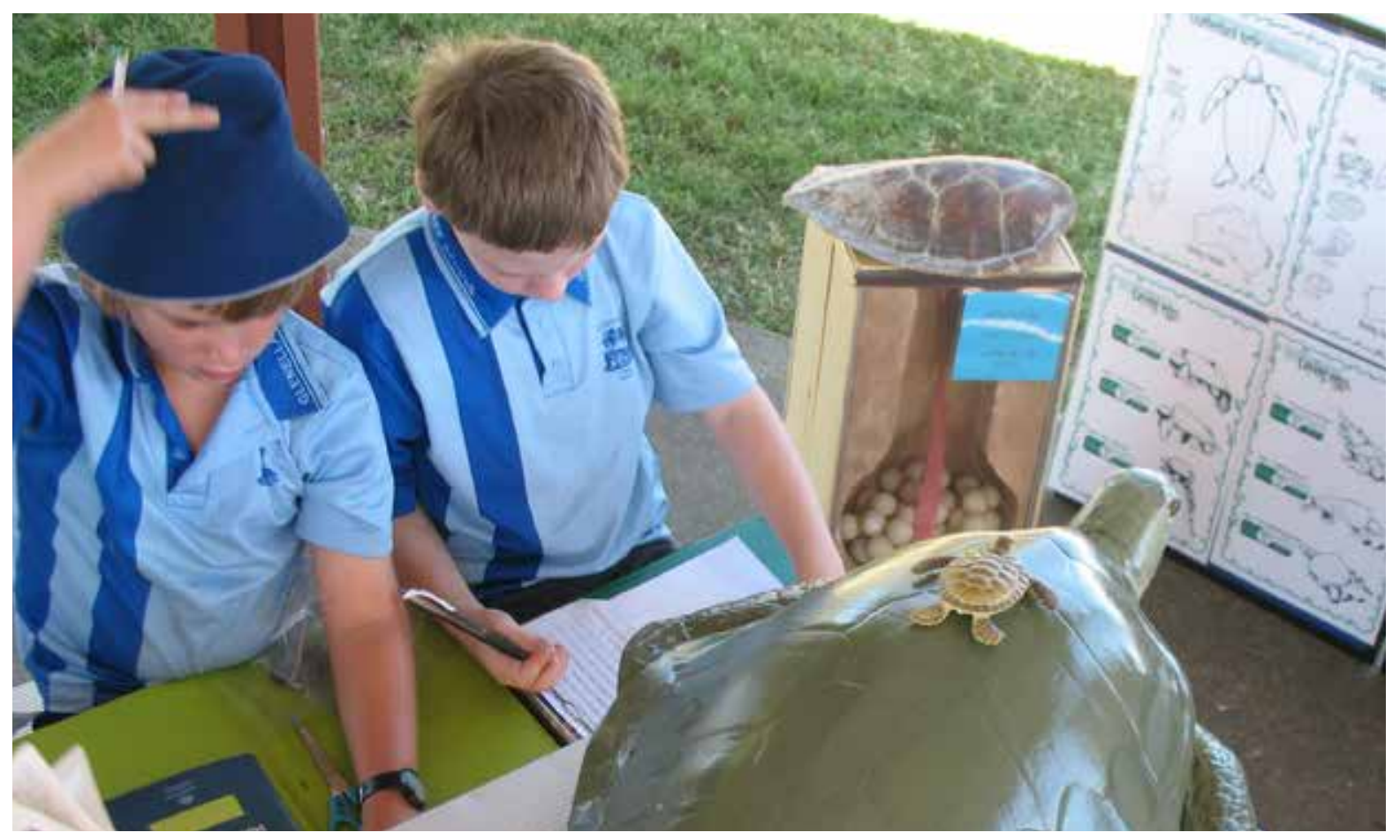




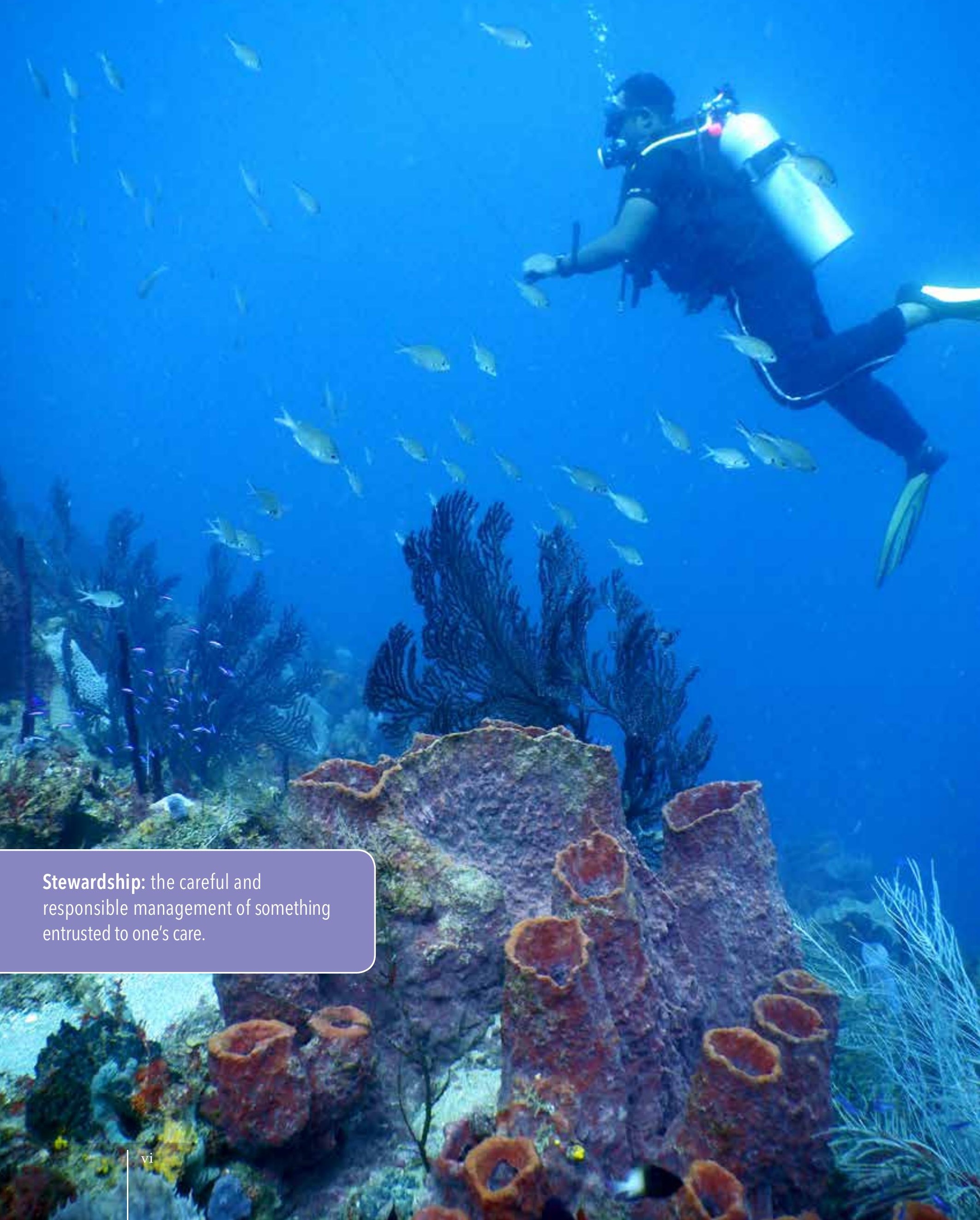




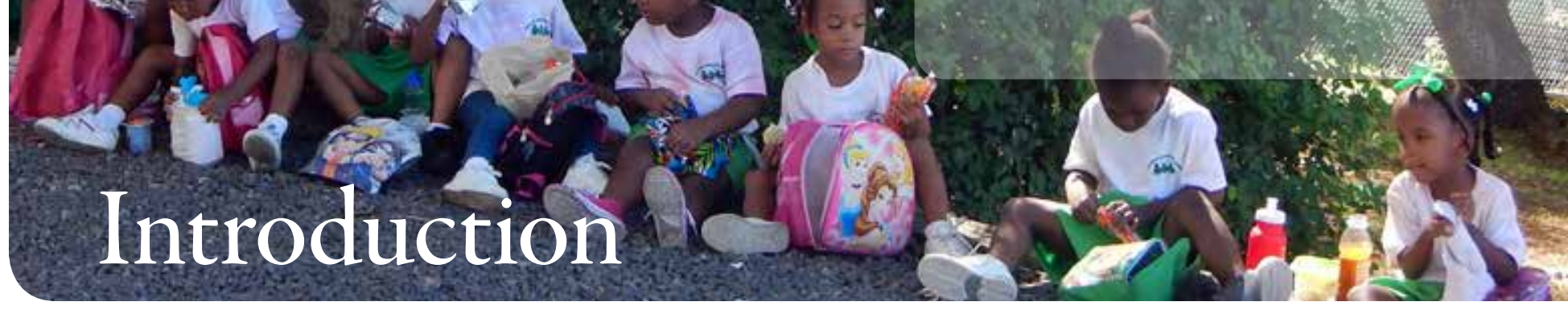

\section{Why reef stewardship, and why a guide?}

This guide has been written to inspire and empower reef managers and community leaders to develop reef stewardship programs. Stewardship is a way of empowering local communities to take a more active role in sustaining the natural resources on which they depend. Stewardship programs create a framework for greater participation and more organised allocation of resources, resulting in stronger alignment between community activities and government (or NGO) initiatives and, ultimately, better outcomes for coral reefs and communities. We hope that by enabling more formal stewardship programs this guide can inspire a community of practice that will accelerate learning and contribute to the global movement toward peoplepowered conservation of coral reefs.

\section{Stewardship recognises that people and coral reefs are connected}

Coral reef ecosystems support an estimated 25 per cent of all marine life. As well as providing habitat for an amazing diversity of animals and plants, coral reefs are the source of income and wellbeing for millions of people living in coastal communities. Just as reefs rely on a healthy ecosystem to survive and thrive, human society also benefits from healthy marine and coastal environments.

Around the world, indigenous peoples, coastal communities, industry groups, government agencies and nongovernmental organisations are working together to help improve the health and resilience of coral reefs. However, despite decades of top-down investment in protection and restoration, the global decline of coral reefs is showing little sign of slowing. Continued degradation of coral reefs is impacting biodiversity and habitat quality, with increasingly serious consequences for livelihoods, economic growth, social development and cultural integrity. Greater effort, innovative ideas and fresh energy are required if we are to avoid the coral reef catastrophe predicted by experts.

\section{Coral reefs need our help}

Fortunately, governments and communities around the world are recognising the urgent need to better manage and protect coral reefs. Marine protected areas, zoning, management of fisheries, and Ridge-to-Reef programs are all helping to improve the outlook for coral reefs and communities that depend on them. However, with billions of people living in low-lying coastal areas, this intensive human activity is reducing the natural resilience of coral reefs and making them more vulnerable to global pressures like climate change.

Conventional management approaches are necessary, but are not sufficient by themselves to address the decline of coral reef ecosystems. People living in coastal areas must be empowered to take a greater role in the responsible management of their local reefs. More than ever, coral reefs need community stewardship if they are to continue to provide economic, cultural and social benefits to humanity.

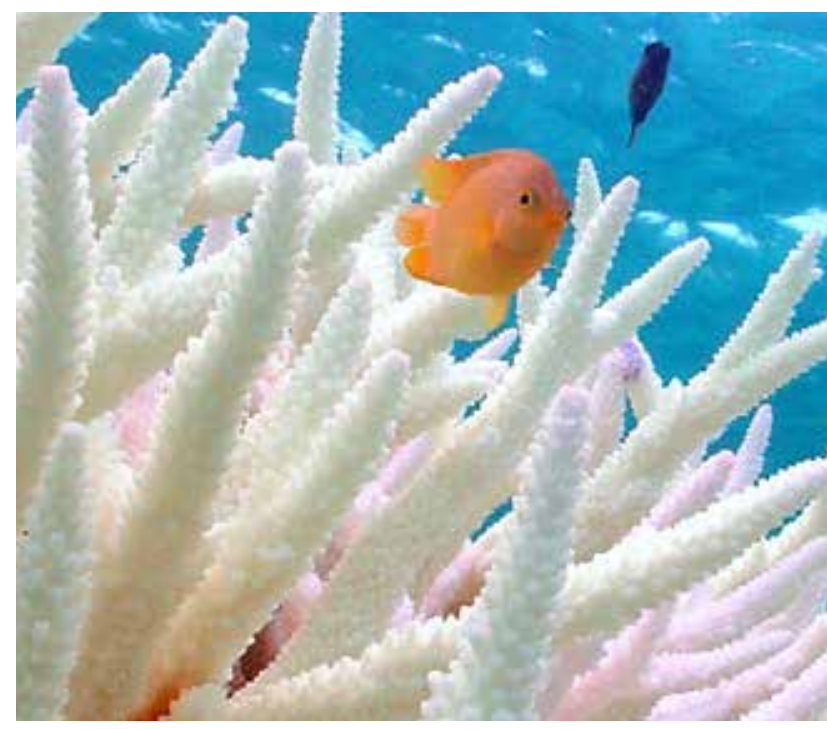

75 per cent of the world's coral reefs are currently threatened by a combination of local and global pressures.

(Reefs at Risk Revisited, WRI) 


\section{Changing behaviour: the foundations of stewardship programs}

At the heart of a stewardship program is the desire to encourage community members to adopt and sustain reef-friendly behaviours. Conservation initiatives are increasingly using behavioural theory and social-based marketing tools to better understand and influence behaviour. Below we put the spotlight on a useful theoretical framework for behaviour change, and an effective campaign using social-based marketing to influence behaviours for conservation outcomes.

The Theory of Planned Behaviour is a useful starting point toward a deeper understanding of how attitudes, social norms and perceptions of personal agency combine to promote the adoption of behaviours. The diagram below summarises these attributes and how they operate cognitively to influence behaviour choices. For an overview of how behavioural research can inform conservation, see the report by Akerlof and Kennedy 2013: http://www.climatechangecommunication.org/sites/default/files/reports/NudgesforConservation_GMU_061013.pdf.

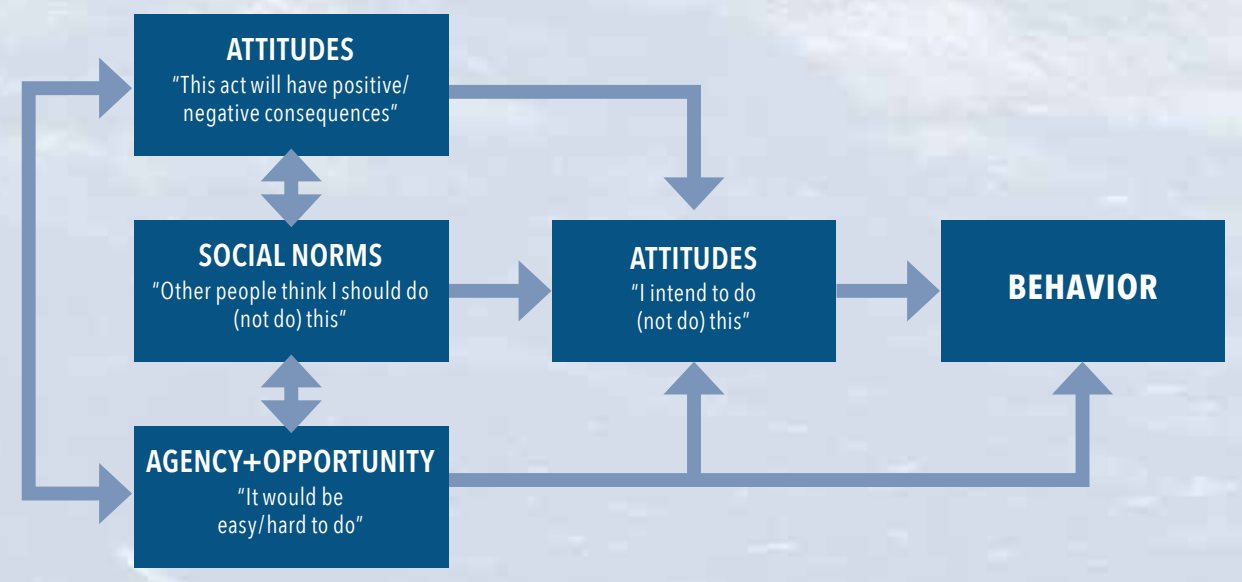

The organisation Rare has a central mission to "inspire change so people and nature thrive". Their longrunning and very successful Pride campaign uses social-based marketing approaches to not just raise awareness or educate people about an issue, but to actually catalyse action and change social norms across society. The diagram below illustrates the Theory of Change framework that underpins Rare's behaviourchange campaigns. For more information: www.rare.org/pride.

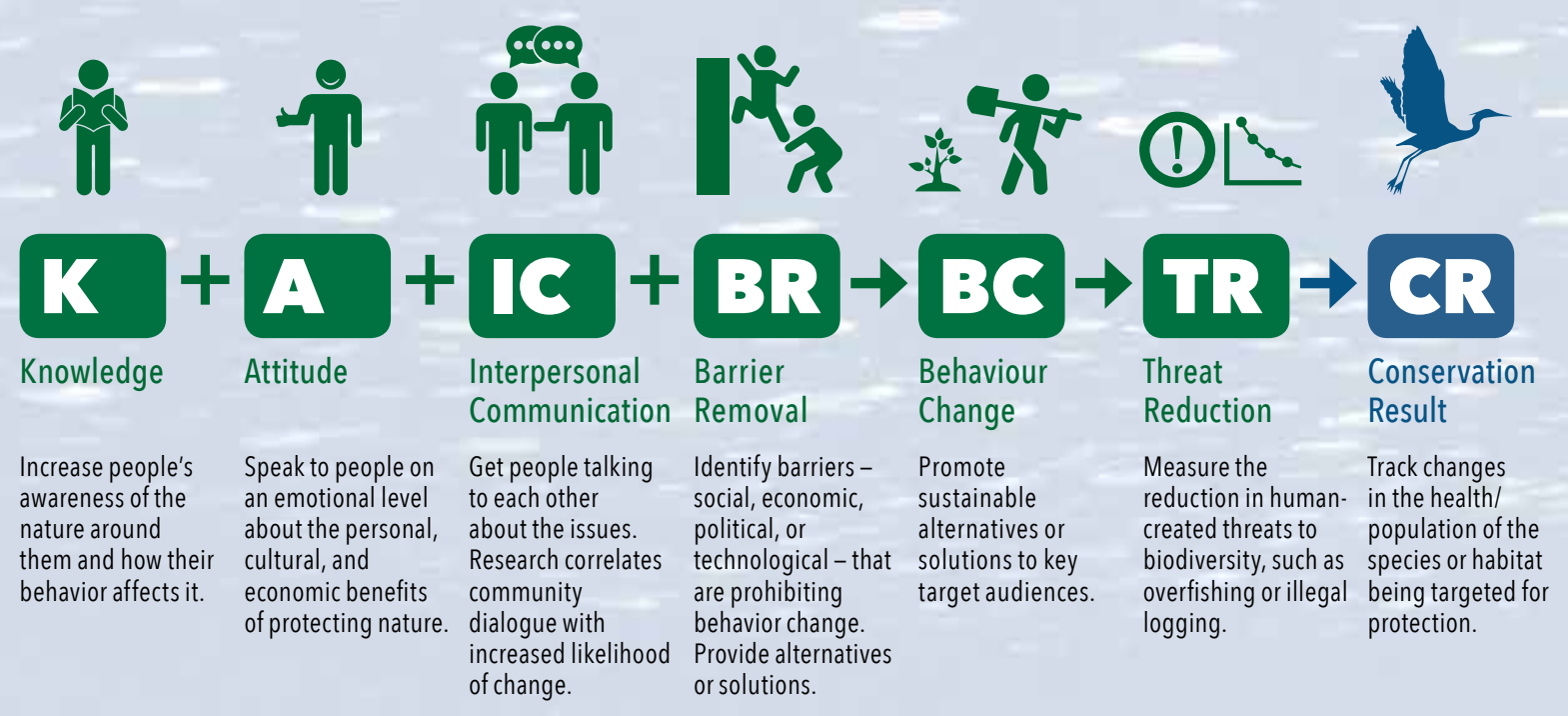




\section{Stewardship is about action}

Stewardship programs are not a cure-all for the ills that are confronting coral reefs, but in many places around the world they could be the key to unlocking the people power needed to transform the outlook for local coral reefs. Ecosystem stewardship encourages and empowers citizens to actively respond to change and to shape the future of coral reefs through personal and collective action. Stewardship programs incorporate education and awareness activities, but their ultimate goal is to reinforce and increase behaviours that can protect reef ecosystems through conservation and sustainable practices. Behavioural change theory and social-based marketing tools are increasingly being used to help program managers ensure that stewardship programs deliver real-world outcomes through changing attitudes and behaviours (see text box).

\section{Stewardship programs are proving successful}

Stewardship is not new. In many places, such as Australia and islands of the Pacific, there has been a long tradition of custodianship, where communities take responsibility for the sustainable use and management of their local reefs ${ }^{1}$. Other locations, including nations in the Caribbean, are leading a community-centric revolution in natural resource management where governments are actively sharing power and responsibility between the managers and resource users in formal co-management arrangements ${ }^{2}$.

Building on these experiences, stewardship initiatives are increasingly being recognised in reef management programs and strategies as vital to the future of coral reef ecosystems and the communities that depend upon them (e.g. Reef 2050 Plan for the Great Barrier Reef ${ }^{3}$ ). These initiatives are gaining momentum and attracting attention as a way for communities to share in the efforts and the responsibility of managing coral reefs. Stewardship creates opportunities for people, even those living far inland from the coast, to play a role in everyday decisions that can have downstream effects on coral reefs. Stewardship programs also create an opportunity to recognise and celebrate communities and individuals who are already making significant contributions to the health of coral reefs.

\section{Stewardship programs contribute to management outcomes}

Reef stewardship programs aim to provide a more formal structure for the broader community to engage in the protection and management of their coral reefs. The growing importance of formal stewardship programs in coral reef management reflects a broader trend toward greater community involvement in natural resource management often referred to as co-management (Figure 1).

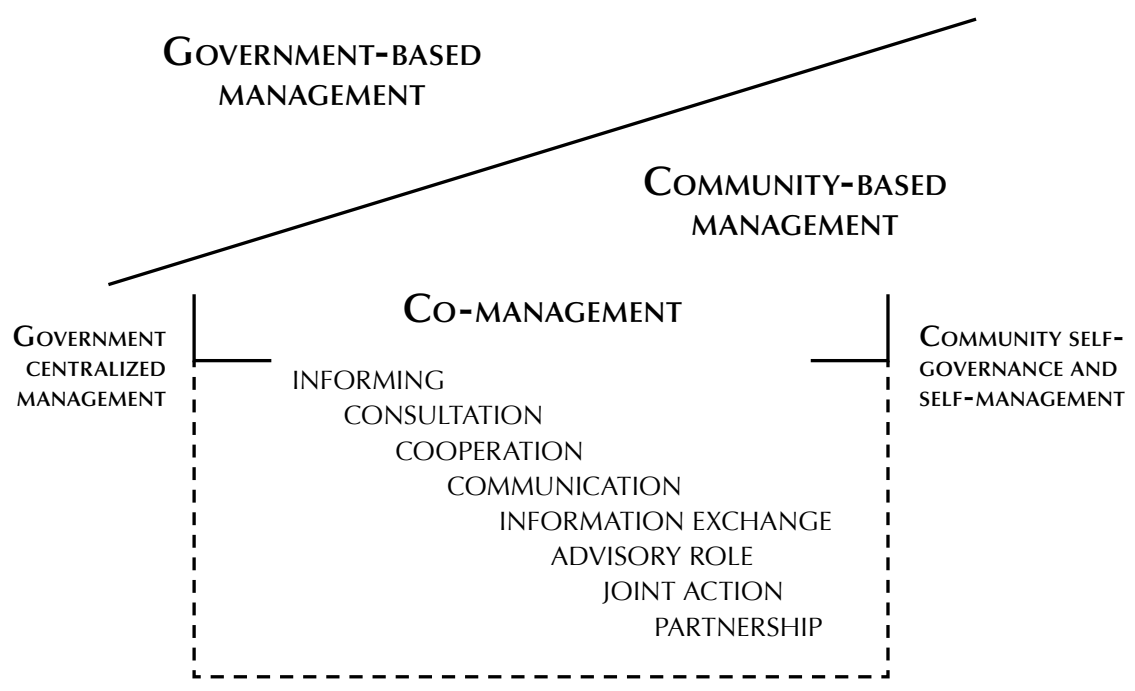

Figure 1: Stewardship is a way of empowering communities and resource users to share in the responsibility and efforts of coral reef management, delivering many of the benefits recognised in co-management approaches. 
Stewardship programs engage participants who directly depend on marine areas (users) as well as those whose actions might affect the reef through indirect or downstream connections. They aim to change attitudes and behaviours by raising community awareness of the benefits provided by reefs as well as pressures affecting them. They can also lead to increased compliance with regulations and inspire and facilitate local actions to build reef resilience. Stewardship programs build trust and communication between managers and resource users, and lay the foundation for managers to capture many of the benefits of stewardship and other co-management approaches.

\section{Benefits of Stewardship ${ }^{4}$}

Resource management functions that can be enhanced through stewardship and co-management:

\section{$\checkmark$ Gathering of data}

$\checkmark$ Making logistical decisions, such as who can harvest and when

$\checkmark$ Allocation decisions

$\checkmark$ Protection of the resource from environmental damage

\section{$\checkmark$ Enforcement of regulations}

$\checkmark$ Enhancement of long-term planning

$\checkmark$ More inclusive decision-making

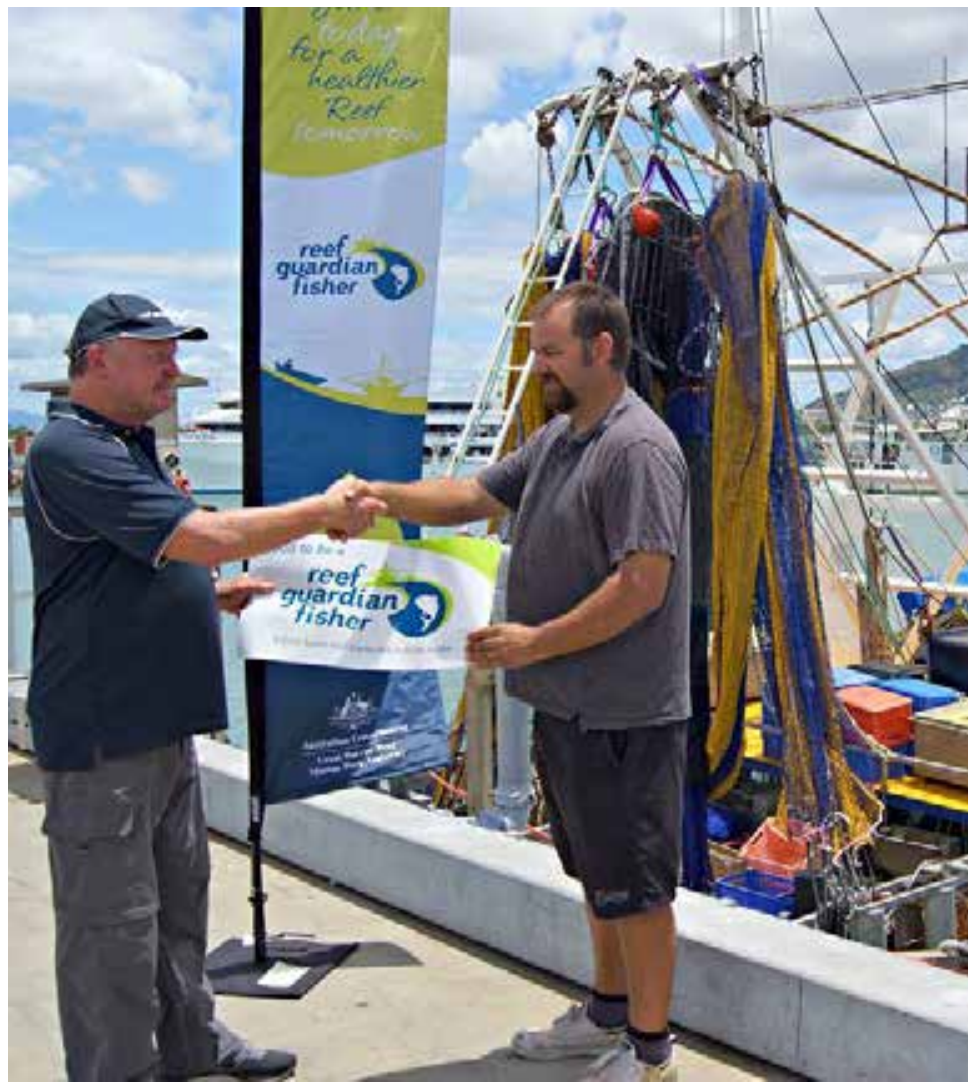

At a practical level, stewardship programs create a platform to recognise and encourage reef-friendly behaviours. These can range from individual actions that reduce direct impacts on the reef (such as fishing in a sustainable and legal manner), to indirect actions like reducing pollution or litter upstream. Through recognising and promoting leaders who are setting an example of reef-friendly behaviours, stewardship programs can influence attitudes and social norms within communities, which in turn can be powerful drivers of behavioural change 5

Importantly, stewardship programs give reef managers additional strategies to complement existing management. Engagement with non-user communities (such as farmers) can enable managers to influence behaviours of people responsible for upstream pressures on coral reefs (such as agricultural pollution). Stewardship can also enable much greater responsiveness in reef management. Communities involved in stewardship (especially where it includes community-based monitoring) are more likely to detect and predict the consequences of their activities, and take voluntary action to avoid or reduce impacts ${ }^{6}$. Voluntary responses by the community are likely to be more rapid, less costly and more effective than top-down management responses that often rely on regulatory mechanisms. Examples of responsive action through stewardship include voluntary moratoriums on commercial fishing aimed at reducing pressure on corals during periods of environmental stress ${ }^{7}$. 
In some situations, especially relating to fisheries, communities have initiated the regime of natural resource management, or are equal partners in management with government authorities ${ }^{8}$. Customary tenure, delegated custodianship and co-management are strong expressions of environmental stewardship by local communities. This guide may help coral reef managers understand and engage with community stewards in these situations, but its main purpose is to assist staff of management organisations in their efforts to increase participation and support among communities that historically have not been empowered to contribute to reef management.

\section{Stewards are exercising a moral responsibility}

In many communities, environmental stewardship presents an important opportunity for individuals to acknowledge and exercise their moral responsibility to care for nature, mother earth or God's creation. Many cultures and religions teach the importance of respecting nature, of gratitude for the beneficial gifts that humans receive from the creator, and of wise use of resources for the benefit of all. Stewardship programs can provide valued opportunities for community members to demonstrate their commitment to these teachings. Churches and other religious organisations can be important partners and participants in reef stewardship projects.
Johannes, R.E. 1978. Traditional marine conservation methods in Oceania and their demise. Annual Reviews of Ecology and Systematics, 9, 349-364.

Ross et al. 2009. Co-management and Indigenous protected areas in Australia: achievements and ways forward. Australasian Journal of Environmental Management, 16, 4.

2 Brown, D.N., Pomeroy, R.S. 1999. Co-management of CARICOM (Caribbean Community) fisheries. Marine Policy, 23, 549-570.

3 Commonwealth of Australia, 2015. Reef 2050 Long-Term Sustainability Plan, http://www.environment.gov.au/marine/gbr/long-term-sustainability-plan

4 Pinkerton, E., ed. 1989. Cooperative management of local fisheries: new directions for improved management and community development. University of British Columbia Press, Vancouver, BC, Canada.

5 Ajzen, I. 1991. The theory of planned behavior. Organizational behavior and human decision processes. 50, 2, 179-211.

6 Danielsen, F. et al. 2007. Increasing conservation management action by involving local people in natural resource monitoring. $A M B I O, 36: 566-570$.

7 Beeden, R. et al. 2014. No-anchoring areas reduce coral damage in an effort to build resilience in Keppel Bay, southern Great Barrier Reef. Australasian Journal of Environmental Management, 21:3, 311-319.

8 Dyer, C.L.; McGoodwin, J.R., ed. 1994. Folk management in the world's fisheries. University Press of Colorado, Niwot, CO, USA.

Jentoft, S.; McCay, B.J. 1995. User participation in fisheries management. Lessons drawn from international experiences. Marine Policy, 19, 227-246.
Pope Francis on

environmental stewardship

"The human family has received from

the Creator a common gift: nature.

The Christian view of creation includes

a positive judgment about the

legitimacy of interventions on nature

if these are meant to be beneficial and

are performed responsibly, that is to

say, by acknowledging the "grammar"

inscribed in nature and by wisely

using resources for the benefit of all,

with respect for the beauty, finality

and usefulness of every living being

and its place in the ecosystem. Nature,

in a word, is at our disposition and we

are called to exercise a responsible

stewardship over it."

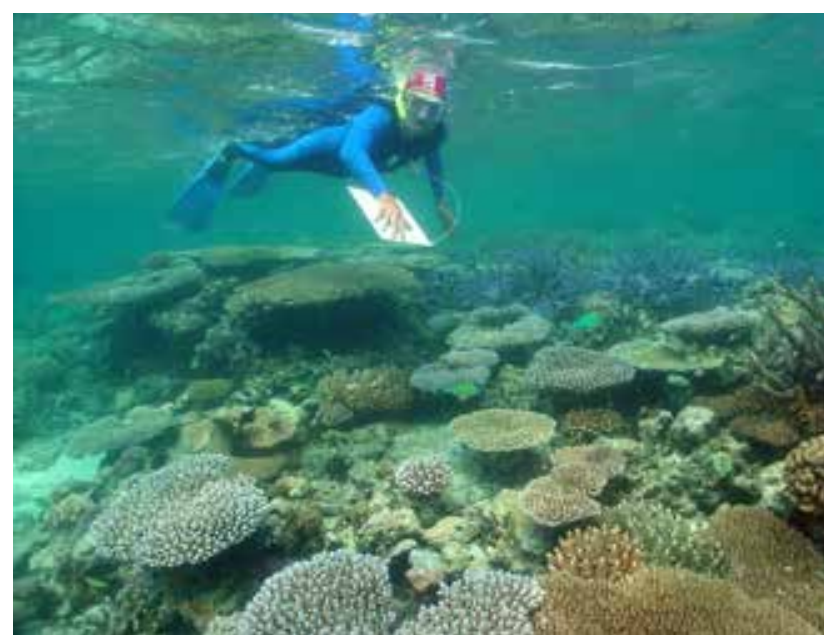




\section{Framework and step-by-step guide}

This guide presents a framework (Part A) and step-by-step guide (Part B) for developing a reef stewardship program that suits the needs of your local community and marine environment. References and additional resources are provided in Part C.

While communities and reef managers are increasingly recognising the benefits of stewardship for reef conservation, there is no one-size-fits-all approach to designing stewardship programs. There are, however, guiding principles and approaches that can help reef managers everywhere to work with communities to design and implement a successful program. Part A outlines the key principles and considerations for stewardship programs, giving you the theory and background knowledge to tailor a framework to your particular situation. Part B guides you through a series of steps that will help you along the path to your own stewardship program, a healthier reef and more involved communities.

With the help of this guide, you can build a program to foster community stewardship activities that contribute to the health of coral reefs and the resilience of coastal communities. The structured approach presented in this guide will help you increase alignment between community actions and management priorities, and develop a culture of reef stewardship that can spread throughout local communities.

\section{Building on experience from Reef Guardians initiatives}

The guidance presented here draws from knowledge and experience in the design, implementation and adaptation of existing reef stewardship programs. Successful programs from locations as diverse as the Great Barrier Reef (Australia) and Grenada (eastern Caribbean) are being replicated in other countries and regions. Despite large differences in culture, resourcing, monitoring activity and governance arrangements, formal stewardship programs built around the Reef Guardians concept have proven highly successful in a wide range of settings. The collective knowledge from these programs has enabled the distillation of valuable lessons and insights that can assist those interested in developing new reef stewardship programs.

The Great Barrier Reef Marine Park Authority’s Reef Guardians stewardship program was originally launched in 2003 with schools; it has since evolved to include programs for local government, farmers, graziers and fishers. The program slogan is Working together today, for a healthier reef tomorrow. Twelve years later, the program is proving that a hands-on, community approach to caring for the Great Barrier Reef and the catchment is essential to the long term protection of the environmental, social, cultural and economic values of the Great Barrier Reef World Heritage Area.

Grenada was the first country outside of Australia to adapt and implement the Reef Guardians stewardship concept. The pilot program, launched in 2013, engaged with schools and farmers to educate and inspire actions to protect the Moliniere-Beausejour Marine Protected Area and catchment. Adaptation of the Reef Guardians concept from Australia to a context as different as Grenada has demonstrated the potential to implement formal stewardship programs across different geographic, environmental, social, economic and cultural situations using a common framework and similar approaches. This establishes the foundation for a community of practice where ideas and experiences can be readily communicated, compared and shared. These are the ingredients that can accelerate our collective efforts to advance reef management through greater empowerment of local communities. 


\section{Standing on the shoulders of giants}

The concepts, experience and science relating to community stewardship of coral reefs and other natural systems have been accumulating for decades, and it is on this foundation of knowledge that this guide is built. While we have endeavoured to produce guidance that is accessible to anyone involved in coral reef management and community leadership, we have also attempted to ensure the guide is grounded in relevant theory and research. Part C - References and Additional Resources lists some of the key sources of work that underpin the guide, and which may be of interest to readers wishing to explore various aspects of stewardship in more detail.

\section{It's about recognition, not just certification}

A key distinction of the Reef Guardians approach to stewardship is that it does not aim to replicate ecocertification programs. Stewardship programs incentivise behavioural change through reinforcing supportive attitudes, shifting social norms and increasing the sense of empowerment in communities. In some cases, this can be aided through specifying best practice management standards and implementing certification programs. However, stewardship is often fostered by recognising and promoting positive actions that people are already implementing, and by encouraging uptake of new reef-friendly behaviours through provision of guidance on design and implementation of activities. It is important to recognise that people will be at different stages of their stewardship 'journey' - while some will be enthusiastic but only just beginning their contributions to reef protection, others will be established, well-recognised sustainability leaders in their field or sector. An effective stewardship program accommodates and unites the diversity of people who share a commitment to helping the reef. Certification and other material incentives might be a desirable complement to stewardship programs, but it is wise to focus on internal drivers such as attitudes and values that are more sustainable foundations for stewardship.

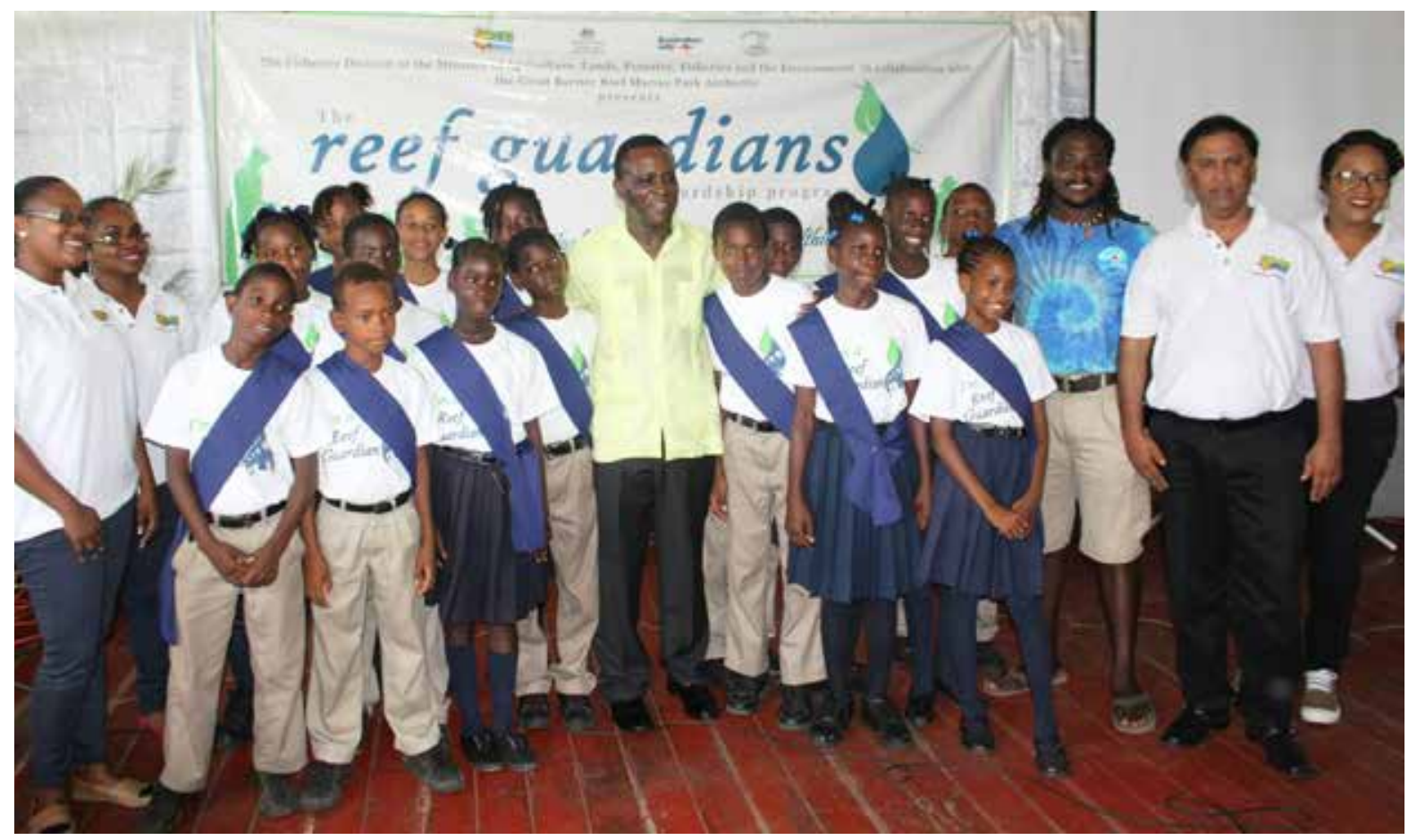




\section{Stewardship programs are more than education initiatives}

Although education has a part to play in the Reef Guardians programs, stewardship initiatives are more than just information-intensive, awareness-raising activities. Effective stewardship programs need to combine learning with targeted actions. Stewardship programs are a way of tapping into the heartfelt passion and connections people have toward coral reefs, and converting this into decisions and actions that can make a difference to coral reef health. Fundamental to a stewardship program is recognition that coastal communities have a strong stake in the future management of coral reefs. Experience suggests most people are willing to share in the responsibility of caring for and protecting coral reefs if given an opportunity and encouraged.

\section{Stewardship is voluntary}

Participation in stewardship activities is not incentivised by direct monetary benefit. Stewardship program participants need to be self-motivated, with an interest in understanding how they can be involved and help coral reefs. Although most people are motivated to participate in stewardship programs because they care for the environment, others may be motivated by their need to ensure the long-term sustainability of their businesses (e.g. tourism operators and fishers). Whatever the primary motivation, care for the environment is likely to grow through their participation. For example, a school in Queensland, Australia was initially motivated to get students engaged in their natural environment to improve class behaviour and academic grades. From the perspective of the teacher, changes in attitudes toward environmental protection or actions taken by students to help the reef were ancillary outcomes. This did not necessarily lessen the value of the students' participation to the reef manager.

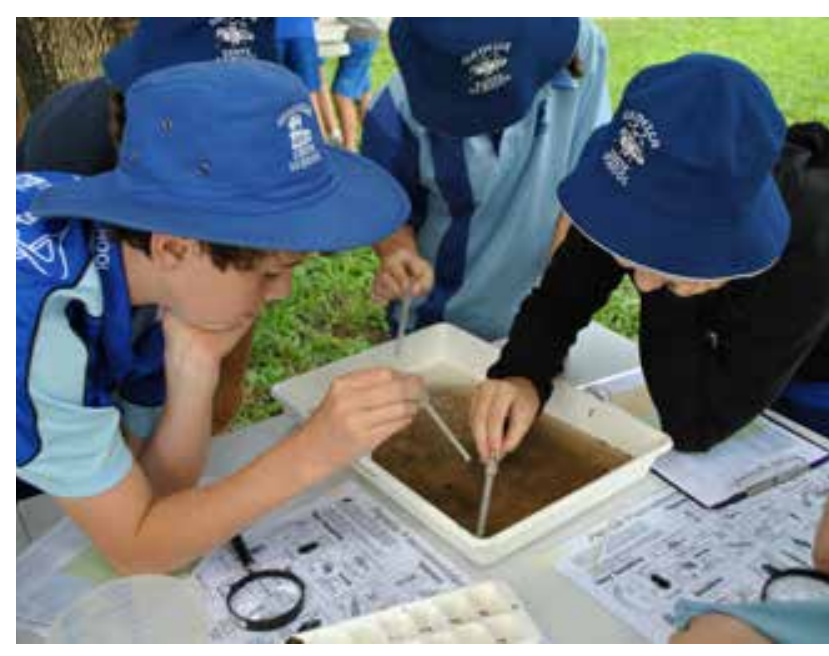

It is also important to recognise that participants' motivation will change over time. A key feature of a successful program is gaining commitment from participants for ongoing and active engagement in stewardship activities. If at some stage in the future participants no longer feel they can prioritise or contribute to the stewardship program, they should be allowed to 'opt out'. This helps to maintain good standards and practices with a focus on active, ongoing commitment.

A strong voluntary basis to participation enables the program to maintain a foundation of mutual, trusting relationships between participants and the host team. Unlike a compliance approach, participants willingly participate or go above and beyond what is expected of them. This internalised motivation is a central ingredient in the effectiveness and sustainability of stewardship ${ }^{1}$.

\section{Sharing reef stewardship success stories}

This guide draws from the experiences of people who have established or been involved in formal stewardship programs across different sectors. Throughout the guide we highlight strategies, ideas and resources that have been utilised to make stewardship an exciting, effective and sustainable partnership between coral reef managers and local communities. We hope that you are inspired by this guide to develop your own stewardship program, and that you will share your story as part of the growing community of practice around coral reef stewardship. 


\section{Reef Guardians in the Great Barrier Reef - a model for reef stewardship programs}

The Great Barrier Reef covers an area of 348,000 square kilometers, and its expansive catchments have a history of agriculture and other land uses that go back over 150 years. These features combine with climate change and a suite of local issues to create a large and complex management challenge. Increasingly, even management agencies with dedicated resources and technical capacity are turning to stewardship as an important contribution to achieving management goals.

The Great Barrier Reef Marine Park Authority (GBRMPA) fosters community stewardship through its Reef Guardians program. This celebrated example of a community-centered environmental stewardship program plays a key role in efforts to achieve GBRMPA's vision of: A healthy Great Barrier Reef for future generations.

The objectives of the GBR Reef Guardians program are to:

1. Raise awareness of Reef values through education and participation

2. Foster partnerships between researchers, managers and Reef users

3. Enhance compliance / adoption of best practice

4. Recognise and promote innovation and those that go above and beyond as Reef stewards.

The program focuses on recognising and encouraging good environmental work undertaken by communities and industries to protect the Great Barrier Reef. The program works closely with those who use and rely on the Reef and the catchment for recreation or business to help build a healthier and more resilient Reef.

An important focus of GBRMPA's Reef Guardians program is the connection from the land to the Reef. The Great Barrier Reef catchment area lies adjacent to the Great Barrier Reef World Heritage Area and comprises approximately 25 per cent of the land area of Queensland.

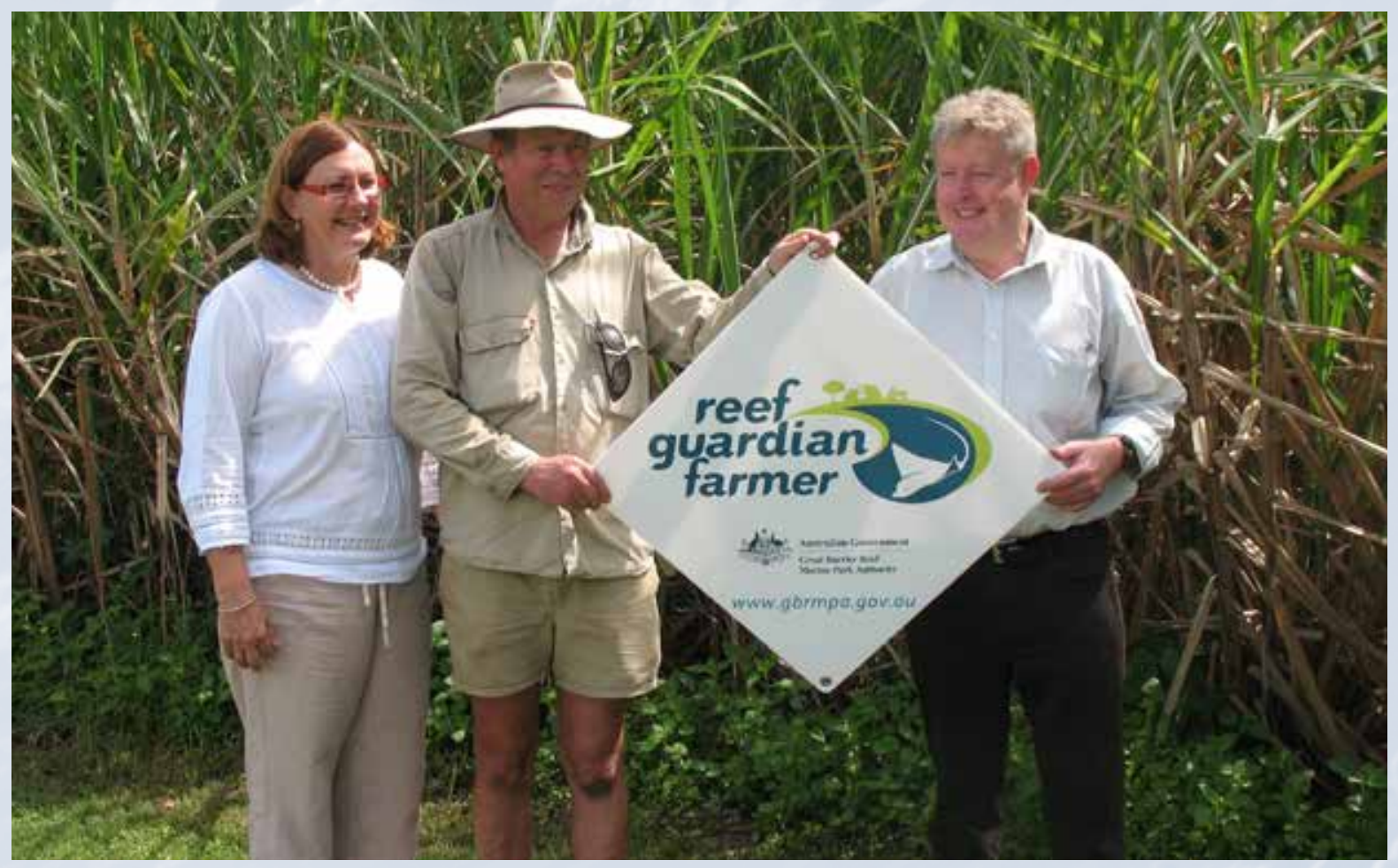


Forty drainage basins comprise the catchment area, which drains directly into the Great Barrier Reef lagoon. The importance of activities on land to the future of the Reef is recognised by Reef Guardians participants and their actions help to reduce their impacts on the catchment.

The program demonstrates a hands-on, community-based approach can make a real difference to the health and resilience of the Reef. Reef Guardians are taking on voluntary actions beyond what is required by law and sharing information. These actions will help to improve the economic sustainability of industries operating in the Great Barrier Reef Region and ensure the environmental sustainability of the Marine Park.

Since its launch in 2003, GBRMPA's Reef Guardians stewardship program has worked with schools to encourage the community to take action for a healthier Reef. The Reef Guardian Schools initiative currently has more than 310 schools and 127,000 students involved in building the Reef's resilience.

In 2007 the initiative was expanded to include local government councils along the Great Barrier Reef coast through the Reef Guardian Councils program. The Reef Guardian Fishers and Reef Guardian Farmers and Graziers programs were launched in 2011 to engage with industries connected to the Reef.

For more information about the Reef Guardians program go to www.gbrmpa.gov.au/our-partners/reef-guardians. You can also keep up to date with Reef Guardians activities by subscribing to GBRMPA's Reef in Brief newsletter or connecting with social media at www.gbrmpa.gov.au.

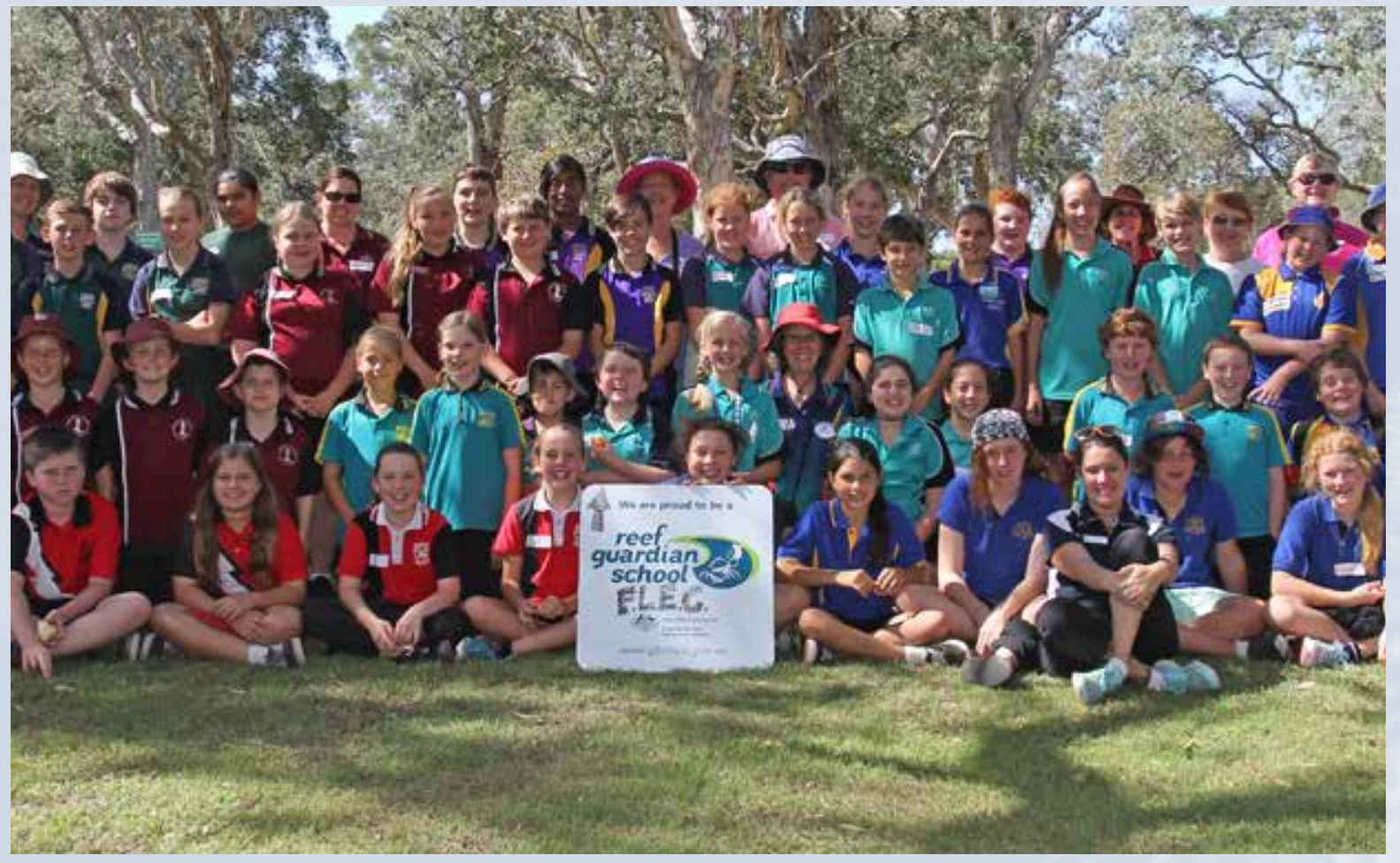




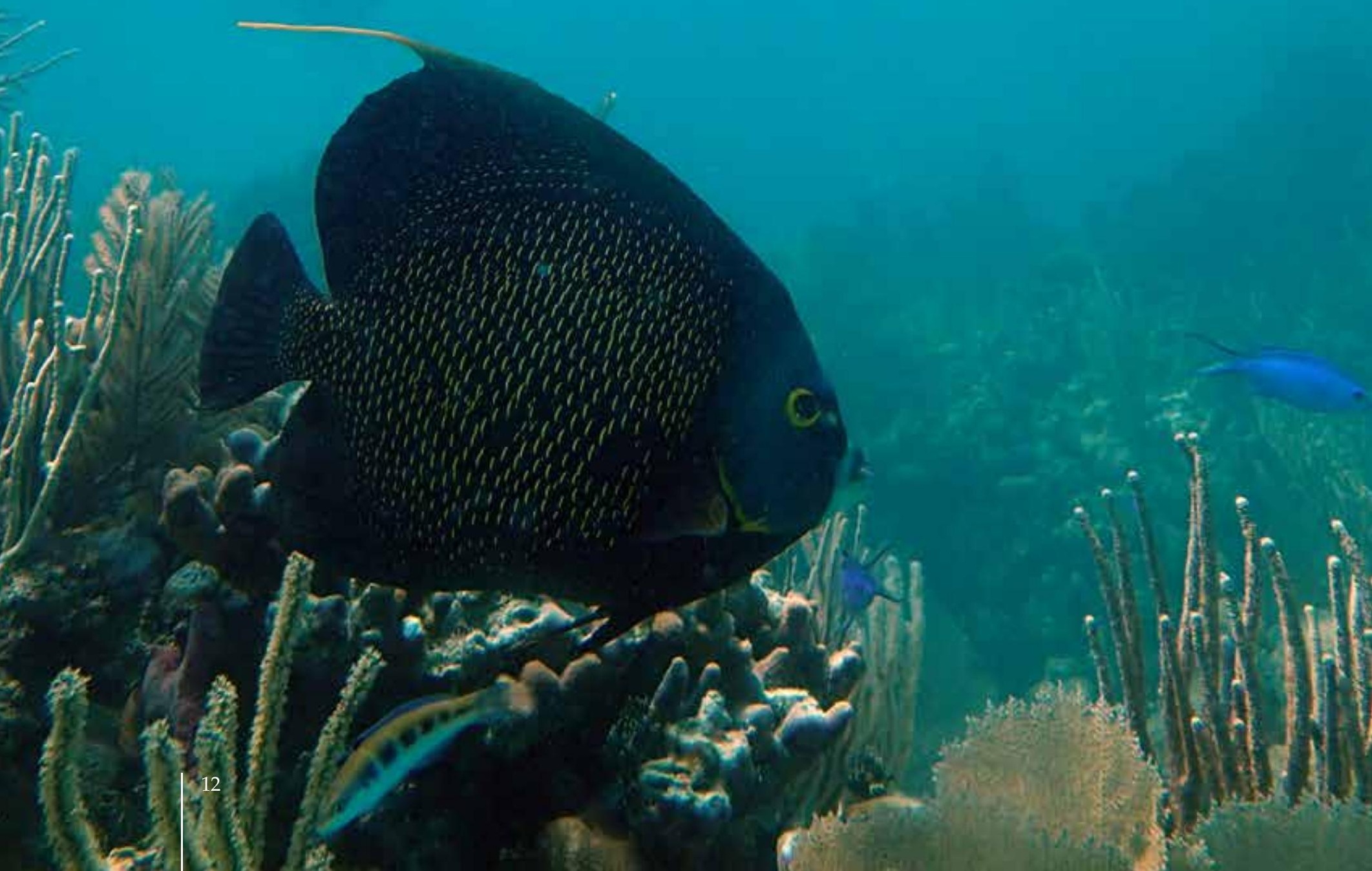




\section{Part A:}

A Framework for Stewardshoup

The first steps in developing a stewardship program are to clearly identify priority issues for local coral reefs and then define how communities can be part of the solution. Reef managers or other program coordinators can then match stakeholder groups or individuals with the issues that are most relevant to their interests and capacity.

Effective stewardship programs recognise good existing practices and encourage community members to make everyday choices that support reef conservation and sustainable use. They also encourage those already demonstrating good stewardship behaviours to be leaders and role models for others in the community.

A key to successful stewardship programs is a genuinely collaborative approach to program design and implementation. Stewardship is fundamentally about empowering local people to play an active and positive role in sustaining or restoring the health of their local reefs. Therefore, the process of engaging local communities, and designing and establishing the conditions necessary for program sustainability and success are critical steps for anyone setting out to implement a formal stewardship program. This section outlines a framework that can help get it right from the start (Figure 2).

This section details:

1. The logic behind reef stewardship programs

2. The design considerations for developing a program

3. The key inputs for a successful program

4. Indicators of success: capacities, behaviours and outcomes that characterise an effective stewardship program.

\section{The logic behind stewardship recognition programs}

Stewardship programs are based on the premise of building mutually beneficial relationships between the host (the reef manager or other organisation with formal management responsibilities) and participants (community members or organisations). Reef managers benefit from increased community support to implement actions that will protect the reef, and the opportunity to trial and foster communitybased voluntary actions that enhance regulatory measures. Participants benefit through learning, opportunities to engage in management planning and programs, capacity building and access to resources. Relationships are the cornerstone to positive changes in attitudes, knowledge and skills (stewardship capacity). These in turn lead to stewardship behaviours that support desired long-term, positive outcomes for the reef ecosystem and community (Figure 3 ).

Some stewardship actions will directly benefit the biodiversity and conservation of the marine environment, such as replanting riparian areas of wetlands or improved treatment of livestock waste, while others may target gaps in management capacity, such as through building community capacity to assist with monitoring ecosystem health.

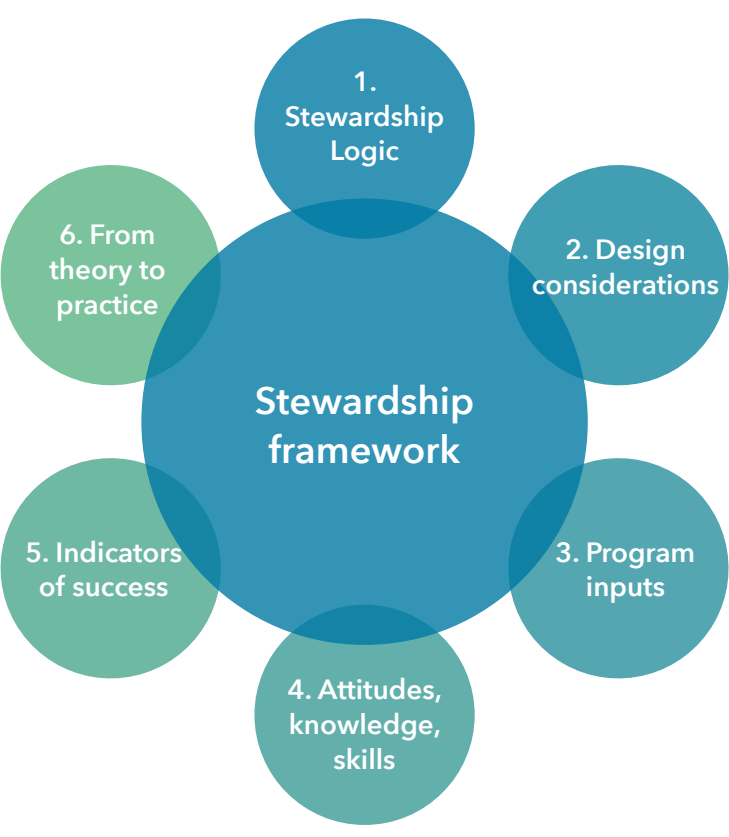

Figure 2: This section guides you through six key areas of theory and knowledge that provide the foundations for developing a framework for your stewardship program. 


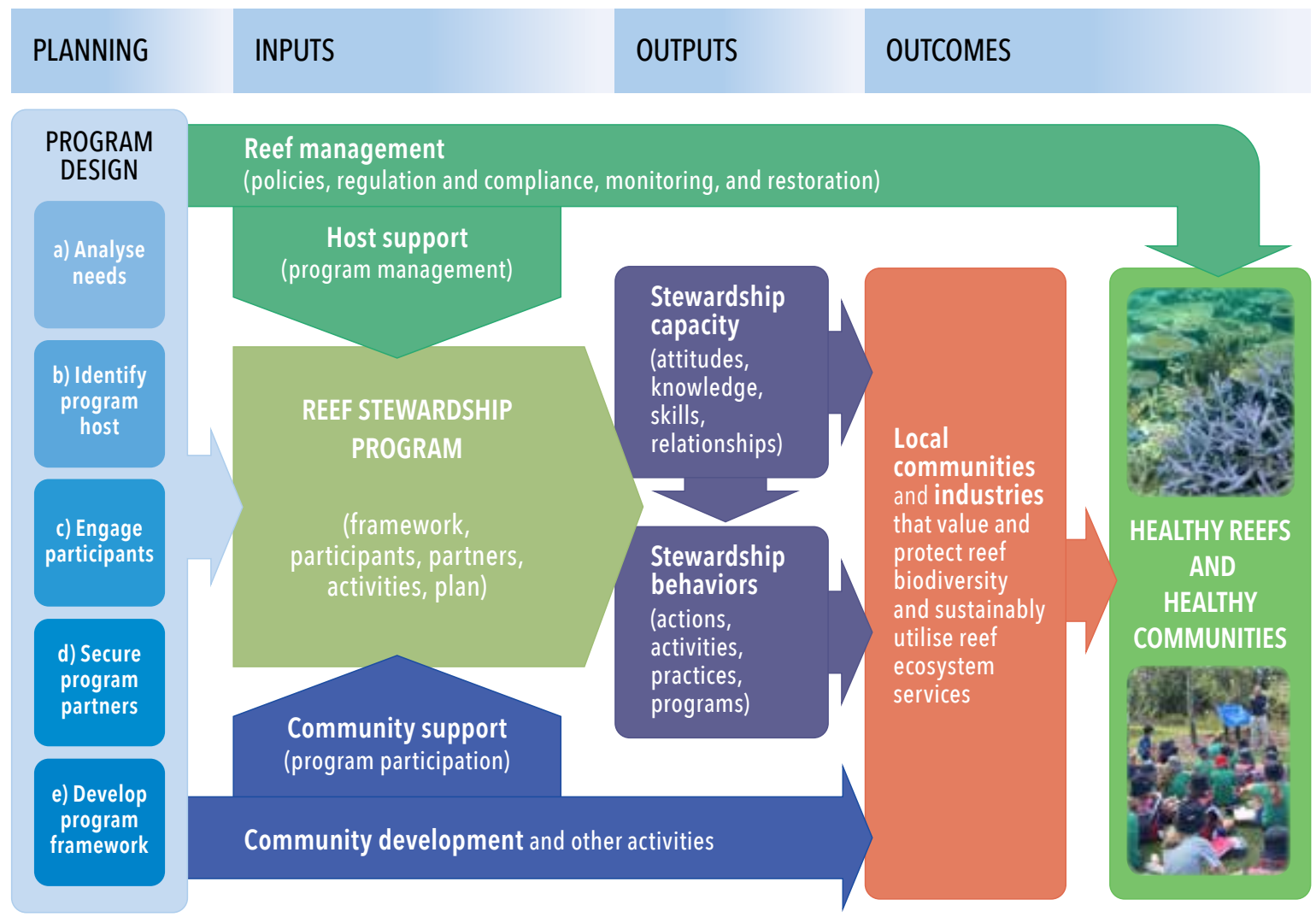

Figure 3: As illustrated in this flow diagram, implementation of a stewardship program is a journey shared by reef managers and the community. It requires inputs from reef managers as well as from program participants. The benefits include increased capacity among participants and an increase in behaviours that lead to improved resilience of the reef ecosystem and the coastal communities involved.

\section{Design considerations: building blocks of a program}

Thoughtful and strategic design of stewardship programs can result in benefits to both reef ecosystems and to local communities. Reefs will benefit from more effort and greater coordination of activities designed to reduce pressures and increase resilience of the ecosystem. In particular, a well-designed program will match the skills, capacity and interests of participants with priority and tractable issues for reef management. Communities involved in reef stewardship programs benefit from an improved understanding of the importance of coral reefs to their lifestyles and livelihoods, and from learning about their condition and their vulnerability. Participants also gain insight into policy and management processes that regulate use of coral reef resources, increase their access to decision-making processes and have new chances to gain knowledge, technical skills and leadership capacity.

Participatory monitoring programs, where members of local communities assist scientists or reef managers to collect data, or where community members are entirely responsible for recording and interpreting information about their activities or ecosystem conditions, can be especially powerful for raising awareness and motivating stewardship behaviours. Stewardship programs that include participatory monitoring can also facilitate community-led responses to events or emerging issues like coral bleaching or crown-of-thorn starfish outbreaks, providing critical support to reef management. Through these benefits, stewardship programs can make meaningful contributions to the social and ecological resilience of coral reefs and coastal communities. 


\section{How stewardship builds resilience of coral reefs and coastal communities}

$\checkmark$ Promoting best practice and behaviour change: Reef stewardship can foster improvement in reef-friendly actions through recognising and promoting good behaviours and practices. These serve as models and standards that influence the attitudes and behaviours of others, thereby spreading best practice. It utilises the concepts of social norms and social diffusion to create a network of people working together to protect the reef.

$\checkmark$ Building awareness and understanding: Stewardship programs help to educate the community about reef-related issues and support participants to implement actions that will address these issues. Participants are also more informed and able to contribute to planning and management decisions.

$\checkmark$ Bolstering reef management: Ongoing work by management authorities to protect the reef is supported by stewardship. Participants' behaviours can be targeted to better align with key ecosystem needs and management priorities.

$\checkmark \quad$ Complementing existing policy approaches: Enforcement and compliance remain essential management tools, but in some cases regulation can achieve greater results when coupled with stewardship.
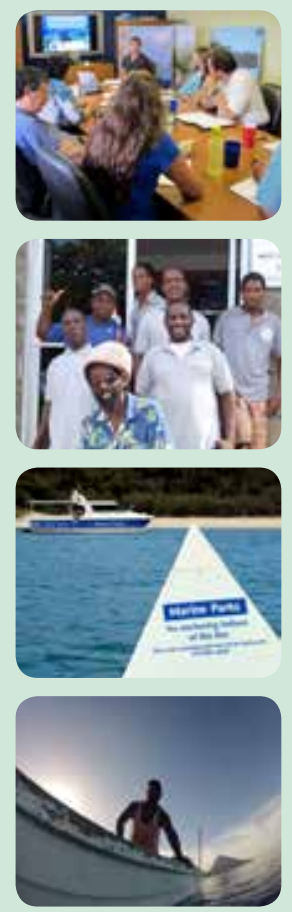

Key steps in the design of a stewardship program (Figure 4) include:

a) Analyse the needs and opportunities

b) Identify the program host and secure institutional support

c) Select and engage participants

d) Seek and secure partners

e) Develop program framework (guiding principles).

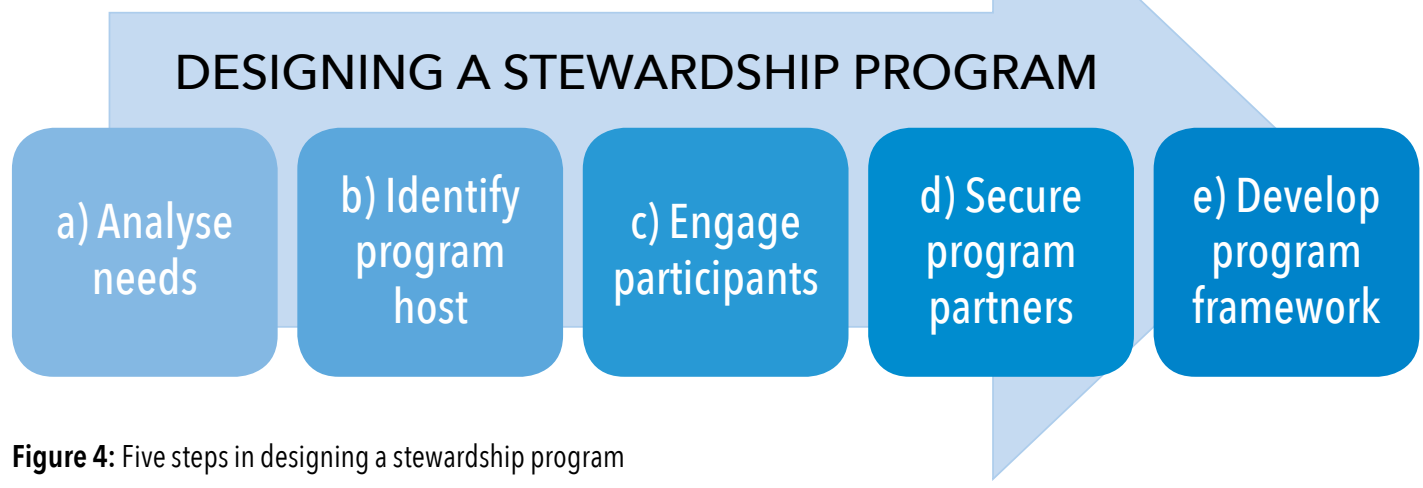




\section{a) Analyse needs and opportunities}

Understanding the key issues and needs of your marine environment is perhaps the most important consideration when designing a reef stewardship program. This ensures that program activities produce tangible and relevant outcomes for the reef and for program participants. A needs

a) Analyse needs analysis should be conducted as early as possible in the design phase of the program. This process usually involves reef management authorities and other key stakeholders to ensure a breadth of input and early engagement with potential participants.

A needs analysis is a systematic process for identifying and prioritising key issues and gaps in current reef management programs and activities. It can be a formal or informal process, but it should be based on factual knowledge while also allowing perceived issues and reef management needs to be explored. Stakeholders will often bring different perspectives to such discussions, and these can reveal new management issues or help identify gaps between the current situation and the community's aspirations for engagement (i.e. some of the management gaps may be in the area of community engagement as well as in the area of ecological management). The analysis can be used to map the range of challenges and help all participants in the analysis contextualise the different issues. Gaps or needs can then be prioritised on the basis of perceived importance. The size of the gap, the reason for the gap and the importance of filling the gap provide the foundations for scoping and prioritising potential stewardship activities.

Stewardship activities can contribute to reef outcomes in a diversity of ways; some will have the potential to directly affect reef health (such as voluntary no-anchoring areas) while others may only indirectly benefit the ecosystem (changes in fertiliser use on farms) or even focus more on broader environmental attitudes (waste composting projects at school). Some activities might have small impacts on the health of the reef, like an individual composting their waste at home, or a larger impact such as the relocation of a community dumping site away from a coastal area. Developing participatory monitoring programs can be a particularly powerful way to engage community members with issues of reef conservation and sustainability.

A key consideration for the design of activities and the larger program is how to maximise the return on effort for all involved. Which are the most worthwhile behaviours to foster that will help build reef health and resilience? The needs analysis step, done well, will help you find this balance. Part B Sections 1.1 and 1.2 provide further information on conducting a needs analysis and identifying targeted behaviours for reef protection.

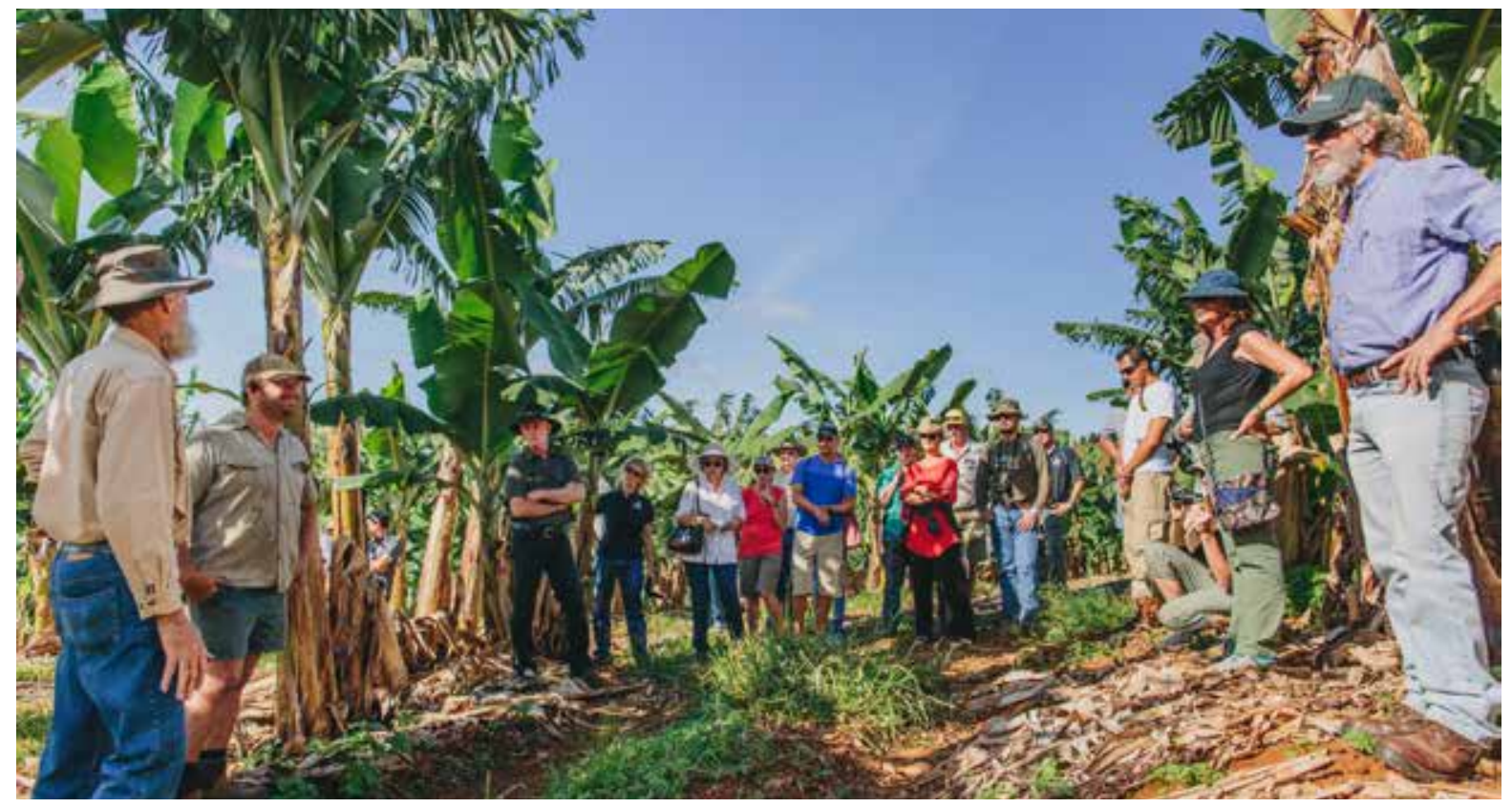




\section{b) Identify program host and secure institutional support}

The program host plays a crucial role in any stewardship program. It is recommended that the host organisation or agency hold both a position of trust within the community and a position

b) Identify

program of influence over the management of the reef. Coral reef management authorities (whether government departments, non-governmental organisations, or co-management situations within host communities) are ideal agencies to manage the development and implementation of reef stewardship programs. Hosting the program within a management authority brings the added benefit of directly aligning stewardship actions with the ongoing management of the reef, and strengthens links between the management agency and the people who use and/or rely on the reef or its catchment.

It is worth noting that the host organisation should also be a community leader demonstrating exceptional stewardship in its own everyday practices. It is not enough to simply develop, fund or manage a stewardship program; all other management activities should be consistent with those attitudes and behaviours the program seeks to encourage.

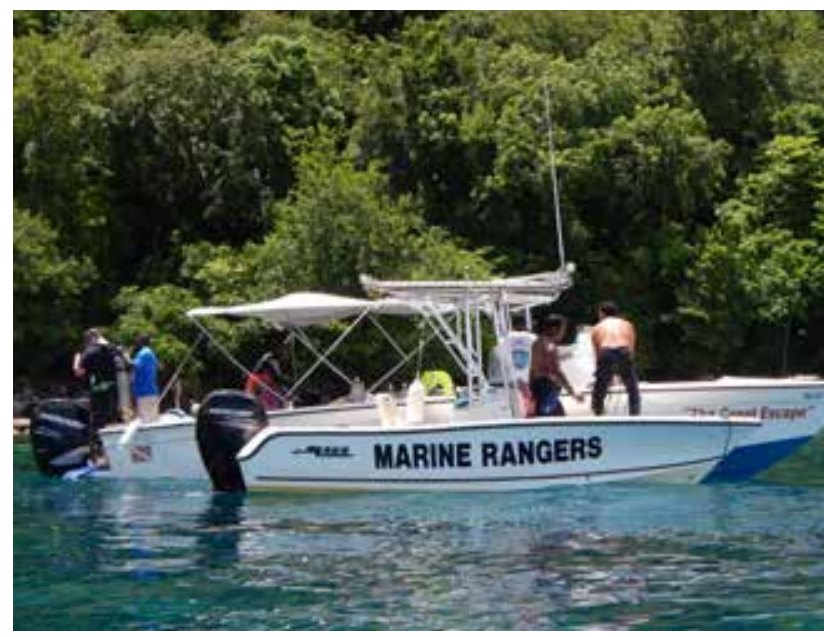

\section{c) Select and engage participants}

People are the 'heart and soul' of your stewardship program, so selecting and engaging the right participants is crucial to success. Understanding the attitudes, values and motivations of people will help you select the most appropriate participants, and guide you in your engagement efforts. Managers of stewardship programs will benefit from application of basic market analysis tools and approaches, which are designed to understand and categorise a group of people (your potential audience or customer base) on the basis of attitudes, beliefs, motivations and constraints relevant to your objective. In many cases, this can be revealing and powerful in identifying groupings that do not necessarily align with normal stakeholder categories. For example, fishers and farmers who voluntarily invest in business practices that reduce threats to the reef out of an interest in protecting nature for future generations may have more in common with each other, than with other fishers or farmers who only adopt sustainability practices that result in increased business profitability.

By differentiating a group motivated by concerns of inter-generational equity from another group motivated by business returns (even if each group includes a mix of sectors, such as farmers, fishers and tourism operators), you will be able to more effectively and efficiently tailor your communication efforts. Messages that speak to people's values and current behaviours tend to resonate much more strongly, accelerating engagement and creating stronger alignment and momentum for change. You will also have a better understanding of the range and distribution of attitudes and behaviours within the broader community to use as a baseline against which you can monitor and evaluate the success of your program in increasing reef-friendly attitudes and behaviours. This type of market segmentation also helps program managers and coordinators identify early adopters and champions of stewardship initiatives that potential participants can more readily relate to. People are more likely to emulate or follow leaders who hold motivations or demonstrate behaviours that they associate with.

\section{Early adopter:}

An early customer of a given company, product, innovation or technology, who promotes its use and encourages its adoption by others. 
Participants in stewardship programs are usually individuals, but they can also be businesses, large corporations or entire sectors exercising social and environmental responsibility through organisational decisions and/or incentivising behavioural change of staff members. Ultimately though, it is the behaviours and actions of individuals that lie at the heart of a stewardship program. Therefore, a successful stewardship program is likely to actively target individuals who are already demonstrating behaviours, or at least attitudes, that align with the priority issues and needs identified in the gap analysis. Naturally, participants will vary in their understanding of reef issues, their current level of involvement in reef-friendly practices and their underlying attitudes and motivations. However, with an understanding of the values and mindsets within your community you are well placed to help people identify leaders and other community members that can serve as mentors and peers in their stewardship journey.

\section{How marketing theory can help target stewardship program activities}

Marketing theory can help answer questions about how best to group a population (community of stakeholders, audience, market) and how to identify groups that are 'investment ready'. It can also help determine the constraints operating to prevent other groups from being receptive to stewardship initiatives, and inform strategies to overcome these constraints. Below are suggestions for steps to help understand and segment the 'market' for a more effective and efficient stewardship program.

1. Gather information on community attitudes toward the environment. This may be available from government environment agencies, statistics offices and / or NGOs.

2. If resources permit, work with local researchers / psychologists / marketeers / market researchers to evaluate the demographics and psychographics of the population relative to their use and attitudes toward coral reef resources.

3. If resources are limited, develop a simple survey on attitudes toward coral reef resources. Survey questions could include: How valuable are the reefs to community members? Have the reefs changed in the past decade? What are the primary drivers of change? How well are reefs currently managed? Is there fair access? What would the respondent like future reef condition to be? What actions have they taken / do they support to sustain reefs? How likely are they to take action to support reef condition? Aim to keep the survey short and focused.

4. Work with local community leaders to get a representative cross section of the community to complete the survey, and / or set up some focus groups to go through the questions and provide feedback.

5. Collate the information and look for common patterns, attitudes, insights and actions that can serve as a baseline for the stewardship program evaluation.

6. Look for different 'segments' - groupings of the community with common attitudes, motivations and beliefs about the reef. Consider whether these align with traditional stakeholder groupings (e.g. fishers )or whether there is a better descriptor for these groups (e.g. 'early adopters').

7. Use these groupings to structure your stewardship program activities and performance indicators. For example, you may wish to shift a certain portion of your community from one group to another as a way of increasing program sustainability.

8. Resurveying the community at the end of your pilot phase, or at intervals during the program, to evaluate progress and inform program improvement.

A stewardship program can be kick-started by focusing efforts initially on identifying and acknowledging existing reef-friendly actions within target groups. Sometimes, individuals, industries and communities are already voluntarily taking actions that directly or indirectly contribute to reef health, and formal recognition of these behaviours or programs can accelerate engagement and uptake of the concept of stewardship. Identifying and promoting these actions can be a powerful way to entice others to commit to reef-friendly 
behaviours and join the stewardship program. By building social norms around stewardship behaviours, and by creating networks based on motivations and values (and which therefore are likely to span across sectors), the program can become more effective and self-sustaining. Before long, potential new participants may actively seek out the host organisation to request to join or establish a program of their own. This is a great sign that the program and participants are starting to influence others' behaviours.

Many of the program's early adopters might already be recognised industry leaders in management practices, providing a platform to demonstrate sustainable practices that benefit the reef. It is important to recognise that these individuals are often active participants in other community forums and therefore may have ongoing, regular commitments outside of the program. Keep this in mind when planning engagement activities to make sure participants don't suffer from 'engagement exhaustion'.

\section{d) Seek and secure partners}

A partnership approach is crucial to the success of stewardship programs. Partnerships with other organisations that can share in the roles of hosting and supporting participants can strengthen networks and help with sharing knowledge and provision of resources necessary for program

d) Secure activities. Partners may be organisations representing participants, or they may be other agencies or corporations with an institutional interest in supporting reef stewardship. Traditional custodians, local experts, cultural leaders, other environmental organisations, government, community groups, local businesses, major corporations or volunteer organisations can all be valuable partners. Partnerships will expand and develop over time to support the program. However, engaging key partners early in the program design and planning will give them a greater sense of involvement and ownership of the initiative. It is also good to identify shared goals and objectives of the program with partners. They may be willing to provide more in-kind or financial support to the initiative if it also helps them (or their organisation) to achieve their own aims and priorities.

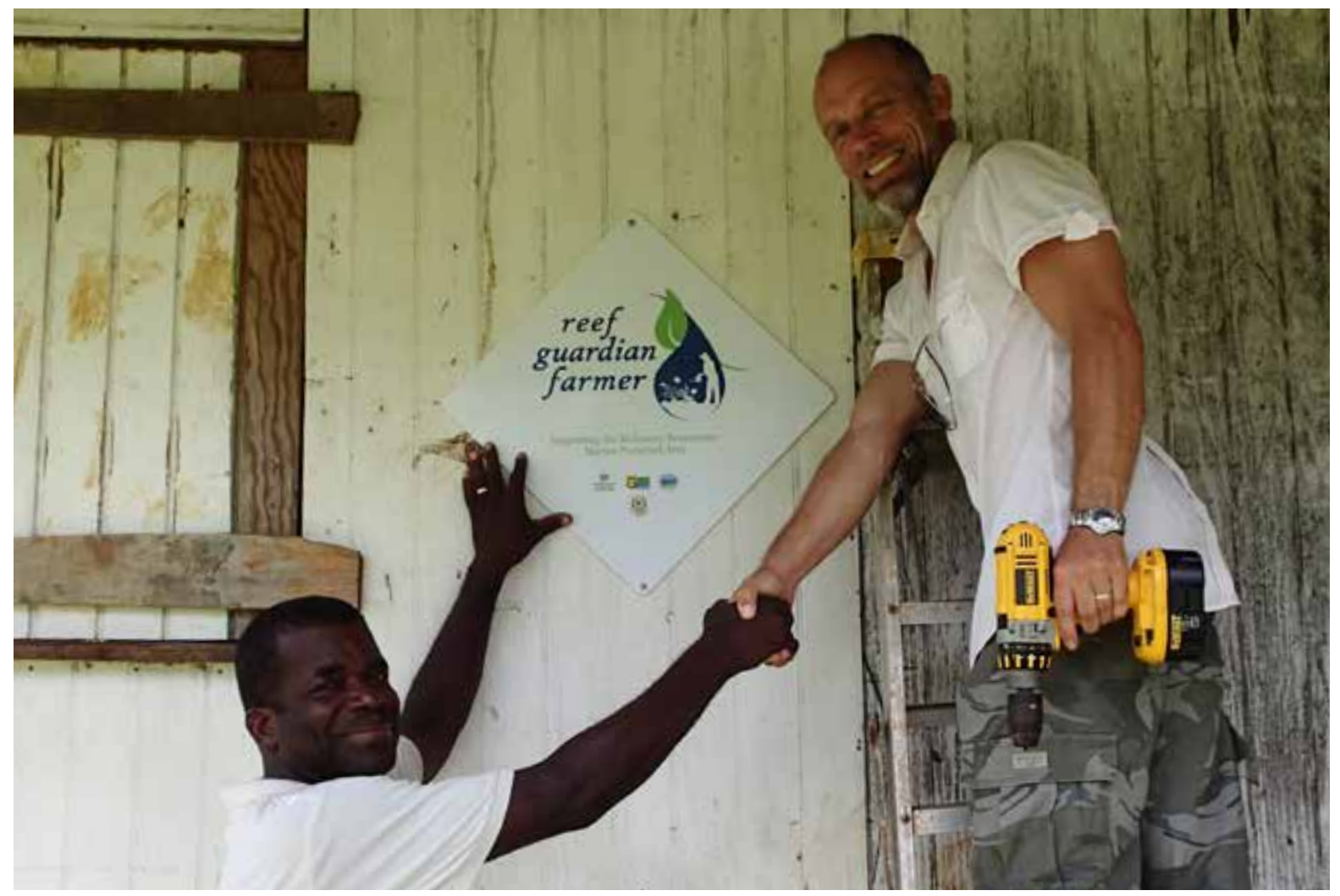




\section{e) Develop program framework built on guiding principles}

Guiding principles provide a framework to inform the design, development and implementation of an

e) Develop

program

framework effective reef stewardship program. They help translate the strategic goals into shorter term operational decisions, and thus ensure the program stays aligned with the core values of stewardship and the overarching vision, while allowing tactical adjustments that are inevitably required for effective program management.

The following ten principles are drawn from experience gained through designing effective reef stewardship programs for the Great Barrier Reef and the Caribbean.

1. A program is only as good as its people, and stewardship programs are about partnerships. Reef managers, program participants and the local community need to work together to achieve outcomes. Honest and respectful relationships, collaboration, and inclusiveness are essential to the success of the program.

2. Develop the program WITH the participants FOR the participants. The community should have a sense of ownership of the program right from the start. Decisions about program design and direction should be made in conjunction with participants to build a shared vision. This will also help align community interests with reef management needs.

3. Partnerships are a two-way process. The program should invest the time, energy and resources necessary in building the stewardship capacity of participants and communities. Capacity is a key driver of empowerment in individuals, and a person's sense of control or agency is an important determinant of their intentions and behaviour. Therefore, a focus on developing the skills, competencies, and knowledge of individual stewards will increase the likelihood of the desired behaviour change occurring, and propagating throughout the wider community. Ideally, participants will also share in the responsibility of the program's success by actively contributing their knowledge and experiences to inform program development, showcasing their stewardship activities to the community, and participating in program events.

4. A stewardship program recognises and promotes good practices; it does not focus on the bad. Promote those people and actions that go above and beyond what is required by regulation. Participants may be at different stages of their stewardship journey so it is important to allow diversity in the processes to achieve best practice outcomes with different individuals and across different sectors. Develop and seek agreement with participants on a set of standards/activities that broadly support desired program outcomes.

ST: Tip

Where there are leaders already

undertaking stewardship activities in

your local area, there is a significant

opportunity to leverage this progress.

Identifying, developing, mentoring,

supporting, and rewarding leaders

within the community will help to

build program momentum and

broaden support for the program.
5. Participation is voluntary. For stewardship programs to be sustainable they should be built around the participants' desire to be involved voluntarily. Funding for programs is often short term and uncertain. Ensuring that the stewardship program is built around the shared vision of its participants, the host, and the reef management authority will give the best chance of its continuation into the future. While programs can provide financial or in-kind support, such as seed grants for projects or training, direct financial reward should not provide the basis for involvement.

6. Inspiration and empowerment are key ingredients of program sustainability. Stewardship programs seek to inspire and influence behaviour change through understanding a community's connections to the reef. They depend on people who inspire and motivate others to act, who see beyond the short term to the benefits in the long term. Empowering communities to understand reef issues and take positive actions is a vital task of participants and the program team. 
7. Reliable, clear and concise information is essential. The program should provide audience-appropriate information on new science, relevant research, advances in technology, and practical experiences from other stewardship initiatives. Networks of knowledge holders can facilitate learning and communication exchange that can support constant improvement and best practices. Participants should also be supported to provide feedback and knowledge on standards, advances in practices and program activities to help guide the development of the program.

8. Piloting the program is essential. Before implementing a stewardship program on a broad scale, program managers should evaluate whether the program can cost-effectively achieve the planned outcomes though a pilot phase. The length of the pilot phase will depend on the scope and aims, and on progress. Most existing Reef Guardians programs were piloted for a minimum of nine months, and often up to two years. Evaluations of the program success should occur at different time intervals during the pilot to assess whether the strategies are having a long-term impact (environmental, social, economic and/or cultural indicators of success). It is tempting when a pilot is ineffective to try to fix it quickly through administrative intervention, but it's important to work with community to get it right and continue revising the pilot in a collaborative manner until it is effective.

9. Monitor, evaluate, review and improve. Monitoring effectiveness of your stewardship program is essential for continued learning and improvement. The nature and extent of stewardship engagement will naturally evolve throughout the program, and there are many unknowns associated with implementation of any management initiative. Involving program participants in monitoring and evaluation can be powerful: it can strengthen ownership of the program by participants, increase their sense of responsibility for outcomes and encourage initiative and responsiveness amongst communities. These are key ingredients of an effective and sustainable stewardship program.

10. Adapt and improve. One of the great benefits of stewardship programs is that they can be readily adapted in partnership with the participants. A key principle for any stewardship program to be successful is for it to be adaptable in response to information and insights gained through monitoring and evaluation parts of the program. The benefits of applying a philosophy of ongoing improvement include better outcomes, efficiencies, participation and enjoyment of those involved.

\section{Monitoring and evaluation (M\&E) - more than an afterthought}

Asessing and monitoring program effectiveness is often neglected. Yet, it is the hallmark of successful long-term programs. Monitoring and evaluation should be considered during the planning stages of a stewardship program to enable clear and measurable peformance indicators to be set and to facilitate collection of baseline information.

Good M\&E helps ensure your stewardship program is:

$\checkmark$ Adaptable to changing conditions

$\checkmark$ Achieving its objectives

$\checkmark$ Meeting participant expectations

$\checkmark$ Collecting evidence to secure sustained funding

$\checkmark \quad$ Providing feedback to build support from community and management.

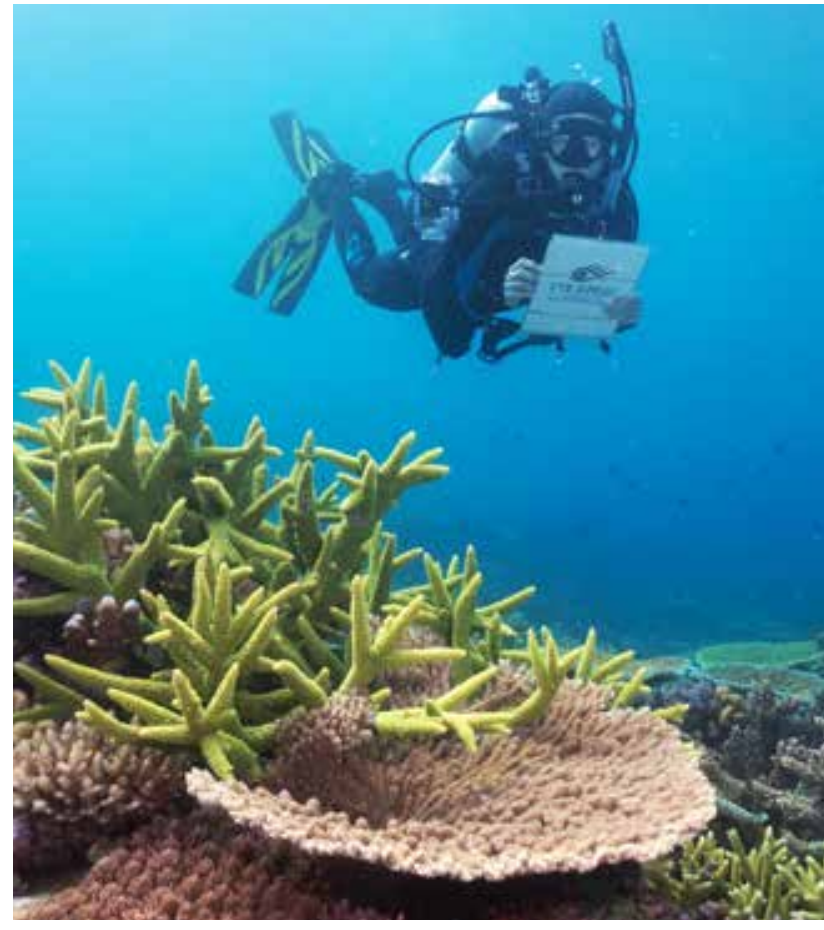




\section{Inputs: program support}

Stewardship is based on voluntary participation by people who care about the health and future outlook for coral reefs. While regulatory mechanisms such as laws, permits and fines can be important to set minimum standards and reduce the risk of individuals causing unacceptable harm, stewardship is aimed at inspiring and enabling actions that make a positive improvement to the health of the reef. Stewardship programs therefore must be built on a foundation of shared values, trust, cooperation, respect and recognition. Building the necessary relationships and capacities among participants requires a diversity of inputs from both the host organisation (program support) and from the participants (community support) (Figure 5). Whether formal or informal, a stewardship program is a form of contract between the host and the participants, with both parties having responsibilities to provide the relevant support and inputs if the program is to be successful. A general understanding of these inputs can be crucial to developing a realistic implementation plan for a stewardship program.

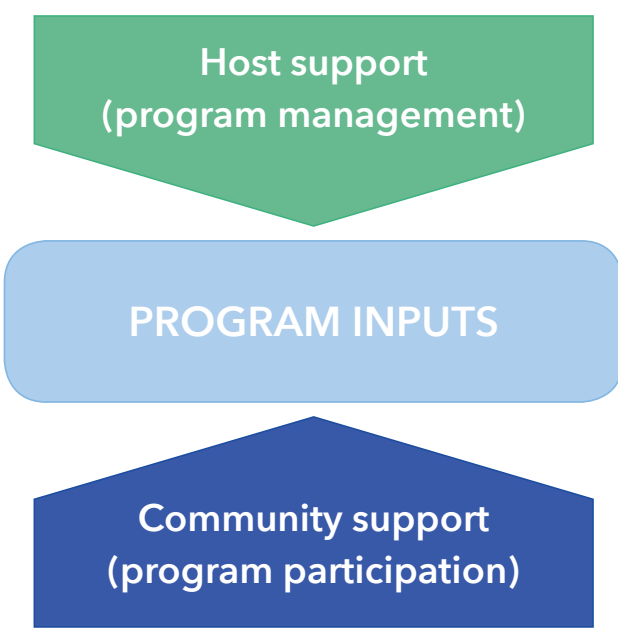

Figure 5: Community support through active participation and host support in the form of program management are essential inputs for a successful stewardship program.

\section{Host support - inputs from the program} management organisation

The host organisation can provide program support through a range of inputs, including:

- Education and access to information: Serve as a facilitator for participants and communities, providing access to information and knowledge they need to make informed and positive environmental decisions.

- Training, resources and knowledge: Build stewardship capacity by providing support, training, and resources to enable the uptake of desirable actions to address key reef issues.

- Recognition and promotion: Promote and provide recognition of actions that benefit the reef environment. Communicate and showcase participants and program achievements to the broader public and communities.

- Practical and administrative support: Provide practical direction for the program and administration services that facilitate the successful day-to-day delivery of the program.

- Communication channels and networks: Foster and promote networks of sharing and knowledge between participants, the host organisation and partners to effectively communicate key program messages and achievements.

- Ensure transparency and manage public expectation: Provide a sound governance arrangement for the program in the short and long term.

\section{Community support - inputs from program participants}

There are many ways that participants can share in the responsibility of the program. These inputs collectively represent the community support to the program, and can include:

- Interest, time and resources: Support exchange of knowledge, and the sharing of best practices. Participants should willingly give time and personal resources to the program and showcase their stewardship activities to others.

- Understanding and awareness: Foster community and industry awareness and understanding of reef issues through promoting activities that support the ecological, social, cultural and economic objectives of reef stewardship. 
- Cohesive relationships: Well-structured networks connect individuals and communities. This can help to normalise practices and build solidarity and a sense of contributing to the 'bigger picture'. Well-connected communities are more likely to share information and resources, and learn from one another. Participants will foster cohesive networks through regularly engaging with others in the program, community and the program host.

- Connection and value of the reef: Reef communities hold a range of values for their reef and surrounding environments. These values may be cultural, spiritual, economic, social or physical, or a mixture of these, and demonstrate continuing connections with the region and its natural resources. They will form the basis of participants' aspirations and motivations to engage in stewardship to protect the reef.

- Responsibility to protect the reef now, for future generations: Participants have a sense of responsibility, rather than necessity, that guides their thinking and actions.

- Leadership - enabling and encouraging others to follow: Important in all areas of capacity building, leadership has been found to be integral to the success of stewardship programs. Effective leaders convey a shared vision that motivates and empowers people, focuses activities, and provides confidence in the management process.

\section{Stewardship capacity: attitudes, knowledge and skills}

Stewardship begins with good intentions, but it takes more than that to make a contribution to improving the resilience of local coral reefs. Helping to ensure that your community of participants has the capacity to translate attitude to action is an important function of a stewardship program (Figure 6). Understanding capacity needs and implementing activities that can build capacity should be the focus of collaborative efforts involving the program team, participants and the broader community.

Knowledge of the attributes of stewardship can help program managers and community leaders identify critical capacity requirements. Some of the attributes that underpin effective stewardship are summarised below.

\section{Attitudes}

- Appreciate and advocate for the importance of natural and social capital

- View regulations only as a benchmark to achieve and exceed

- Prioritise protecting the local ecosystem in daily decisions, practices, values and ethics

- Inspire and motivate others

- Believe in shared responsibility and working together towards a common cause

- Actively share opinions and knowledge to influence the beliefs and behaviours of others

- Lead by example.

Knowledge

- Understand the role of a healthy ecosystem in social wellbeing and economic opportunity

- Recognise limits to ecosystem services and demonstrate awareness of 'carrying capacity' of reef and catchment systems

- Perceive the implications of personal actions for the health of the reef ecosystem

- Understand the importance of social networks and how to influence people

- Aware of importance of full life cycle of products and services.

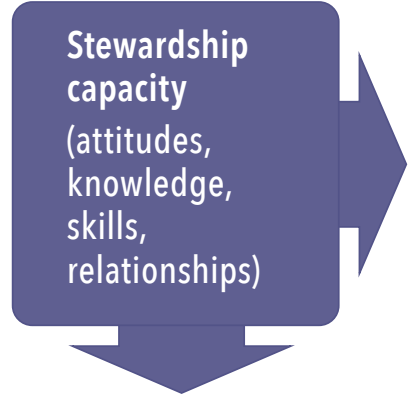

Figure 6: It is essential that participants in a stewardship program are supported to develop the necessary capacity to act as good stewards.

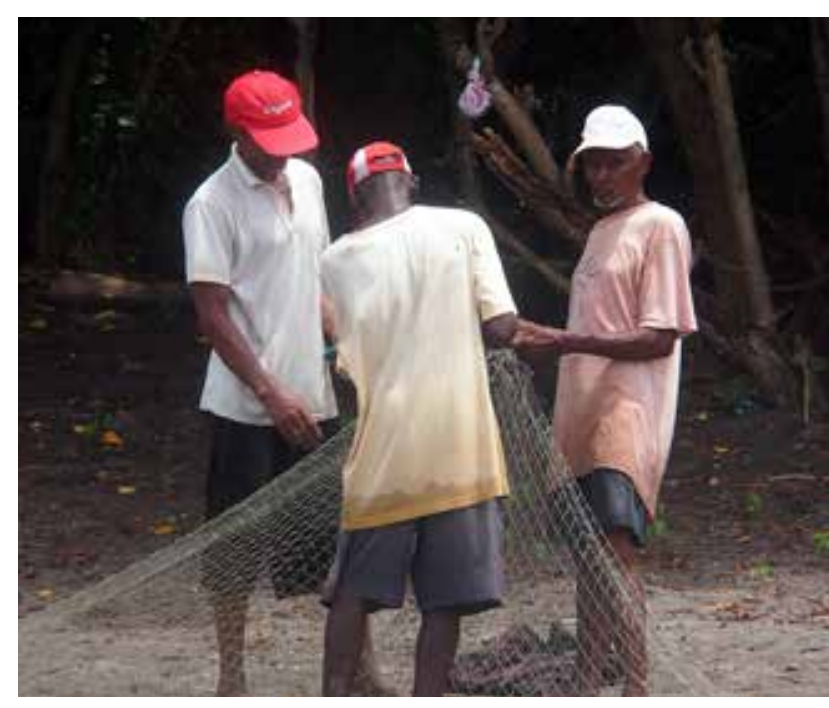




\section{Skills, technology and tools}

- Familiar with ecosystem monitoring indicators, methods and tools

- Knows how to work with industry to influence practices and policy decisions

- Has the technical and planning skills to adapt and improve activities in response to monitoring and feedback

- Keeps up to date with training and advances in new technology

- Incorporates sustainability ideas and tools into home and business management

- Routinely utilises new technology and practices in pursuit of continuous improvement.

The phases of a stewardship

program and examples of indicators

of success

Foundational activities - for example,

gaining management approval and

commitment from participants to be

involved.

Planning activities - this may include

gap analyses, audits of existing

activities and action planning.

Short-term outcomes - such as the

number of participants, amount of

media coverage or an audit of the level

of participation in program activities.

Medium-term outcomes - these may

include the number of new partnerships

formed and indications of sustained

stewardship activity.

Long-term outcomes - do ecological

monitoring results show an improvement

in reef health attributable to stewardship

activity? Is there evidence of participants

influencing others in their community to

take up reef-friendly actions?

Aspirational goals - are the collective

outcomes from the program contributing

toward the vision for reef management?

\section{Indicators of success}

Stewardship initiatives should have goals for each of the main phases of the program to help define success and assess progress and performance. Before a program is formally launched, there will be a need for foundational and planning activities. Once under way, the program should be steered by shortterm, medium-term and long-term goals, all guided by the overarching vision, which is informed by aspirational goals. For each of these phases, the program should have clearly defined outcomes and indicators of success.

Although the overall aim of reef stewardship programs is to build the health and resilience of the reef, indicators of success may also be social, economic or cultural. Program managers and community leaders will find it is valuable to measure behavioural change as well as indicators of environmental outcomes. Behavioural change is likely to be measurable over shorter time frames, and some of the key outcomes for sustainability of the program relate to behaviours, so a focus on behaviour may make sense for your program objectives and related monitoring and evaluation efforts. A program logic, log frames or causal chain analysis can help connect short-term actions with longer term outcomes and this can greatly aid planning and reporting (Figure 7 ). When deciding on indicators of success, it is recommended that you give attention to setting the timing of each program phase, and the timing and process for reporting.

Indicators of success can include administrative outcomes (such as signing an agreement with a partner or signing up a participating school), behavioural outcomes (target number of people participating in the program or a specific activity) or environmental outcomes (targets for reductions in litter or improved water quality). As the program progresses and matures, indicators can be expected to evolve from administrative to behavioural, and eventually environmental outcomes. Having a logical frame that connects activities to outcomes can help map indicators at each stage to higher level outcomes, even illustrating how program activities are contributing to the long-term vision for reef management. 


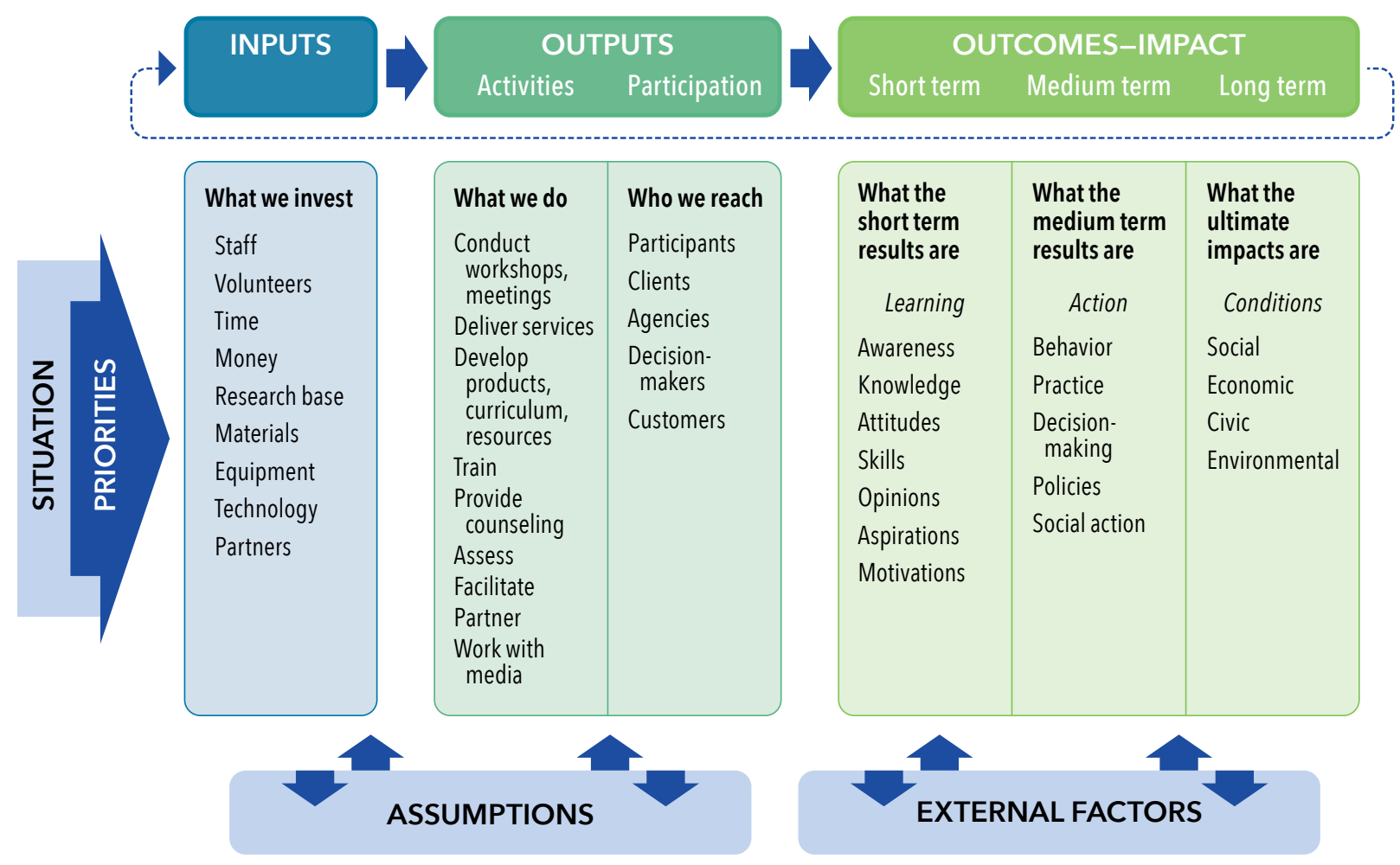

Figure 7: An example of a program logic framework, showing how inputs are mapped to outputs, which are connected to outcomes (impacts of the program). Program logic planning also encourages explicit statement of priorities and recognition of assumptions.

\section{From theory to practice}

Now that you have a framework for formalising and increasing stewardship activities, it is time to put theory to practice. The next section provides a step-by-step guide to help you design your own reef stewardship program, but be sure to allow time to lay a strong foundation for your program. It is important that you invest effort in planning the process, securing the necessary support from management, engaging community leaders and involving stakeholders/sectors meaningfully. It is tempting to rush in to planning and initiating activities, but remember that true success comes from sustainability of the stewardship program. Sustainability is much more likely through a measured, strategic approach to building relationships and program planning. If you get it right from the start you and participants will benefit in the long run.

The step-by-step guide in the following section provides much of what you need to get started; each stewardship program will be different, so we have focused here on providing the general concepts and lessons from previous programs that are likely to be helpful in most situations.

\section{The journey of stewardship begins with a single step}

Stewardship programs can be as simple or as complex as you wish - if you are daunted by the prospect of establishing a formal program, start simply and allow the program to evolve over time. Remember that stewardship is a shared responsibility: once you start the conversation you may find that stakeholders and partners quickly step up to share the burden of organising and running a program. Additionally, the number of formal reef stewardship programs is increasing all the time, so it is likely there is someone near you, or in your extended network, who you can contact for guidance and advice. These days help is only an email away! 


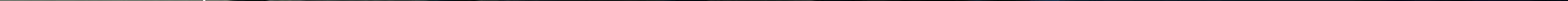




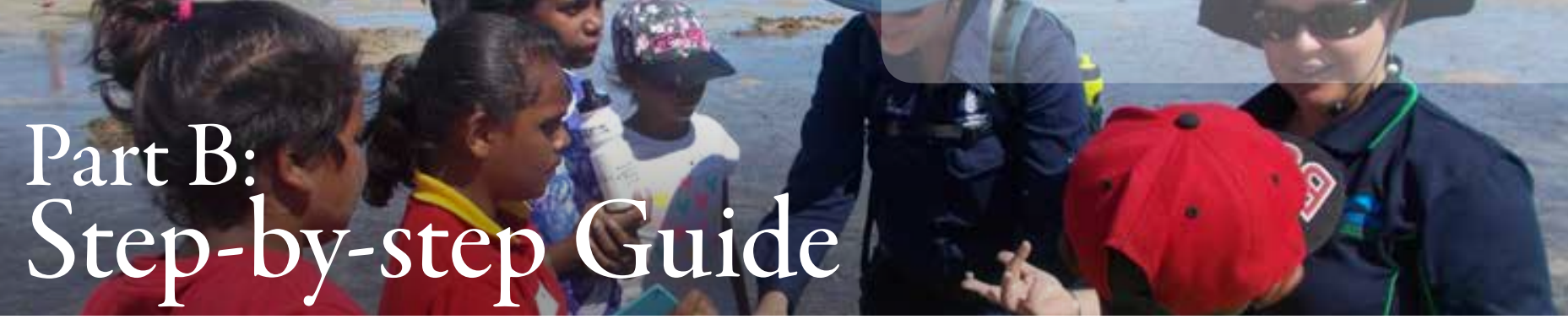

Congratulations! You have decided to embark on a reef stewardship journey. Perhaps you've seen another stewardship program in action, or discovered some of the ways stewardship can help achieve management and conservation goals.

Each and every stewardship program is bound to be different. The community-based nature of reef stewardship requires an individual and flexible approach be taken in each circumstance. This guide provides general guidance to enable you to design and implement your own program, but it should not be used as a specific blueprint. The geographical location, participants and partnerships, resources available, and capacity will set the specific scope and character of each program. Other considerations, such as who manages the program, how participants are engaged, and how they can contribute will also influence the journey and ultimately the outcomes for your stewardship program.

The step-by-step guide is comprised of four sections, covering 14 steps to help you develop your own reef stewardship program (Figure 8).

The resource section at the end of the guide provides additional information and links, including worksheets that can assist you through certain steps in the process.

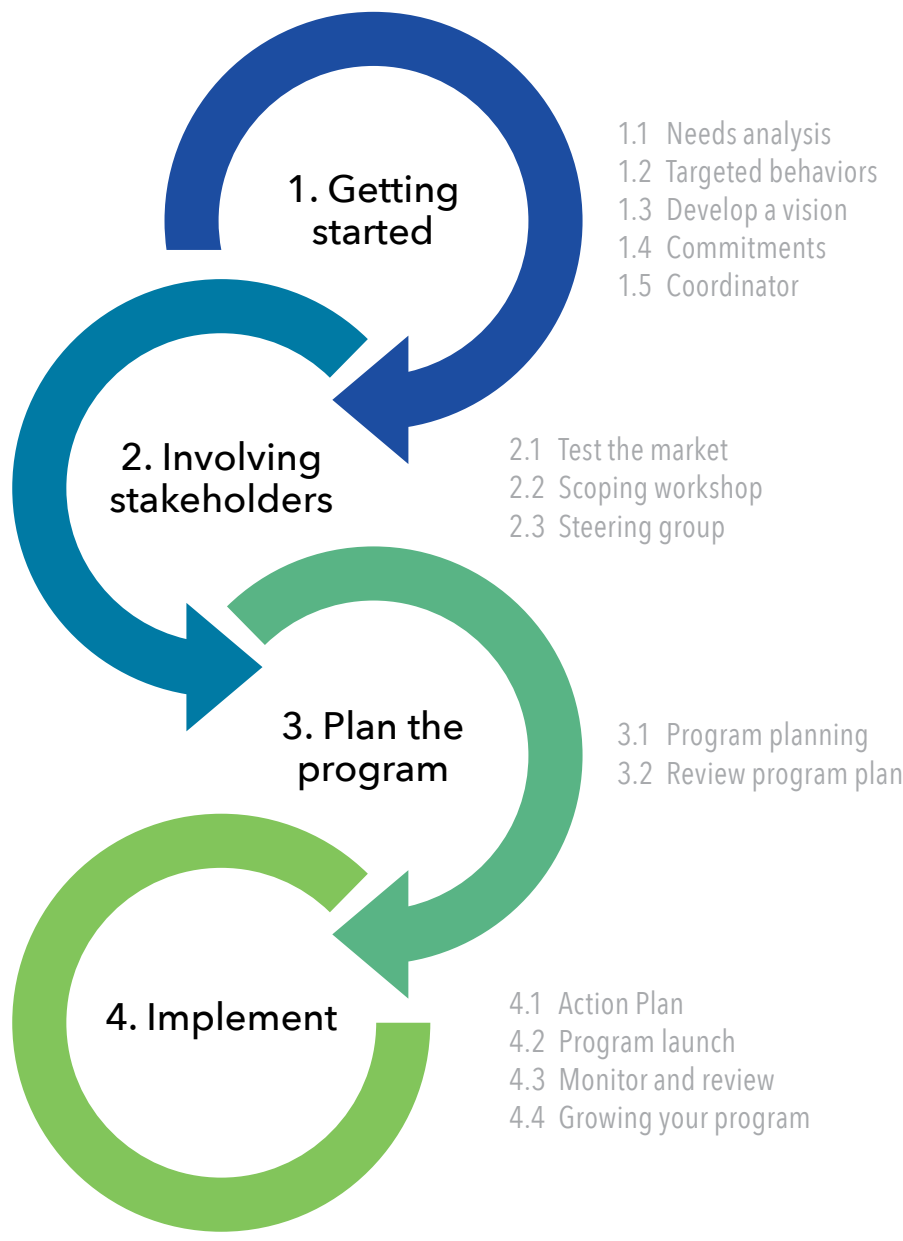

Figure 8: Four stages to developing your own reef stewardship program. Each is covered in its own section in this step-by-step guide.

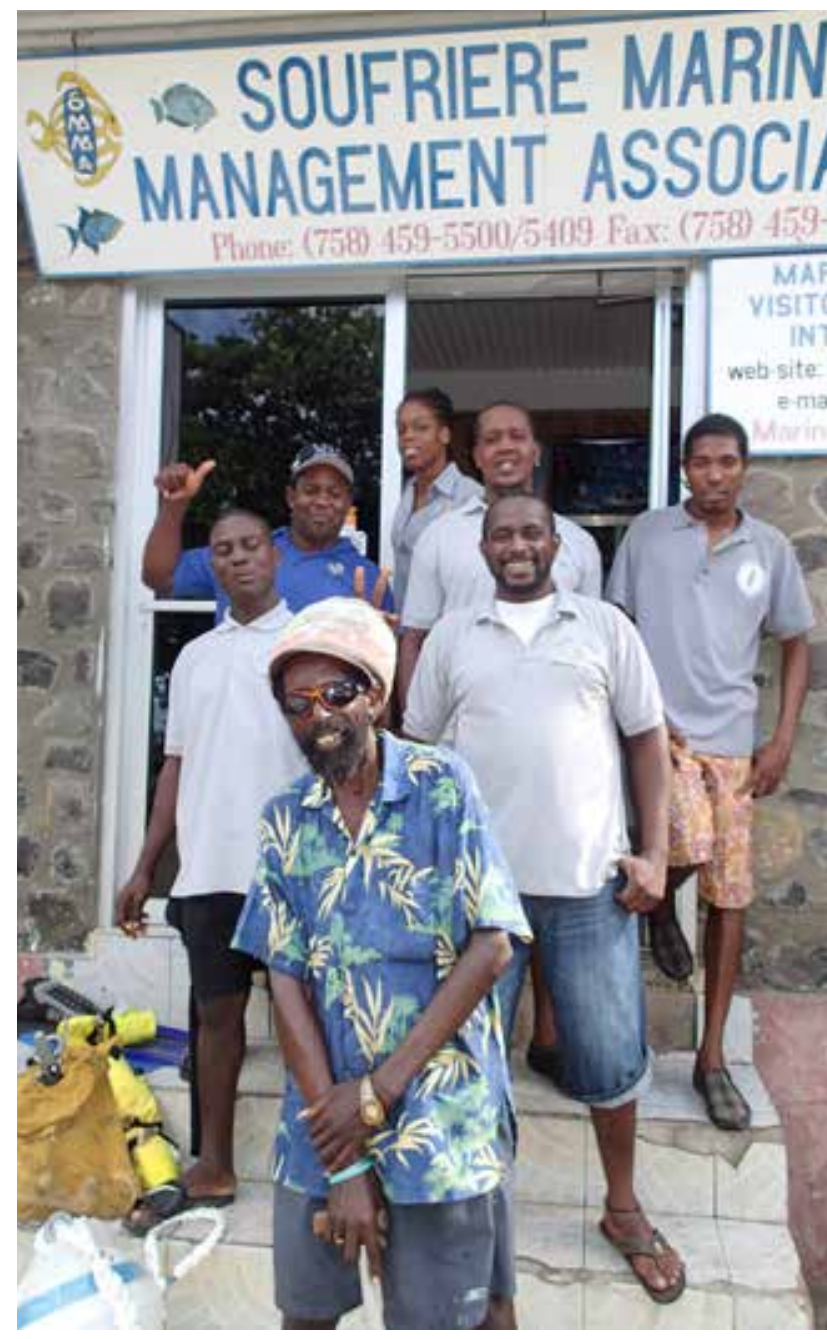




\section{Getting started}

The following five steps will help you get started. It is recommended you follow them sequentially to maximise success in the early stages of your program or pilot project.

1.1 Conduct a needs analysis

1.2 Identify targeted behaviours

1.3 Develop a vision and framework

1.4 Gain commitment

1.5 Establish a local coordinator.

\subsection{Conduct a needs analysis}

A needs analysis is the essential first step on your journey to a reef stewardship program. This step can be used to gain an understanding of the skills and interests of your reef community and the priority issues for reef management.

Reef management authorities often will have identified key stresses and issues affecting local coral reefs, and this should be the starting point for exploring possible solutions and actions that could be the focus of a stewardship program. Combining this analysis with a participatory process that determines what is important to the community can help you focus your efforts within the list of management priorities.

A needs analysis is best done as a collaborative process

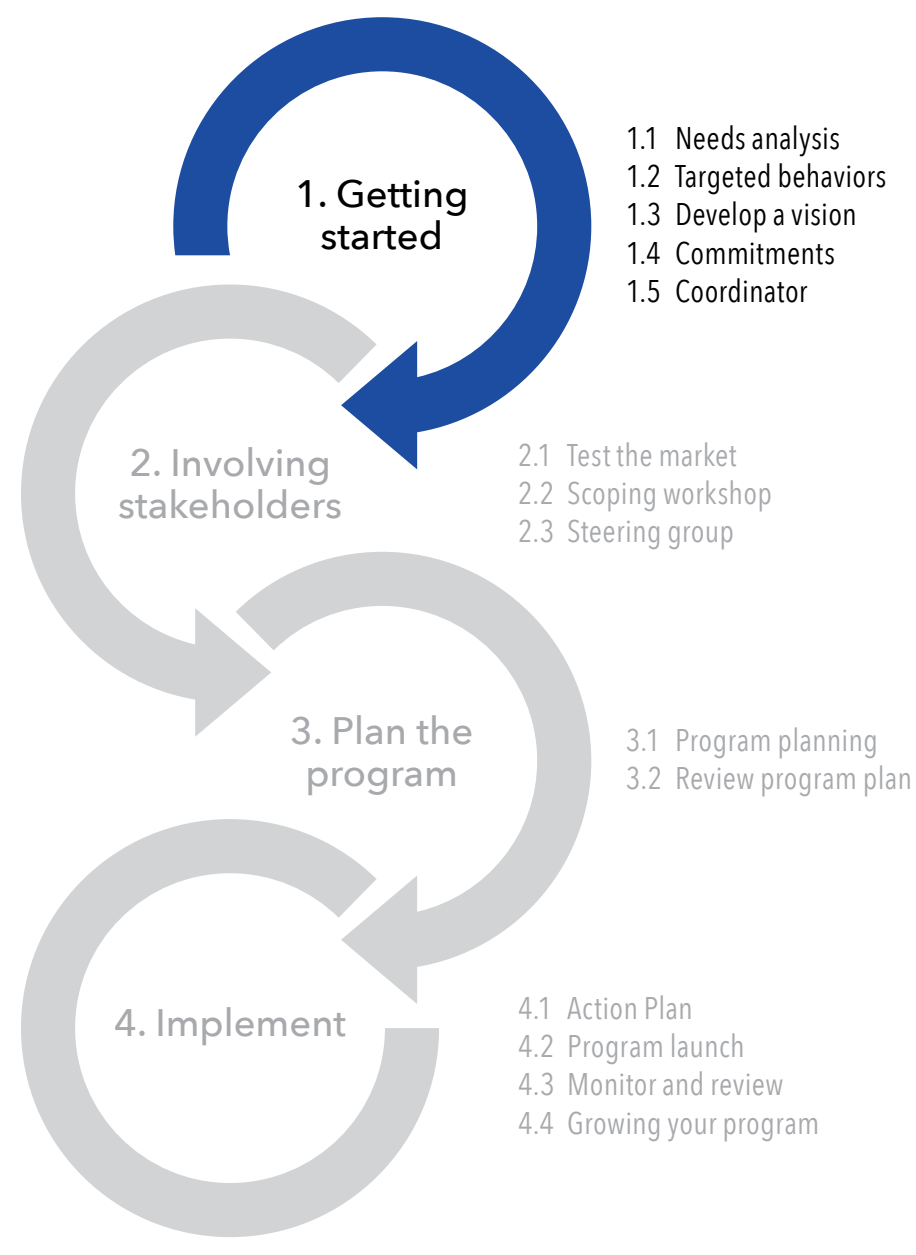
involving reef managers and key stakeholders. The results of any surveys done as part of a market segmentation analysis can inform discussions about stakeholder interests and priorities. Stakeholders (resource users and groups whose activities can impact the resource, such as farmers) are best represented by relevant engagement officers within the organisation, or by members of stakeholder groups who have leadership positions and/or good relations with the management agency. The process can involve a workshop format and/or a desktop review. Either way, it will be helpful to work through the following four steps (Figure 9).

Identify and prioritise potential impact areas

The key is to start broadly in identifying the gaps between the desired and current conditions. This will help identify priority areas of focus; for example, poor water quality, overfishing or climate change impacts. You can also explore specific geographical impact areas to discuss priority areas of the program.

\section{Stakeholder mapping}

Mapping is a collaborative process to determine a key list of groups, organisations and individuals across the stakeholder spectrum and analyse their perspectives, interests and relevance to your marine environment. Are they sources of impact? How do they use or rely on the reef? Could they potentially be involved in the solutions?

\section{Identify possible solutions}

With our priority impact areas and key stakeholder groups identified, we can combine the two to explore the sources of impact and potential solutions. Examples might include increased monitoring, targeted activities, 
raising awareness, building capacity, or increasing support for traditional management activities.

\section{Situation analysis}

Identifying appropriate solutions within the context of your situation will then provide an indication as to whether a reef stewardship program could be a viable option to closing the gap and, if so, what it could achieve. Will it build health and resilience of your marine environment by targeting key impacts? Will it serve as an awareness and recognition program influencing others to act? Could it be all of these? What resources would be required?

The time required to complete a needs analysis will depend on many factors such as your experiences, scope of assessment and availability of data to inform your decisions.

\subsection{Identify targeted behaviours}

The goal of stewardship programs is to recognise and encourage behaviours that will contribute to the shared goals of reef managers and the community. There is likely to be a large number of activities of potential interest, so it is important to identify those that are most relevant and achievable, and most likely to result in meaningful outcomes. You can identify potential activities by answering questions such as: Which behaviours can lead to good reef water quality? What actions improve fish stocks? What can school children do to change attitudes and behaviours of the wider community in relation to the reef?

It is good to identify targeted behaviours early in the design phase to help guide the scope and orientation of the program. It is recommended to combine this step of identifying target behaviours with the needs assessment workshop as reef managers and other key stakeholders will already be together and thinking about objectives, targets and actions.

Following the steps below will help you to identify which behaviours are the most worthwhile to target through your stewardship program.

Select a focal issue. From the list of priorities identified in the needs analysis, select one as a focus for your stewardship planning discussions. The following steps will use reef water quality improvement as the focal need to illustrate the process.
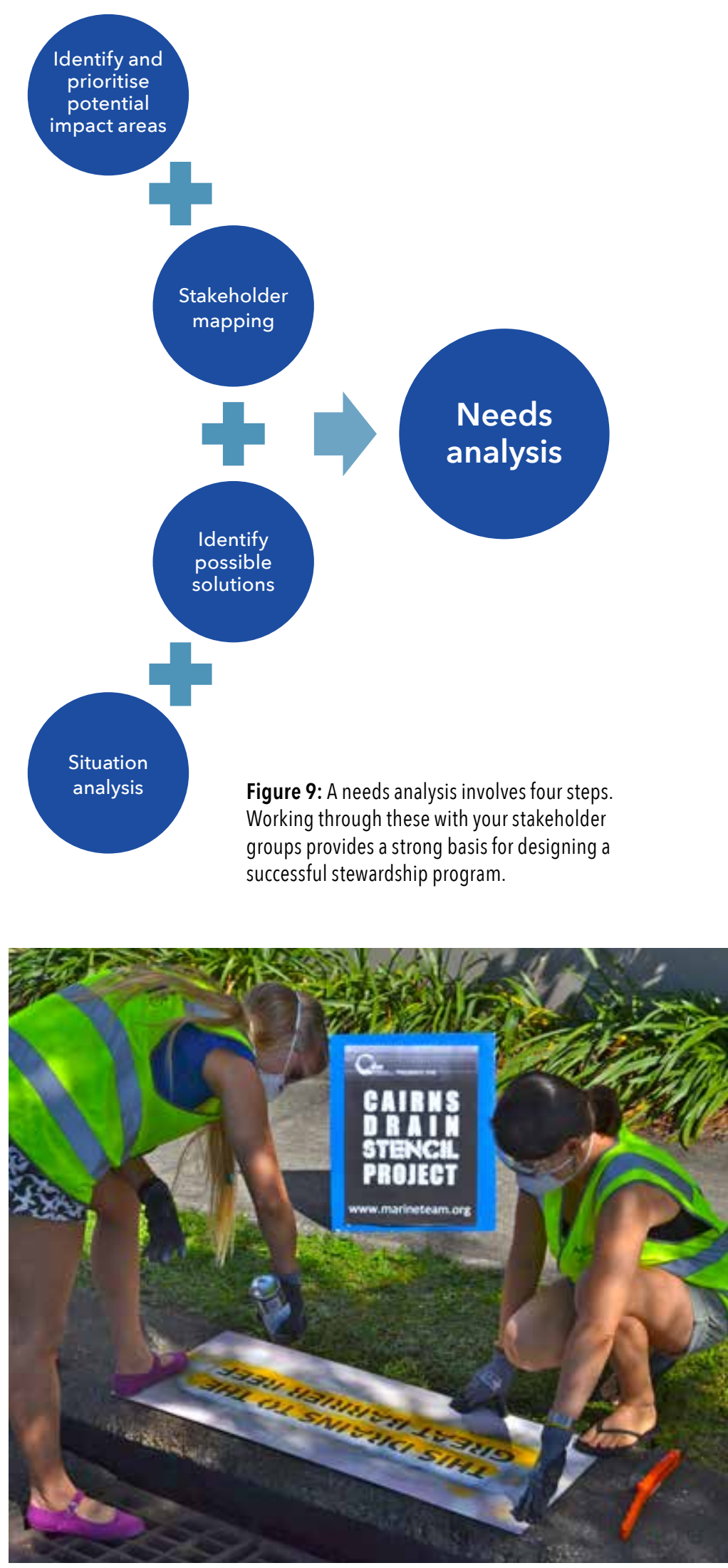
Select a target sector. Use the stakeholder mapping information from the needs analysis to guide discussions. Which sectors (residential, industrial or rural) have the most impacts on reef water quality?

Recognise different sources of impact. Using the farming sector as an example, we would seek to determine if there are different categories of impacts from this sector (e.g. vegetation clearing, loss of ground cover from overgrazing, excess fertiliser use, herbicides and pesticides that damage streams or marine organisms).

Define targeted behaviours. Behaviours should be 'end state' and 'non-divisible'. End state refers to the end behaviour that will lead to the best, desired outcome. For example, encouraging farm supply shops to stock biodegradable chemicals is not end state if your targeted behaviour is reduced application of pesticides and herbicides by farmers in the catchment. It may still be a useful way of encouraging targeted behaviours, but it is important that it is not mistakenly used as an end state for on-farm behaviour. Non-divisible behaviours are those that cannot be divided further. For example, programs might encourage farms to "reduce their impacts on streams and waterways". But there are a variety of options for a farmer to reduce downstream impacts of their operations, and these will vary in the barriers to uptake. Try to define your behaviours as specifically as possible to ensure they are definitively linked to the outcome you seek. For example, "replant streamside vegetation to reduce loss of soils and fertilisers from the farm".

Prioritise targeted behaviours. Once your list of targeted behaviours is complete, compare these to determine which are likely to be most readily achieved. The following criteria can help prioritise your targeted behaviours:

Impact - if you choose to address the effect of upstream farms on reef water quality, for example, decide which aspect of farm operations could be modified to generate the greatest improvement in water quality.

Existing uptake - are your participants already engaged in the behaviour you want to encourage, in some degree at least?

Likelihood of uptake - how likely is it that they will engage in the new behaviour? Perhaps you can identify comparable behaviours that are easily transferred across to the specific behaviour you are targeting, or identify some early adopters who can demonstrate the behaviour and assist peers to change.

Seek multiple benefits. If you would like your program to address multiple impacts across different sectors, it can be helpful to create a matrix listing behaviours against impacts (outcomes) for each sector or need that you wish to focus on. You can then identify behaviours that will have the greatest impacts across multiple areas. Focusing on these will deliver efficiencies both in the outcomes and also in the inputs required.

Although this may seem like a time-consuming approach, it will help you make more informed decisions in program planning and help you select indicators for monitoring progress. The priority activities/behaviours may change as new information from participants, partners or research is gathered during the pilot phase. In later sections you will extend the planning to define solutions, actions or activities that can help foster certain behaviours. Behaviours may also have positive outcomes other than addressing specific environmental issues, such as reducing overall pressure on the reef, building social resilience, fostering leaders to influence and motivate others, and assisting reef management ${ }^{1}$.

\subsection{Develop a vision and framework}

This step helps you develop your program framework (or strategy document) that sets out the path to stewardship success.

The framework comprises a vision characterised by clear goals, specific objectives and achievable strategies. It draws on discussion and outcomes from the needs assessment and behaviour identification workshop sessions.

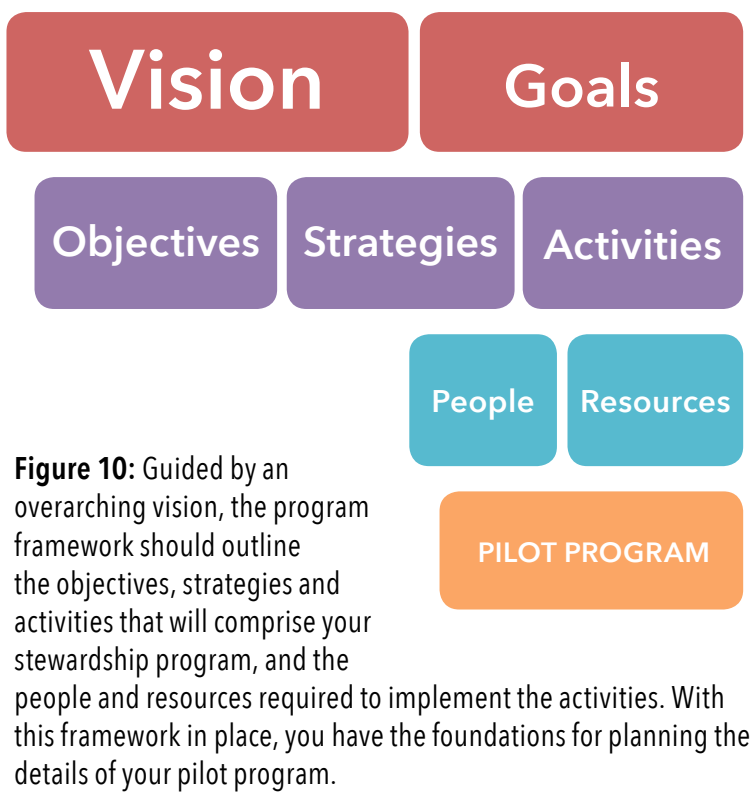




\section{From aspirations to actions: a brief review of the elements of a strategic plan}

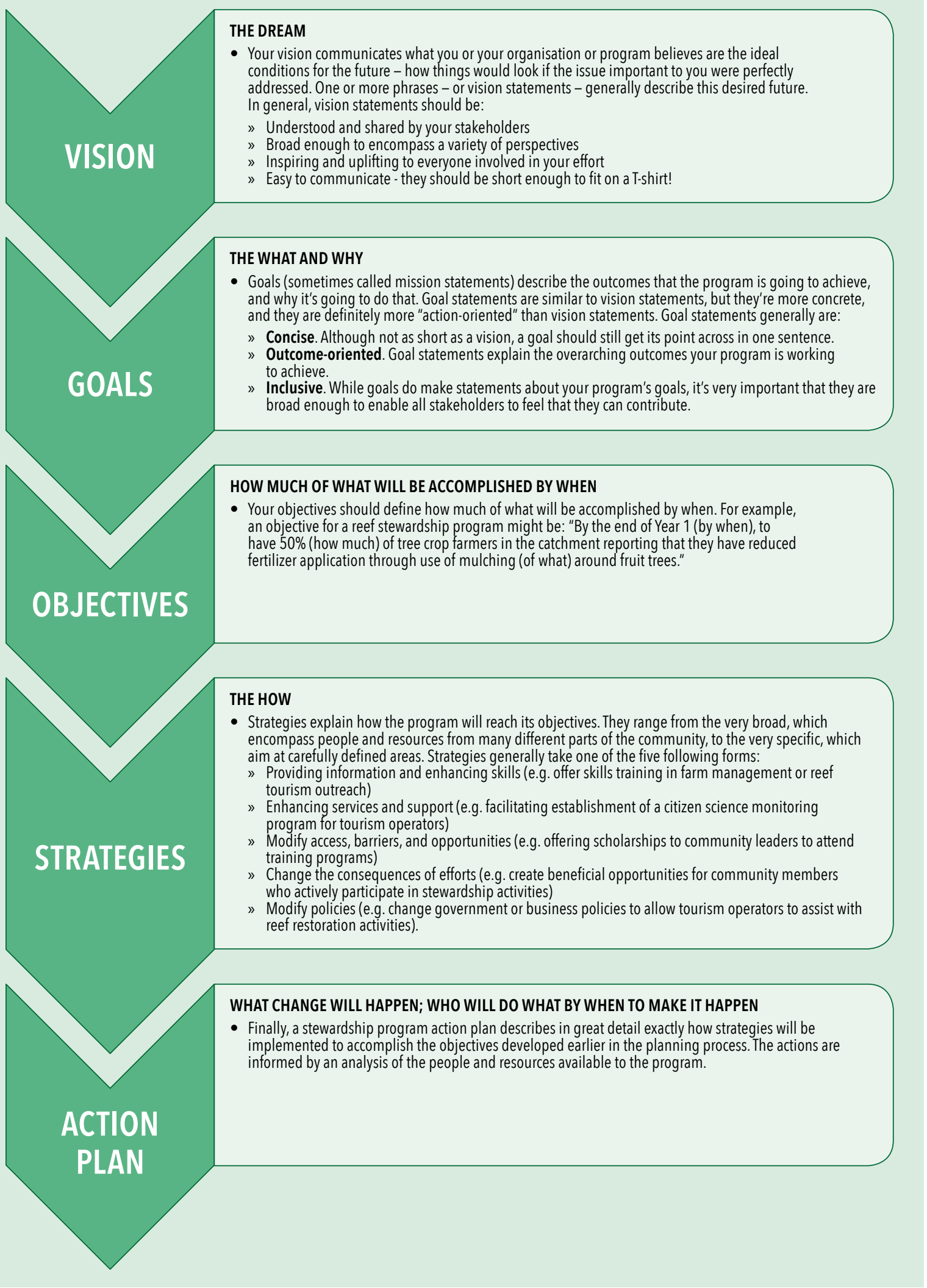


At this early stage it is advised to keep it simple. Most of the detailed design of the program will be accomplished with your participants and partners during the development and implementation phase of the program, but a simple framework document can greatly aid and accelerate this process.

Some simple steps to assist you develop your program vision and framework are provided below.

\section{Vision}

The first question to ask is "What do I want the program to achieve?" How can stewardship contribute to the broader vision for reef management? Given this vision, what are the long-term goals of the program? In an ideal world, what will the program achieve after 10 years of successful operation?

\section{Approach}

How are you going to achieve the goals and contribute to the program vision? Each and every stewardship program will be different, even if the desired outcomes are similar. After all, participants, resources and capacity will influence - usually strongly - the approach you take to achieve your vision. The key elements of a framework (Figure 10) are explored below.

Objectives: After you've decided on your vision and goals, you need to work out how the program can contribute to these long-term outcomes. Program objectives are broadly stated and help to direct both the short- and medium-term implementation of activities and actions.

Strategies: What are the conditions (interest, resources, capacity, political support, etc.) necessary to achieve the objectives? What strategies will the program put in place to ensure these conditions are met?

Activities: What actions and activities will you undertake to implement the strategies to accomplish the program objectives? For example, if fostering behaviour change to address anchor damage is an objective, what will need to be done, by whom and in what time frame? Remember that only an outline of the types of actions is necessary for your program framework. The detailed actions will be defined as part of the program plan development process later on (Section 3).

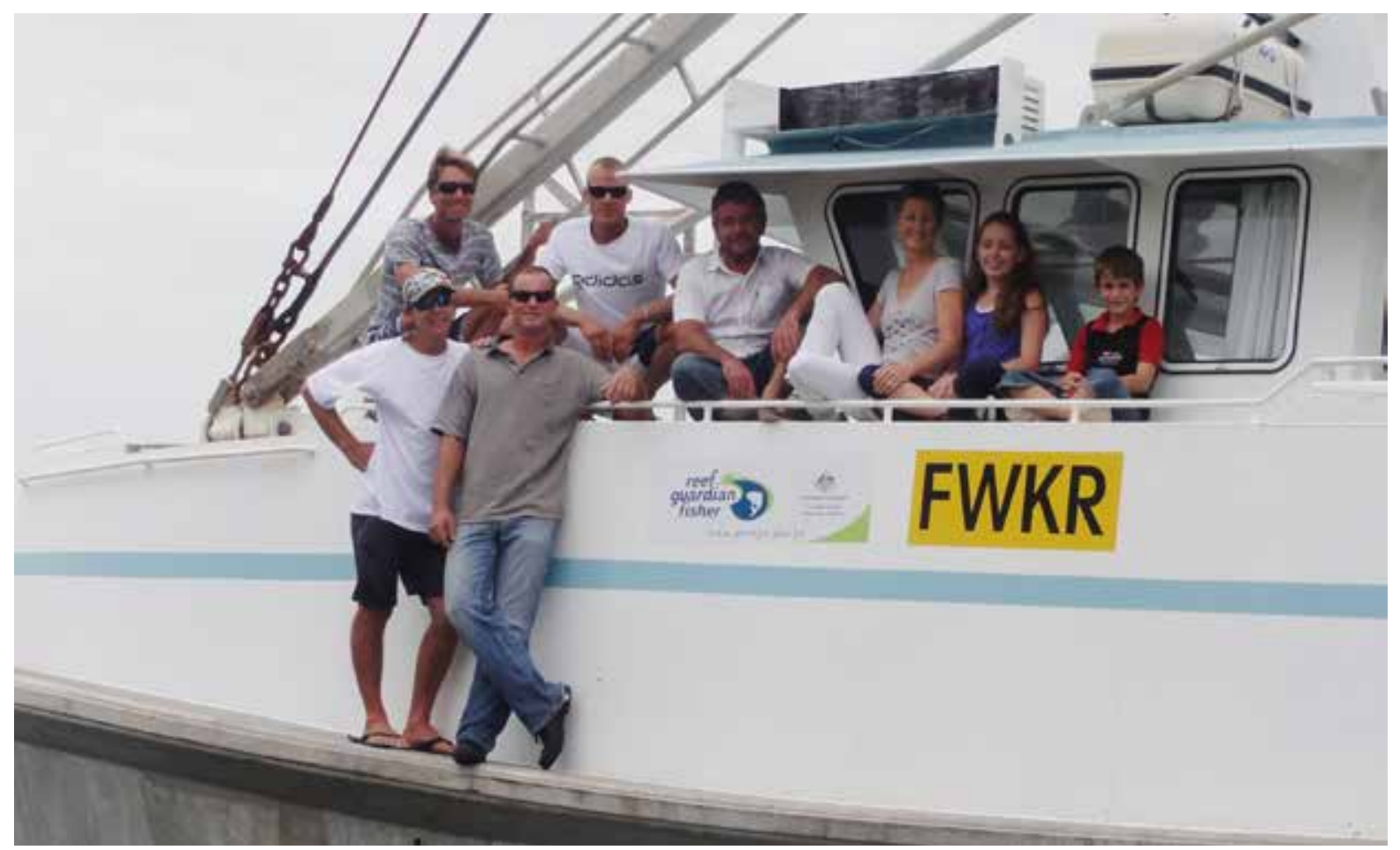




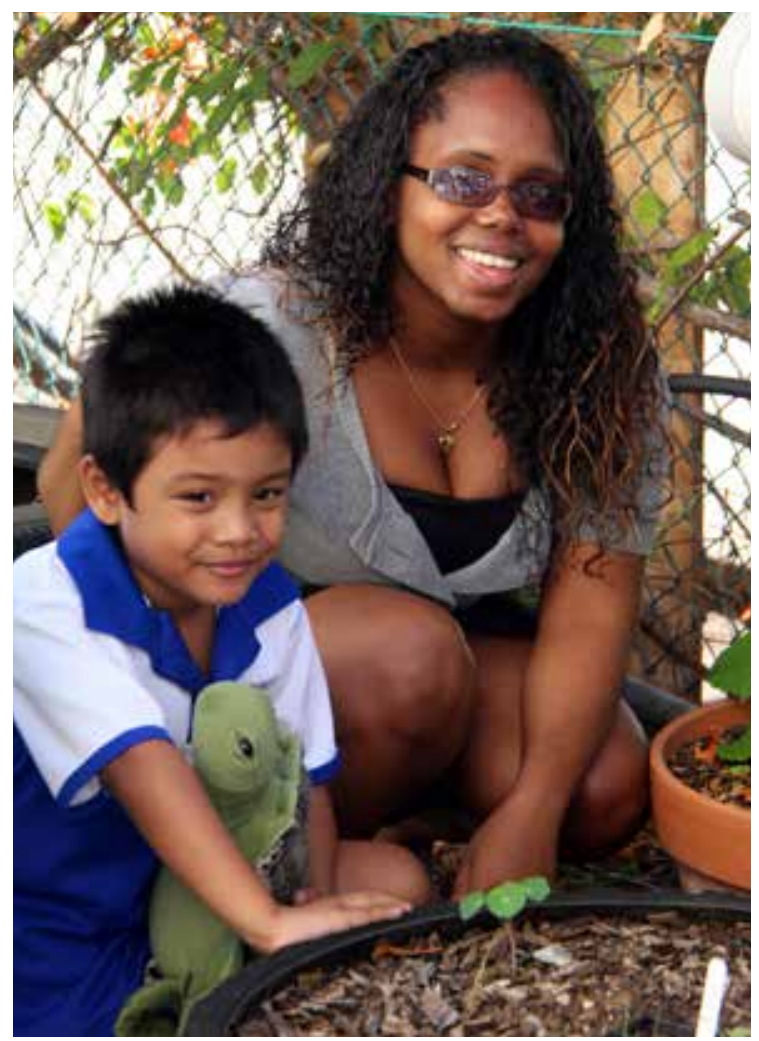

People: Who are the sectors that you plan to engage with? How do you plan to gain commitment from participants to be involved as well as community and partnership support for the initiative?

Resources: What resources will you need: e.g. staff, funding (in-kind and financial), materials, skills and knowledge? How will you acquire these resources?

\section{Piloting}

A pilot program can be important for testing the concept and the planned approach, for demonstrating the idea to partners, and for convincing participants and key decision-makers that a reef stewardship program is a worthwhile long-term commitment. This has been the approach taken by existing Reef Guardians stewardship initiatives in Australia and Grenada.

A pilot is a smaller scale, short-term program that helps an organisation learn how a large-scale program might be implemented. In an attempt to improve upon the program design prior to launching a full-scale program, pilots are often conducted to work out the feasibility, probable time commitments, financial and in-kind resources, challenges and expected successful outcomes. This is important to keep in mind when exploring your vision and approach for the program (pilot and beyond) as your objectives will vary over time. Again, the details of the pilot program are best fleshed out later in the process - for now it is adequate to describe the general scope and intent of the pilot program.

\subsection{Gain commitment}

Gaining commitment is an important part of a reef stewardship program. Commitment is required from key players such as:

- the host organisation and program team

- community leaders and senior public officials

- funders

- other partners charged with managing the marine and adjacent catchment environment, and

- the individual reef stewards who will form your participant network.

At this early stage you should be looking only to gain commitment from the host organisation and marine management authority (if they are not also the host). Gaining commitment from potential program participants is covered in Section 2. Later sections also discuss the use of formal commitments as mechanisms for assisting behaviour change, such as public declarations and signage that acknowledges and promotes program participation.

Commitment from the host organisation and from the management authority (where they are different entities) may be in the form of a resolution or endorsement of the program concept. It may be necessary to present a formal project concept or proposal in order for relevant decision-makers to approve staff allocating time and resources to the program. At the minimum, a formal briefing or presentation about the vision and 
intended program approach may be required to gain necessary approvals. This will also help build a case if funding is required, and outline to management the key partners and other community stakeholders that will contribute to the success of the program through possible in-kind or financial support.

The host organisation needs to recognise the program as a priority management activity so staff and participants can have assurance of support during the period of the pilot and possibly beyond. A strong monitoring and evaluation component to the program can be critical in giving management confidence that the program's effectiveness can be monitored and adjustments made in response to changing conditions.

\subsection{Establish a local coordinator}

The success of a stewardship program is highly dependent upon enlisting a coordinator to oversee its management on behalf of the host organisation. Recruiting the right coordinator takes time and effort as this person needs to understand the community and local issues. They should be passionate about the reef and the role of community, and they should be approachable, trustworthy and reliable: they will be the community face of the program.

While the coordinator doesn't necessarily have to be local, this will be beneficial, as they are likely to spend a lot of time in the community with stakeholders and participants to provide guidance and support through the different program phases. A coordinator who knows the region, has experience coordinating

\section{Choosing the right coordinator}

When developing a position description for your stewardship program coordinator, you might like to consider including some of the following knowledge, skills, experience and responsibilities.

\section{Knowledge, skills and experience}

- $\quad$ Strong track record in community engagement and outreach activities

- Ability to synthesise technical and scientific information to communicate key messages to participants and community

- Excellent communication skills (verbal and written) Media experience will be beneficial

- Skills or experience in producing communication products

- Knowledge of environmental issues relating to coral reef management

- Experience working with government organisations and conservation groups

- Demonstrated commitment to conservation and community development

- Good record keeping and project monitoring skills

- Experience in program planning, project management and event management

\section{Responsibilities}

- Serving as the program's contact point and liaison

- Planning and coordinating events

- Ensuring appropriate and timely input and advice to management, participants and other key stakeholders as required

- Supporting on-ground project activities and sourcing extra support (e.g.grants) as required

- Supervising design and production of communication and outreach strategies

- Actively build cohesive relationships with participants and other key stakeholders

- Manage stakeholder expectations of the program

- Foster partnerships and engage scientists, partners and decision-makers in program activities 
similar programs and believes in the vision will further enhance implementation. In their outreach role, the coordinator will be more effective if they are known by participants and key stakeholders (or can quickly establish relations), and able to quickly foster positive relationships.

Local coordination can be provided by an individual or a team of people (depending on your program scope). Coordination personnel may be recruited from inside or outside the host organisation, managed internally or as an external consultant. Your coordinator must be willing to commit for the period of the program pilot and hopefully beyond. You might also consider identifying other existing staff that could provide support and guidance to the local coordinator as needed. Choose the governance structure for the role that will allow necessary flexibility and leadership, while ensuring accountability and continued commitment.

Experience working with similar programs in the target sector(s) will be beneficial (though not essential) to help the coordinator understand the priorities, issues, culture and activities associated with the stakeholder group.
湿: 俩

Your local coordinator should be

someone who can inspire and influence

others, who is a good communicator,

and is also organised, experienced

in program implementation, and

passionate about conservation. 


\section{Involving stakeholders}

Once you've developed a vision and have gained management commitment, it's time to start involving potential participants - after all, what is stewardship without people?

This section guides you through three steps for getting people excited about and supportive of the program concept, initiating community ownership and establishing collaborative governance.

2.1 Early advice and engagement: test the market

2.2 Scoping workshop: take it to the people

2.3 Establish a local steering group.

2.1. Early advice and engagement: test the market

Instead of approaching your target audience straight away, it is a good idea to meet first with some key influential members of the sector groups to test your ideas for a stewardship program. Valuable feedback and guidance is likely to come from industry peak bodies and any local committees identified in your stakeholder mapping that can provide input and advice to program planning. This is also where your market segmentation analysis, if done, will provide extremely valuable information about your stakeholders attitudes, motivations and existing behaviours.

Building relationships with key stakeholders in the initial development stages is critical to the support and success of your program. You might wish to form an initial advisory group comprising a selection of internal and external participants that may have important knowledge about or perspectives on the issues. Contact them to make sure they are interested and willing to participate. The aim of the group will be to provide high-level advice and input about the program concept, approach, target audience and behaviours. They can also act as project 'champions', who can use their networks and community profile to encourage wider community support and involvement.

People are more responsive if you frame the discussion within their perspective. What are their values? What is their understanding and knowledge about reef issues? How could they potentially contribute to the program? To set the scene and engage the group on the journey towards a stewardship program, guide them through a Discovery Session (see "How to run a Discovery Session" on page 38). A discovery session is a workshop-style meeting where participants are guided through interactive discussions about the values and issues associated with coral reefs, the nature and potential of stewardship, and potential solutions to reef-related problems that could be assisted through stewardship activities. At the end of the session, you should have the broad concepts and activities of a stewardship program starting to form,

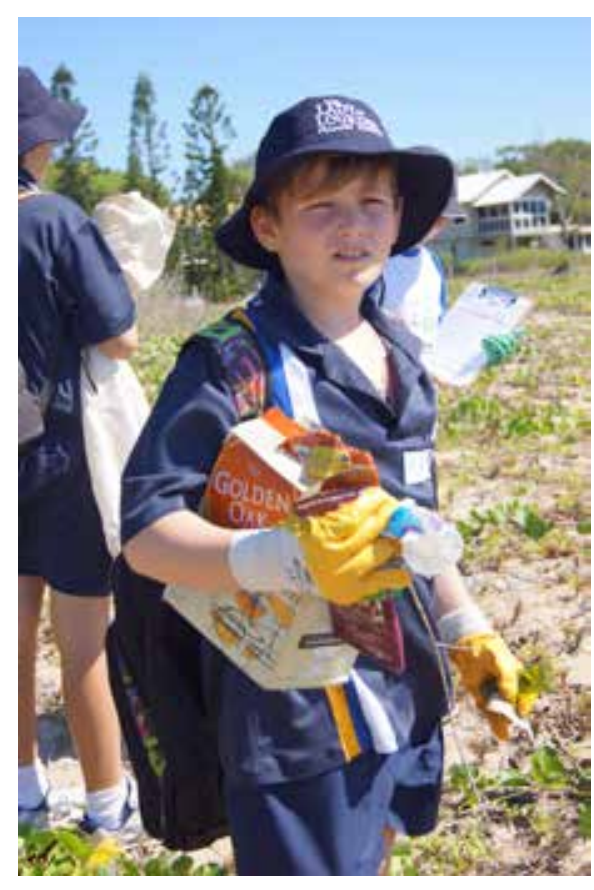


and the group beginning to see opportunities for involvement and the potential benefits to their industry, community or organisation and to the reef ecosystem.

While you have your group engaged, let them know the approach the program will take (developed from activities in Section 1 above) and ask for advice on the next few steps:

- Which sectors or individuals should be involved or targeted for participation?

- What are the barriers and benefits to them getting involved and participating in targeted behaviours?

- Which behaviours should be targeted and prioritised?

- Who should be invited to an initial stakeholder meeting and what would be the best method of approaching them?

- Would any of the group like to stay involved or informed of program developments? Are they happy to continue providing advice and input to help steer the program?

Work out how you will stay in touch with members of the advisory group to keep them aware of developments and continue to give them opportunities to provide input and advice.

\subsection{Take it to the people: scoping workshop}

To start the conversation and engage potential participants, organise a scoping workshop for a targeted selection of stakeholders as recommended by your advisory group in the first discovery session (Section 2.1).

Stakeholders are members of the community associated with the targeted sectors who may be interested in participating or supporting the program. The aim is to introduce the concept, get feedback and recruit possible participants to the program.

A meeting or a workshop is more effective than a phone conference or email correspondence as it helps to draw out individual stories and give participants a sense of involvement and belonging.

-

Choosing which sectors to work with

can be aided by identifying established

leaders within the community who might

be willing to be involved and encourage

others. They may already be doing at

least some of the behaviours you want to

promote and encourage, so can serve as

role models for other participants.

During the workshop, set the scene and guide participants through a Discovery Session (see "How to run a Discovery Session" on page 38) similar to the one you did with the advisory group, but this time with a broader cross-section of potential participants. At the end of the session discuss with the group:

- Who would like to be involved?

- How many participants should be in the pilot program? From which sectors? Where should they be located geographically? Are there any key stakeholders not present at the meeting?

- What might the desirable standards of the program be (identify existing standards and practices)?

- What targeted behaviours are they already participating in or would be likely to participate in? What would be the benefits and barriers to their participation in the targeted behaviours?

- Would anyone like to continue providing input and advice (to form an ongoing steering group)? Is there anyone else who should be involved in the steering group (e.g. other potential participants, experts or industry representatives)?

- What might the initial activities look like?

- What are the next steps? What are the actions from this meeting? 


\section{How to run a Discovery Session}

Discovery Sessions are a way to engage your advisory group, and then your founding participants, in the process of developing the stewardship program framework and the program plan (Section 2.1 and 2.2).

A Discovery Session is usually run as a participatory workshop structured around issues and solutions. This guidance provides some ideas and suggestions for working with your group to explore the issues, collaboratively identify potential solutions, and then engage and excite participants about the opportunity represented by a stewardship program. After you have finished the Discovery Session, refer to other questions to discuss with the group from Section 2.

\section{Explore the issues}

The following questions can be used to structure a session to help the group explore the issues:

$\rightarrow$ What are your participants' connections with the reef? Ask them to provide reasons why the reef is important to them. Environmental?

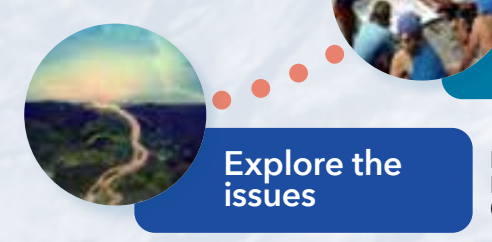

Find solutions together
Pitch it Get down to detail Program vision Social? Economic? Cultural? How are they connected to the reef? Do they use or rely on the reef for their livelihoods or recreation? What are the strengths of their dependency (what would happen if they could no longer obtain the benefits from the reef)? What are their concerns about the reef?

$\rightarrow$ Identify the problems - Discuss the issues, impacts and threats identified by participants, and introduce issues and challenges that are the focus of current management programs. Acknowledge concerns of participants, and explore the alignment and any disparities between local concerns and existing management activities.

$\rightarrow$ Communicate the science and introduce the concept of stewardship. Present an overview of the outcomes of the needs analysis, providing an accessible summary of the relevant science. Communicating this science to the group will be a key aspect of the process of developing a shared understanding and acceptance of the priority issues. It's important not to inadvertently imply blame or negligence in discussing issues, and to focus on solutions. Ensure your group understands the difference between stewardship programs and eco-certification or educational programs.

\section{Finding solutions together}

The steps below can be used to structure a follow-on session to discover potential solutions. You will want to encourage creative thinking, while respecting real-world constraints. Capturing all of the ideas, and then sorting them into categories can help to give value to all contributions, while steering toward a set of solutions that can be the foundation for the pilot program.

$\rightarrow$ Brainstorm solutions: Breaking your group up into smaller working teams, use issues, impacts and threats along with an understanding of the science to propose solutions and stewardship actions. Have participants share the outcomes of the discussions with the larger group afterward to reach an agreement on the priority actions to achieve the best possible outcomes. It is important to encourage participants to be creative and energetic, but also to be realistic about what can be achieved through stewardship actions, and the rate of improvements that can be expected. It can sometimes be necessary to help participants understand jurisdictional issues 
and limitations to the delegation of powers so that they are realistic about the types of activities permissible to citizens. It can be very productive to encourage participants to think about actions that are difficult for reef management agencies to implement, such as working with farmers to address water quality and run-off issues, or working with fishers to help address overfishing or bycatch. Working with schools can help bring the community together to consider ways they can contribute to stewardship activities.

$\rightarrow$ Prioritise solutions: Assist the groups to develop criteria for categorising or prioritising solutions. Ensure criteria are included that are relevant to your program planning requirements (i.e. help differentiate on the basis of costs, capacity requirements, likelihood of achieving expectations, etc.).

$\rightarrow$ Identify leaders: Are there participants or other community members known to participants who are already implementing prioritised solutions? Are there community members who have a track record of community leadership and sustainability action that can serve as champions for the program?

Based on these discussions, you can explore the idea of a reef stewardship program as a way to empower stakeholder groups and local communities to address the issues identified, and to work with other community members for outcomes of benefit to all. The following steps can help you transition toward some specific ideas and commitments that can lay the foundations for a formal stewardship program by the end of the Discovery Session.

$\rightarrow$ Pitch it: Propose the stewardship program as a way to recognise, support and foster these desired behaviours. Could it work? What might it look like? Would they like to be involved?

$\rightarrow$ Get down to detail: Acknowledge the barriers and costs - but also the benefits. What would it take to achieve desired results? What are the benefits to participants of being involved?

$\rightarrow$ Program vision: What are the expectations for the program? What could be the 'brand' of the program? What are the values, what is the image and what reputation do participants want for the program (the brand 'promise')? What is the goal and scope of the program, and what would be required of participants to deliver the brand promise? This can be done in small breakout groups feeding back information to the whole group afterward.

\section{Wrap it up and take it forward}

Bring all of the discussions together in a concluding session. Summarise the key issues and priority solutions that could form the foundations for a stewardship program. Reflect the tenor of discussions honestly, but focus on the constructive ideas and suggestions for moving forward. Summarise the next steps, being clear about what the host organisation is committing to do. It can also be important to be explicit about any limitations and constraints associated with the pilot phase of the program - sometimes enthusiasm from the community in the early stages can exceed the capacity of the host team! It is important to minimise the risk of disenfranchising potential participants through inadvertently raising expectations upon which you cannot deliver. Conclude with an appreciation of the input and participation, and with a commitment to facilitating next steps. 
浑: 而

Small steps and questions are important

to gaining a clear idea of the big

picture. Seeking advice and input is

a great way to start the dialogue and

get people excited about the potential

of the program. Look for leaders and

influencers in your workshop.

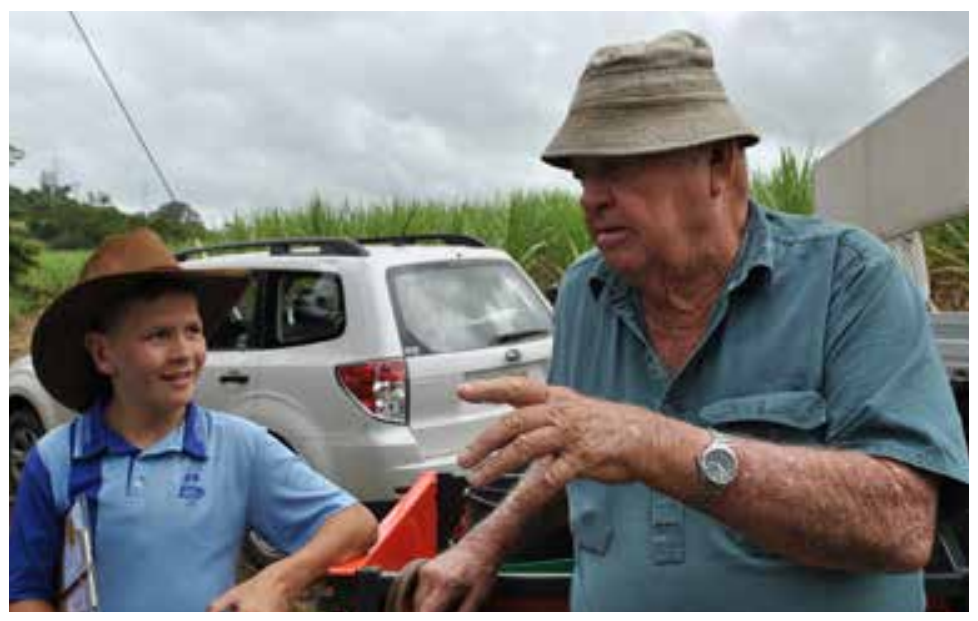

After you've held the meeting or workshop, give stakeholders time to digest the information. Note any attendees who expressed interest to participate in, or support the program at the meeting. You may also consider sending out formal invitations to participate in the program to those who attended the meeting to capture and maintain enthusiasm post-meeting. Keep in mind the number of participants you would like in the pilot program to manage stakeholder expectations.

In the week after the meeting, follow up with participants who have expressed an interest or accepted the invitation to participate. Initially, focusing on a smaller group of individuals who have the strongest interest in the program is likely to be more productive. Confirm their interest, and discuss how the program might work for them and their associates, and how they would like to be involved. Review the outcomes the program is seeking, the benefits to the reef and also to the participants. In this way, you will help establish your initial participants as key influencers within the community. They will be seen as local experts on the program, and help you to engage and inform other potential participants.

\subsection{Establish a steering group}

After connecting with key influencers and your new participants, you should have a better idea of who is best placed to assist you to implement the program through higher level advice and input - a steering group for the program (see "How to establish a steering group" on page 42). This can also be called a stakeholder committee, reference group or working group. Choose the name to suit the context and the preferences of your key participants.

Steering groups form a body of support to the host organisation and coordinator and are essential to help guide the program. They traditionally consider issues, and provide advice and support to the program coordinator on strategic decisions, and can also provide advice on the day-to-day direction of the program. From their unique positions, members can monitor current activities against desired outcomes within the target stakeholder groups.

Other services the group might perform include:

- Informing management decisions (e.g. policy directions)

- Reviewing and providing advice on materials

- Assisting with and attending public events and stakeholder meetings

- Promoting, encouraging and strengthening links between the program and the community.

Ideally, you will look for members to volunteer to participate in the steering group but you may also like to contact other stakeholders from your previous program meetings, including your advisory group. Your first meeting will establish the terms of reference for the group, including the scope of advice, schedule 
of meetings and responsibilities. Stakeholders that might be represented on your steering group include:

- Program participants

- The local coordinator

- Local government staff

- Representatives from the local chambers of commerce

- Industry group representatives

- Other representatives of the management authority

- Educational or school representatives

- Recreational groups and/or services

- Professional bodies/subject associations

- Other influential community members.

Invite members onto the steering group that are appropriate for the sectors you are targeting. In Australia, the Reef Guardians program has established dedicated working groups and steering committees for each program sector (fishers, farmers, graziers, councils and schools).
次: Tp

Advisory groups or committees with similar missions may already exist that you could recruit members from, such as community reference groups and government environment committees.

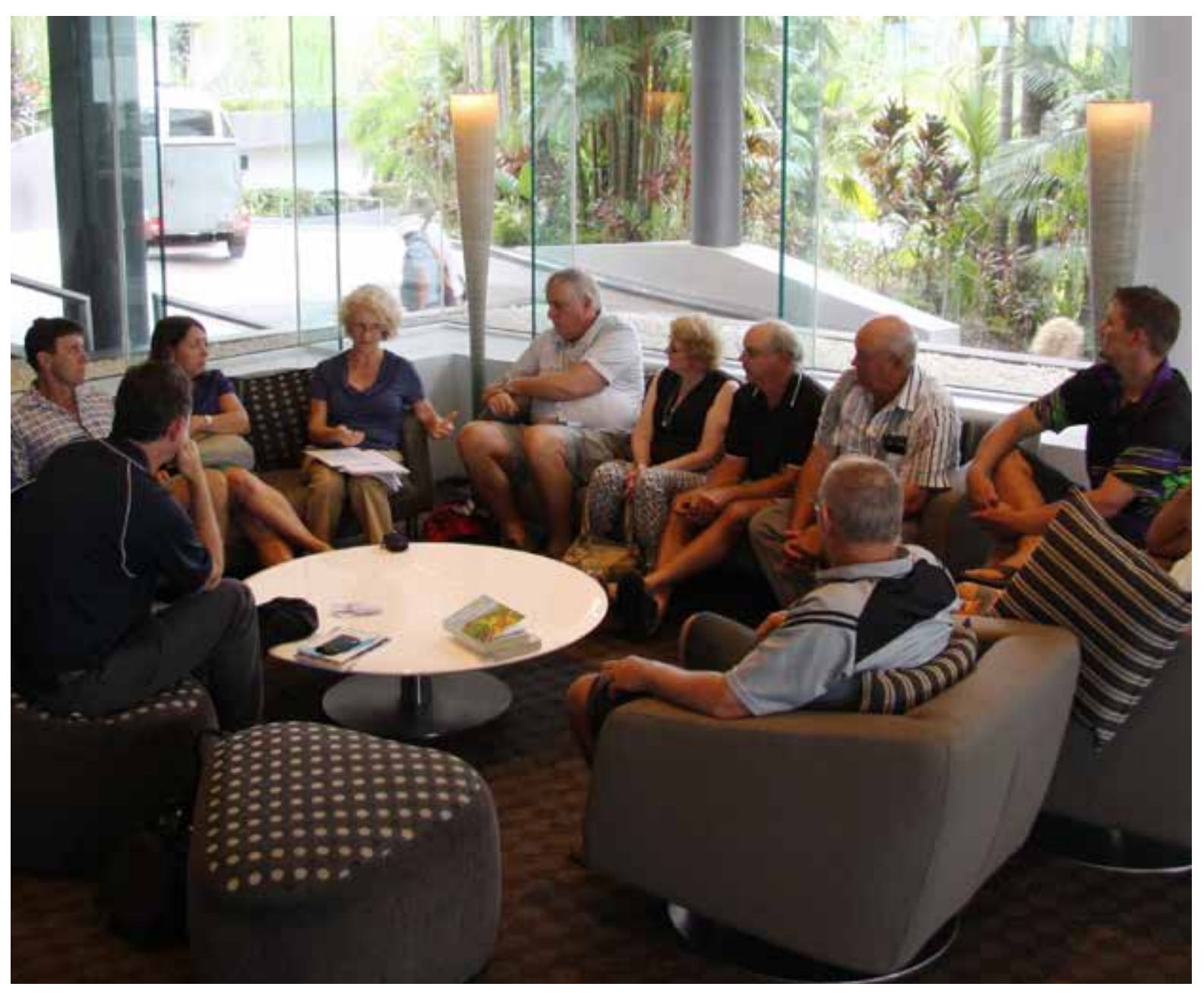




\section{How to establish a steering group}

Advisory and steering groups can be crucial to the success of your stewardship program. Below are some ideas and guidance relevant to establishing a steering or advisory group. Key considerations include composition of the group's membership, the time commitments required of members, establishing a charter for the group, and overall group size.

\section{Membership}

Steering group members need to be committed to contributing honest and informed feedback, and should represent a wide range of views and opinions. When inviting potential members to participate in the steering group, consider the following:

$\rightarrow$ Diversity: Try to include people from different geographical locations and sectors, possessing a range of skills, experience and expertise relevant to the program. Also make sure there are a variety of personalities - introverts and extroverts.

$\rightarrow$ Local values: The majority of the steering group membership should be local people, ensuring local knowledge, needs and values help to steer the direction of the program.

$\rightarrow$ Experience: Subject matter experts or regional representatives may also be able to offer expertise, knowledge and guidance beyond the local or regional level where this is deemed important to achieving the aims of the program. They may be members on the steering group or occasional visitors/participants to meetings.

$\rightarrow$ Influence: Including established leaders and other people with influence in the community can provide a credible status to the program and help with institutional support and recruitment of participants.

\section{Time commitments}

Steering group appointments are often voluntary, although you might like to consider whether it is necessary to cover travel costs or provide a small stipend. Different programs will draw more or less on their steering groups and members will have varied interest in being involved. It is important to remember that the committee may have to provide personal time and resources to the program, and thus you should establish up front any expected commitments from them, such as the frequency of steering group meetings, and the amount of time outside meetings required to fulfill their duties to the group. How often will you meet and for what purpose? Forming smaller working groups to discuss specific topics or issues in the pilot program can also help to reduce the frequency of steering group meetings particularly as the program expands. Don't just have meetings for meeting's sake! You should have clear goals and objectives each time you convene the group.

\section{Charter}

It is important to establish a charter or terms of reference for the steering group. This will clearly set out:

- The purpose and structure of the committee

- The roles and responsibilities of members

- The number of members

- Protocols for communication and reporting procedures

- Frequency and schedule of meetings, and

- Ground rules and decision-making mechanisms. 


\section{Group size}

Size has a big impact on the effectiveness of a group, and a balance should be sought that provides the best configuration for the program needs. A small group $(<5)$, if comprised of the right people, can provide strategic advice and give the project influence among the intended users. Meetings are easy to arrange and manage, and with less members involved it is easier to reach a consensus. Larger groups $(<10)$ can include a greater breadth of people, and thus a wider range of experience and perspectives can be tapped, especially from external sources. This can lead to greater influence within the intended community, but also increase the logistical challenges.

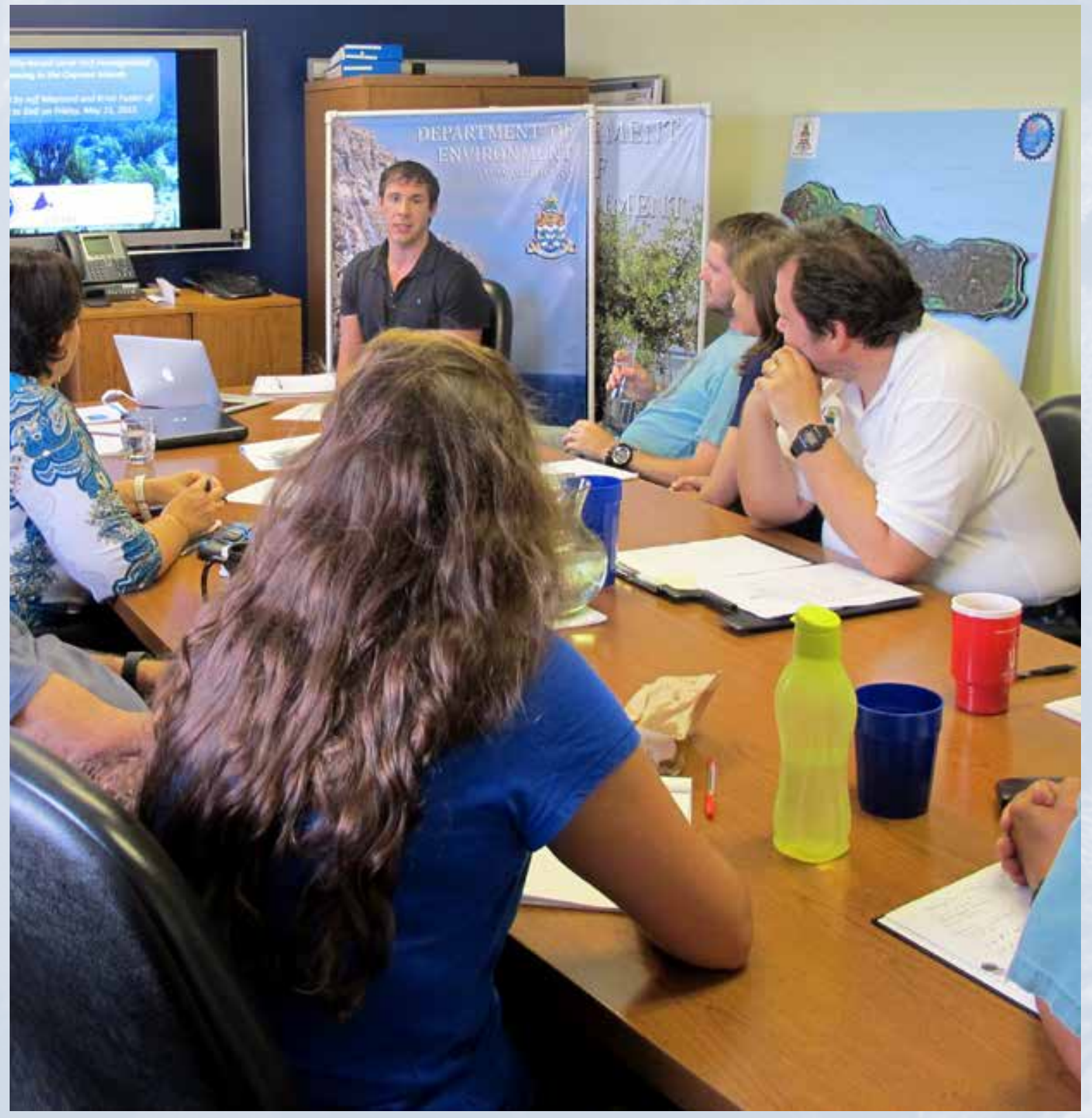




\section{Plan the program}

By now you have come halfway in your journey of implementing a stewardship program. You have:

$\checkmark$ Obtained a mandate from the host organisation

$\checkmark$ Developed a clear vision and framework for the program

$\checkmark \quad$ Identified sectors and behaviours you will target to address key issues

$\checkmark$ Gained commitment from participants to be involved in the program

$\checkmark$ Gained commitment and support from key stakeholders and partners to establish the program

$\checkmark$ Selected a local coordinator

$\checkmark$ Established a steering group

$\checkmark$ Gained more knowledge, input and feedback on the program from your advisory group and discovery session to inform your program planning.

This section is about refining your program framework and developing a detailed program plan through two steps:

\subsection{Program planning}

\subsection{Review your program plan.}

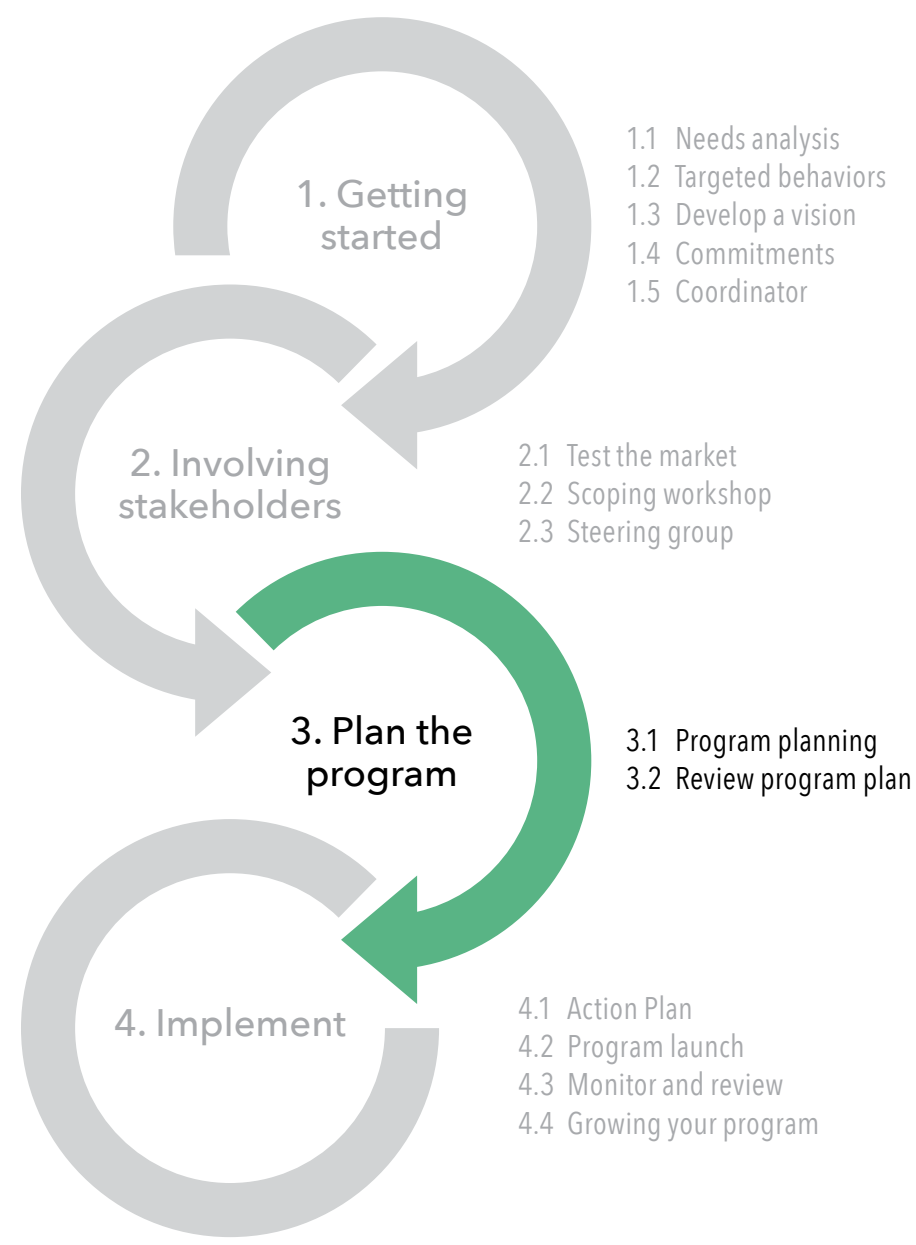

If you need further input or advice during this part of the process, you can utilise the steering group to help inform your decisions and plan the program together. This is also a juncture where you may especially benefit from seeking advice and sharing experiences with program coordinators or consultants involved in other stewardship programs.

\subsection{Develop a program plan}

A program plan provides the detailed description of actions and activities that will be done within the program to implement the strategies that will accomplish the program objectives. The plan is a key document for ensuring the program delivers tangible outcomes within available resources, and for maintaining clarity about roles, responsibilities and objectives among all involved.

The process of developing a detailed program plan involves mapping out the specific stewardship objectives and activities for the target participants, and outlining the resources, responsibilities and steps for achieving these objectives. The local coordinator should develop the program plan with support from the host organisation. It will be used for reporting requirements as well as monitoring and evaluating the success of the program. The program plan should remain in draft until you have proposed the plan to members of the steering group (Section 3.2). At this stage, the plan should focus on the pilot phase of the program. A program plan for beyond the pilot can be developed when more information on the success of the initiative becomes available. 
The more specific your plan, the more likely it will be implemented successfully. But it should also remain flexible enough to accommodate changes and feedback as the program progresses.

Your plan should include:

- Background information - Why is the program needed?

- Participants - How many people will participate in the pilot? From which sector/s? Is the program going to work with individuals, a part of an organisation or at a whole organisation level? For example, are you working with a class or group of students at a school, or the whole school?

- Objectives - What does the program aim to achieve (outcomes)? Use the SMART principles to ensure your objectives are the basis for a successful program (Figure 11).

- Strategies - What needs to be done to enable the program, its participants and the action? Ensure you identify what it will take to build and maintain the foundations for the program.

- Actions - Who will do what to implement the strategies and achieve the objectives and when will it be done? Like objectives, actions should be SMART.

- Resources - Personnel (time), funding and in-kind support required to successfully implement the actions.

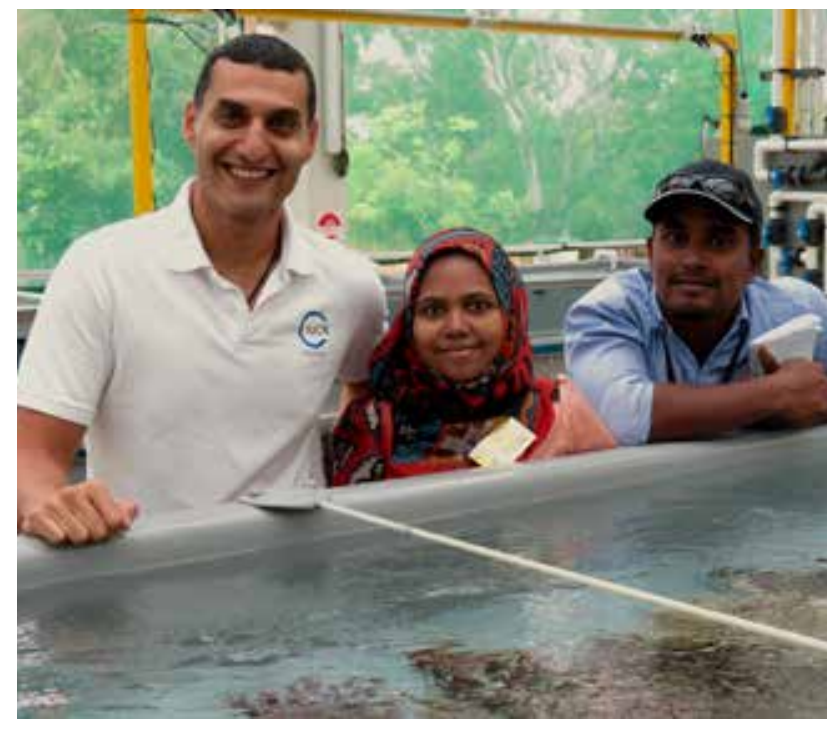

- Communication and outreach strategy - This can be a simple schedule outlining communication products, outlets, timing and target audience. This section should also include a stakeholder and issues management plan.

- Monitoring, evaluation and reporting - Indicators of performance, monitoring methods, reporting schedule, and evaluation and improvement process should be detailed.

The plan should also detail the standards of achievement for all actions, responsibilities of participants and coordinators, and inputs required from each party. A clear articulation of how the program aligns and supports strategies and priorities of the host organisation and partners can strengthen institutional support for the program. The plan should also describe the role of the program coordinator and how they fit into the host organisation.

Other considerations you might wish to include in your program plan, depending on its complexity and the expectations of the host organisation and partners, include:

- The governance structure, including roles and responsibilities of steering group members

- Information management strategy

- Staffing requirements - Where are key personnel employed, and what are their roles and responsibilities?

- Risk management, including implications of inadequate funding or institutional support, and changes in the availability of key individuals

- Identify dependencies or constraints such as funding, political support, need to coordinate with other initiatives or events

- Plan review process - How often will you review and update the plan?

Draft the plan entirely before presenting it to your steering group (see Section 3.2) for review and refinement. This will ensure efficient use of their time, and appropriate support for the actions within the plan. 


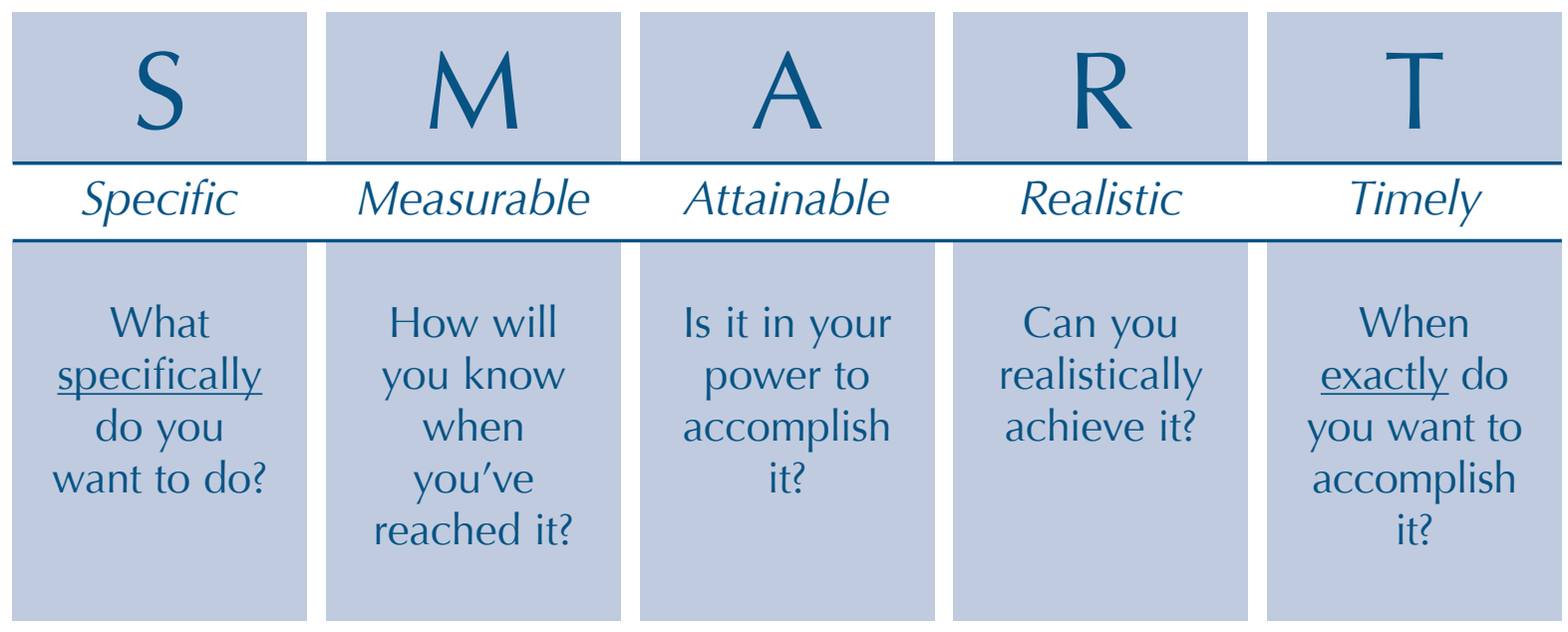

Figure 11: SMART objectives and actions are the foundation for a successful program plan.

\section{Further guidance for program planning}

Particular aspects of planning can be especially important to the success of stewardship programs, including communications and outreach, information management, monitoring and evaluation, and selection of performance indicators. Below is some guidance in these areas, drawn from experiences implementing stewardship programs in the Great Barrier Reef and the Caribbean region.

\section{Communications and outreach strategy}

Communications and outreach are central to the success of stewardship programs. Benefits of effective communications include:

- Raise the profile and credibility of the program

- Increase appeal of stewardship and attract new participants

- Play an instrumental role in implementation of behavioural change strategies

- Help build and sustain support from key public figures, host organisation and partners.

Your program plan will benefit substantially from a communications and outreach strategy. This should outline a clear framework for your communication activities and allocate roles and responsibilities (for the coordinator, host, participants, and other partners). What objectives and activities can be supported by communications? Who are the target audiences? How will you communicate with participants? How will you engage the public? What media will you engage with? Community events? What branding and/or materials will you develop? Be sure to have clear goals and timelines for all communication activities, and remember to monitor and evaluate the effectiveness of your communication and outreach activities for ongoing improvement.

For a reef stewardship program, your communications and outreach strategy should serve the following purposes:

- Communicate and promote the key messages of the program

- Promote actions by stewards to shift community norms toward sustainable behaviours by all

- Align stewardship messages with the interests and motivations of target groups

- Facilitate communication among participants, the steering group, community and other partners, and foster information exchange between these groups. Your strategy should also include key points of contact and methods for handling and responding to requests. 
- Provide promotion and recognition of participants' reeffriendly behaviours and the successes of the program.

- Increase community awareness and understanding about marine issues and actions that can help people to become part of the solution.

If your organisation has a media and communications team or representative, work with them to develop this strategy. They may also be able to help support activities in the strategy.

To help guide your thinking consider the following:

- Target groups and audience: These will be both internal and external to your organisation. Who do you want to inform about the program? Messages need to be tailored so that they are appropriate and interesting for different audiences.

- Key messages: What are the simple and clear ideas that summarise the essence of your program?

- Channels and tools: What tools, communication channels or activities will you use to achieve your goals? When considering activities, you should:

» Look for linkages with other similar initiatives and consider co-promotion with other established organisations

»Create opportunities to get local government representatives or politicians involved

»Create opportunities for different sectors of your program (if you are engaging with more than one sector) to network with one another.

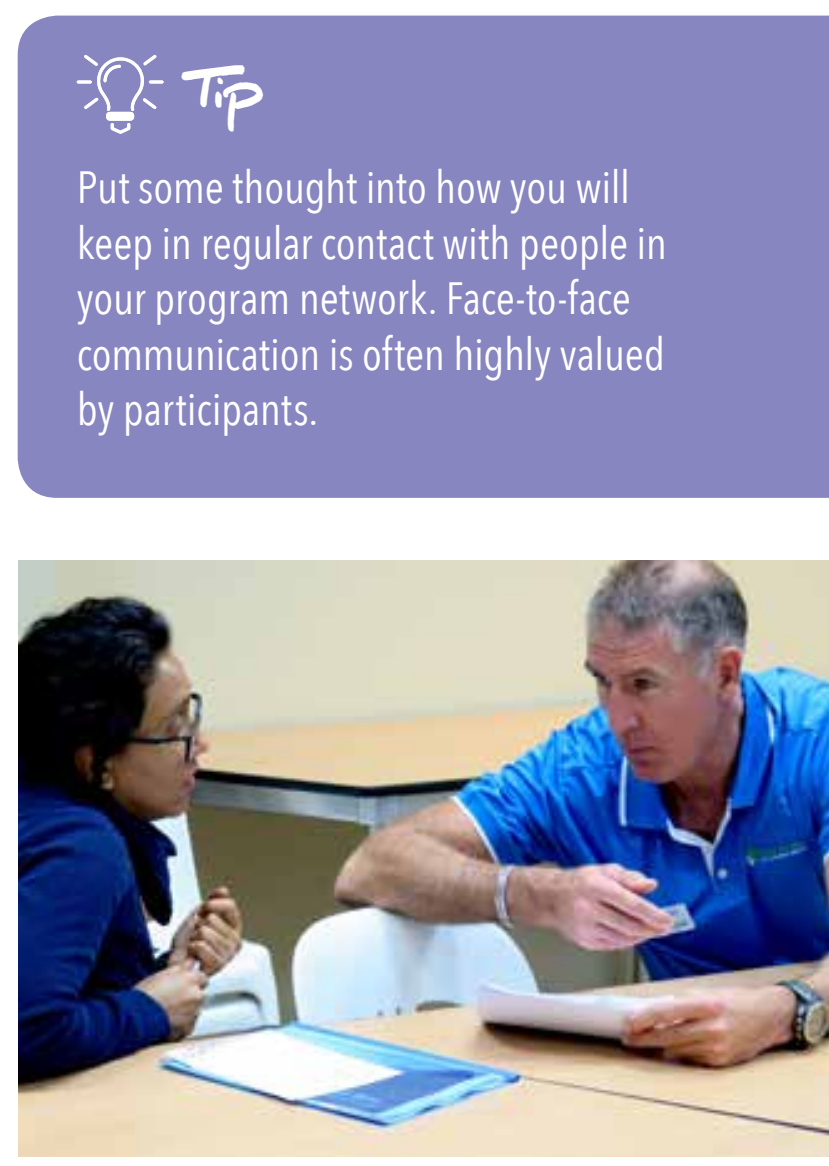

Remember, different tactics and tools are required for different audiences. If you have done a market segmentation analysis to better understand the range of attitudes and motivations of your community, you will be well placed to understand your audiences and target your communication efforts. A huge range of tools and tactics are available to help achieve communication objectives, just some of which include flyers, media (TV, newspaper, radio), publications, articles, newsletters, email promotion, website, participant resource packages, materials (e.g. keep cups, hats, shirts, badges, stickers) and program signage. Choose tools and tactics that will best help achieve each particular aim Remember that information and education needs to be linked to action in stewardship programs.

Strong and catchy branding has proved very successful in existing reef stewardship programs. From a stewardship perspective the brand should encapsulate the desired outcome, reflect the attitudes and behaviours of those who will want to identify with it and represent the 'promise' between all of those who become associated with the brand. The name of your program needs to resonate with your participants and community. It must be clear and visible and get people's attention.

The Reef Guardians brand developed for the Great Barrier Reef stewardship program has been very effective, in part because it intuitively describes the program vision and how people who are identified as Reef Guardians see themselves.

Considerations of intellectual property ownership and brand quality are important when choosing a program name. Associating your program with others of similar vision can help build a strong community of practice around reef stewardship, but you should seek necessary approvals before replicating the brand or image of other programs. It is wise to develop several ideas for branding to take to your steering group for feedback. 


\section{Information management strategy}

Managing information will be one of the biggest responsibilities for local coordinators. At the beginning of the project, try to imagine all the people that will want to access information over the life of the project and carefully consider how you will meet those needs.

It is good practice to track and document the information you gather during the pilot program; for example, outcomes of meetings, reports and products developed, images and media, and costs. This is important to help justify continued support and resources for the program in the future. Also note the timing of reporting requirements (to participants and the host organisation).

A website or area of your website can be set up to serve as an information and resource portal for your stewardship program. This can also serve as an archive of documents that are produced during the program (e.g. guidance materials, meeting records, media briefings, program reports, etc.).

It will also be important to ensure that you maintain records and files relating to the program in accord with the policies and standard practices of the host organisation. At the least, keeping notes and records that will enable others to maintain the program or replicate it at a later date will be crucial to its sustainability.

\section{Program monitoring and evaluation}

Your program plan should include monitoring activities to help you evaluate progress and adjust your plan as part of an adaptive management process (Figure 12). One of the most challenging aspects of developing the program plan will be deciding how to measure success at different stages of the program. Thinking about how you will measure success at the time when you are setting your program objectives will pay dividends here: monitoring, evaluation and improvement is much easier for SMART objectives (see Figure 11 on page 46).

It is important to begin by acknowledging the existing situation (prior to the implementation of the pilot program) to establish your baseline conditions. What behaviours are participants and the community currently engaging in for reef protection? What are the current conditions of the reef (e.g. water quality, coral cover, fish abundance) that you seek to improve through stewardship. The next step is to decide how you can measure changes from these baseline conditions. For example, if your approach is to encourage and influence behaviour change to protect water quality on the reef, how will you know if this has been successful? Counting the number of participants engaging in desired behaviours? Assessing improvements in the condition of key characteristics of the reef ecosystem? Be sure to choose indicators that can be measured using methods appropriate to the skills, resources, and time available to the program. Having monitoring tools and tactics in place from the start will set you up with clear signs as to whether you are heading in the right direction. Indicators of success may change over the course of the pilot so build in a review period to revise indicators as new information becomes available. 


\section{Indicators of success}

Choosing indicators can be a difficult task. It is important to get the right balance between data quality and efficiency; many indicators can provide accurate measures of the condition of a targeted behaviour or reef characteristic, but require technical skills or equipment or costs that are beyond the capacity of the program. The key is to choose indicators that can be readily monitored but which are still informative for program evaluation and improvement.

It will be useful to have indicators for each step in the 'causal chain' that links program inputs to on-ground outcomes. You may wish to use program logic (also called log frames or results chains) to explicitly link inputs, activities and outcomes (see Figure 7 on page 25). These logical frameworks are routinely used for program planning in the private and public sectors, and can be very useful for planning stewardship programs and, especially, for designing monitoring and evaluation plans.

You should aim to define indicators to track success in the delivery of inputs, implementation of activities, production of outputs, and for outcomes expected over the short, medium and long term.

\subsection{Review your program plan}

Now that you've developed a draft program plan, it's time to get input and advice from your steering committee. This step is important before finalising the plan with the host organisation and other management bodies as it helps to ensure:

- Steering committee members share the same vision

- Strategies and activities are achievable and within the scope of the pilot

- Timing of activities is appropriate and achievable

- Participants and partners in the program understand their roles and responsibilities

- Monitoring will enable timely review of progress and outcomes

- Key messages of the program are agreed

- Participating organisations feel ownership of the program concept and approach

- Steering committee members are given the opportunity to propose strategies and directions that have not been considered

- Stakeholder contribution is explicitly valued.

\section{What makes a good indicator?}

- Simple and easy to understand by both experienced users and the general public

- Representative, reflecting the current state of environmental problems

- Scientifically grounded, based on a well-developed scientific platform (appropriate geographic area and/or an appropriate interval of time) and flexible

- Measurable (in the case of quantitative indicators) with a simple measurement unit

- Comparable to current and past measures

- Long-term, taking into account possible future environmental changes

- Policy relevant

- Timely, leaving opportunity for action

- Results-oriented, focusing on measuring achievements

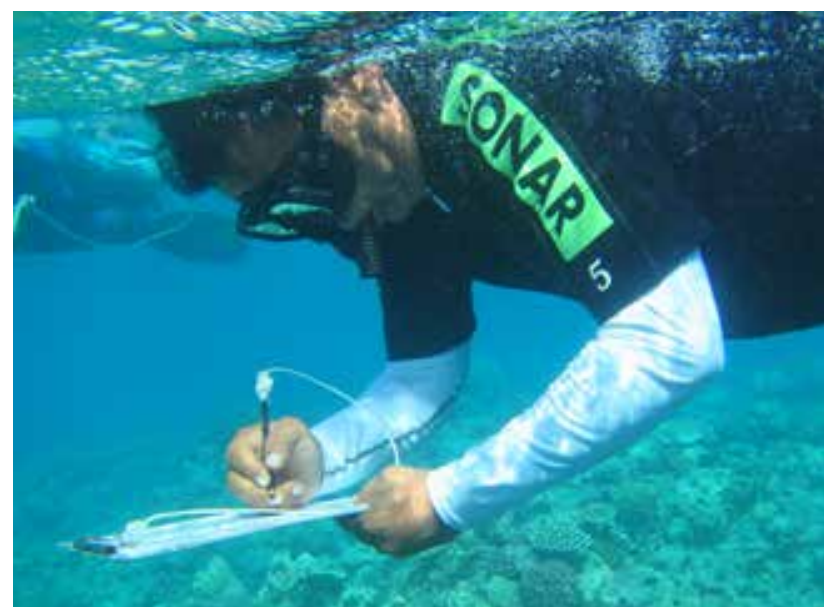


This will also be a good time to discuss the potential communication and outreach strategy for the program in detail. Discuss potential branding of the program:

- What should the initiative be called?

- What should the branding represent?

- Which promotional materials should be developed (e.g. signage, shirts, and hats)?

- Do members of the group have ideas for the launch of the program? If you have a launch date in mind, discuss this with the group to check they can participate.

If you have already developed possible titles and designs of the program branding, propose these ideas to the steering group and get their input. The use of prompts such as program signage has been successful in existing Reef Guardians programs. Signage should be located close in space and time to the target behaviour. Signage should be visible and easy to understand. It should encourage others to take up similar behaviours to contribute to reef protection.

Once the steering group has provided their feedback, agreement should be sought on key issues discussed (e.g. branding/logos, standards, resources, strategies and timelines).

The program plan should be updated to incorporate the group's views and opinions and submitted to management for final approval and sign off. This assures the plan is a shared vision of the program host and participants.

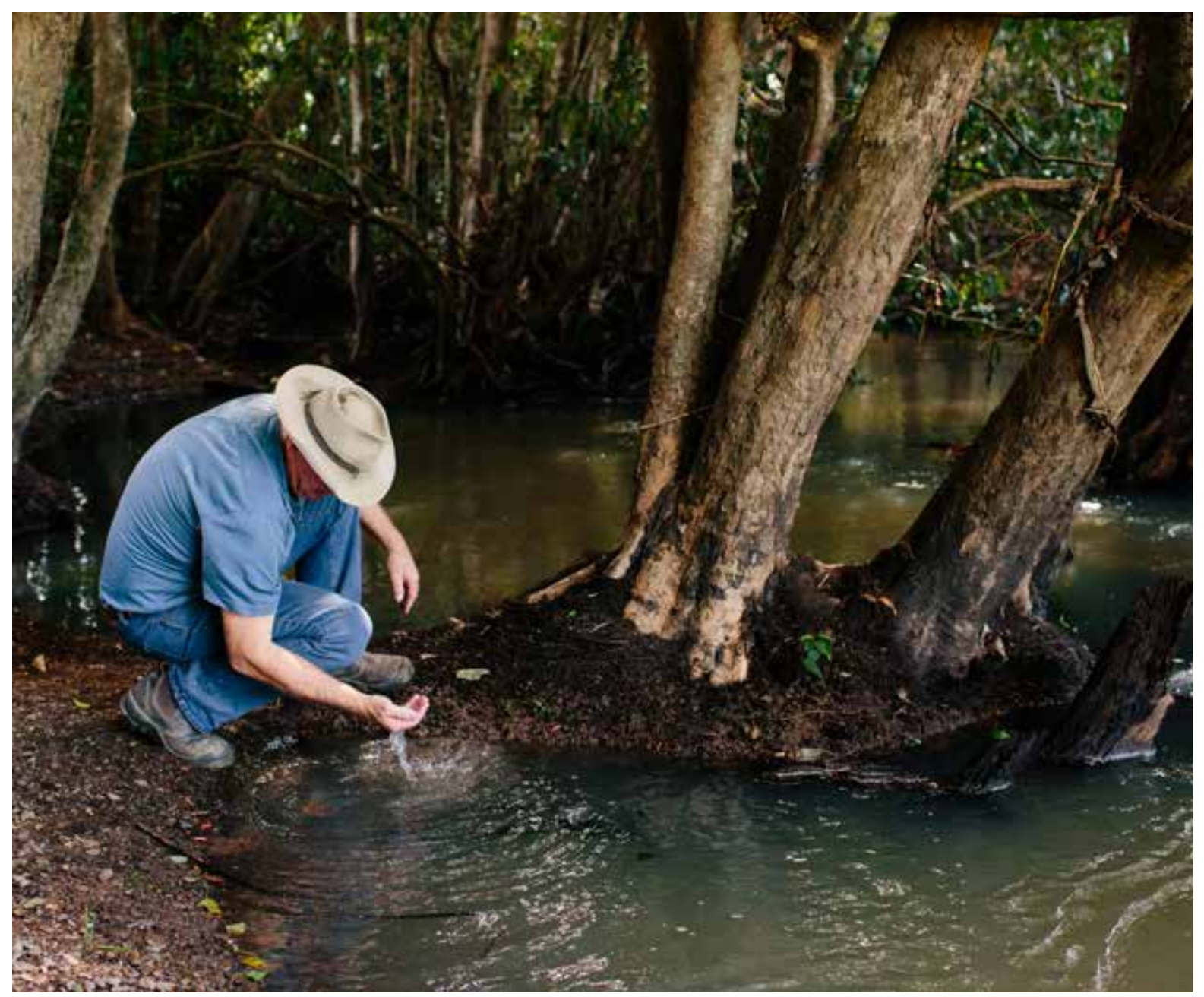




\section{Indicators and outcomes for your monitoring and evaluation plan: some suggestions}

Foundational (inputs, activity implementation and program outputs)

- Commitments received for necessary program resources (personnel, budget)

- Number of meetings facilitated by coordinator

- Number of people attending initial scoping meetings

- Number of participants signing up to program

- Change in awareness and understanding among participants about reef issues

- Completed audits of baseline conditions (existing reef-friendly behaviours)

- Advisory committee established

- Program plan formally endorsed by host organisation

- Monitoring and evaluation plan in place

- Size of audience reached in outreach activities

- Number of brochures and information products released

Short-term outcomes (1-2 years)

- Number of participants involved in new stewardship activities

- Number of new participants joining the program

- Increase in uptake of reef-friendly behaviours by community members

- Reduction in incidence of behaviours that cause stress to the reef

- Improvements in physico-chemical conditions affecting the reef

- Number of partnerships and level of support (cash and in-kind) from partners

- Instances of promotion of stewardship by individuals outside host organisation

- Change in awareness and understanding among participants about reef issues

\section{Medium-term outcomes (2-10 years)}

- Program has been launched in full (beyond pilot) with increased partnership

- Number of instances of participants promoting their stewardship practices

- Incidence of stewardship behaviours and participation across multiple sectors

- Number and quality of submissions to the review of stewardship program plan

- Increased compliance in marine and coastal management areas

- Instances of stewardship participants influencing best practices

- Recognition of participants for stewardship efforts (community awards)

- Reduction in incidence of behaviours that cause stress to the reef

- Improvements in physico-chemical conditions affecting the reef

- Improvements in ecological conditions on the reef

\section{Long-term outcomes (>10 years)}

- Increase in stewardship behaviours within the broader community (beyond the participants in the stewardship program)

- Improvements in ecological conditions on the reef

- Improvements in social conditions in reef-dependent communities

- Improvements in economic conditions in reef-dependent communities

- Increase in community-based reef monitoring

- Reef management organisation recognises the success of stewardship program through institutionalising the program and providing core budget support 


\section{Program implementation}

Implementation is the final step in bringing your program to life. This section provides guidance for working with participants to develop their action plans and the program evaluation framework, launching the program, reviewing the outcomes of the pilot, and implementing a broad-scale reef stewardship program beyond the pilot. There are four key parts to this process:

4.1 Develop action plans

4.2 Launch the program

4.3 Act, monitor and review

4.4 Grow the program.

\subsection{Developing action plans}

Action plans provide a crucial bridge between the program plan and the day-to-day activities of program participants, participating organisations and partners. They help ensure all participants as well as the project coordinator (and host organisation) have a shared understanding of the scope, timing and duration of activities, resources required and outcomes expected. Perhaps most importantly, they describe specific responsibilities, often down to the level of naming individuals against every action. An action plan will also make it easier to monitor and compare the progress of participants in the program, and will facilitate self-

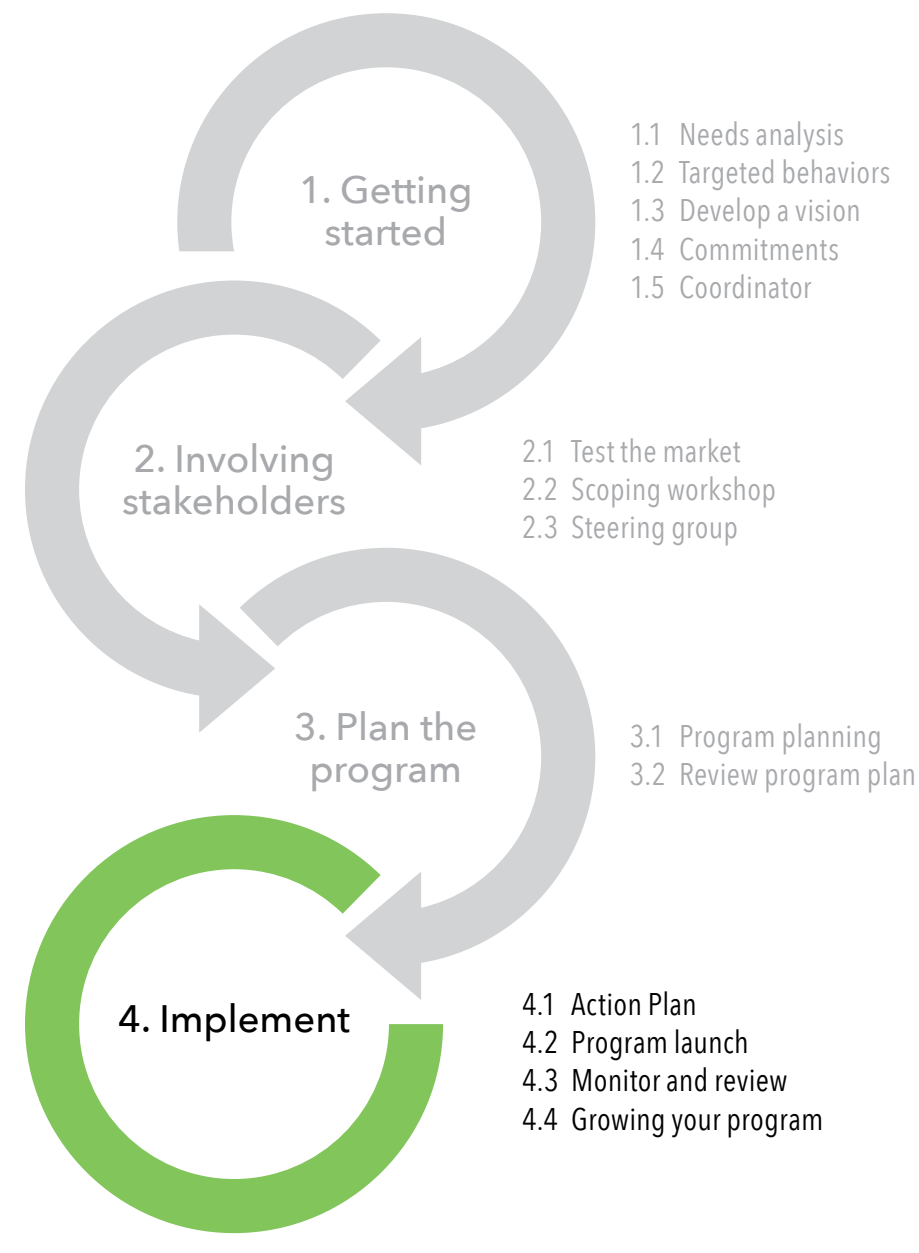
assessment and adaptation to changing conditions.

A baseline assessment will facilitate progress monitoring and evaluation. This section provides guidance for implementing an action planning process, and outlines steps for a baseline assessment.

\section{Action planning}

Action planning is a process for defining roles and responsibilities of program participants. The action planning process and resulting plan should recognise the practices that participants are already doing that align with the aims and objectives of the program, as well as defining additional activities and the steps required for implementation. It is important to include a site visit with participants in the action planning process to help everyone involved identify relevant actions already under way, and use these as a foundation for future activities (see "baseline assessment" on page 54).

An action plan template can help structure the process and provide a framework for the resulting action plan (see page 53 for further guidance in developing an action plan process). The template should include questions that guide the collection of information about the current situation, and to elicit desired outcomes from the participants. It can be important to reassure participants that their information will only be used for the purpose of the program and will not be made available to third parties.

A standardised action plan template can be applied throughout your program, but the specific circumstances and aspirations of different groups or sectors mean that each action plan will be unique. The program plan should build in points of review for assessing and updating action plans. The timing of this will be different for each program (e.g. six-monthly, annually or bi-annually). 


\section{How to structure an Action Plan template}

A template can be very useful to guide the development of action plans. The format and structure of your program's action plan template will depend on your vision and approach, including the sector/s you will engage with. The following is a guide to the information an action plan could contain. You might like to set up a simple form in Word or similar that contains your information fields and boxes or blank sections that you can fill in during the Action Planning session. The final content and structure of the action plan template should be agreed upon with participants and the steering group.

\section{Essential fields}

$\rightarrow$ Name of participant (individual or organisation) - make sure the details are correct to help with communication strategies.

$\rightarrow$ Contact and address details - this may include the use of geographical information systems to map the boundaries and/or activities of the property.

$\rightarrow$ Key contact information - if it is a large organisation, such as a school, who will be the key contact points? It is beneficial to have more than one contact to ensure communication and long-term success of the program, in case a person leaves the organisation.

$\rightarrow$ Online presence (e.g. websites or social media).

$\rightarrow$ Type of sector and category (e.g. farming - growing bananas).

$\rightarrow$ How many participants? This will pertain to larger organisations, such as local government or schools. How many staff? How many students?

\section{Other considerations}

$\rightarrow$ What activities are the participants currently doing to address reef issues (e.g. water, waste, biodiversity, energy)? You may like to provide examples of targeted behaviours for them to chose from as well as leave opportunity to identify other behaviours. Be mindful of the difference between HAVING (e.g. owning a recycling bin) and DOING (e.g. using the recycling bin properly). Remember - the program needs to be built on 'end-state' behaviours.

$\rightarrow$ What standards, practices or programs are they already recognised for? Perhaps they have won awards, passed assessments through their industry body, or are part of other programs and initiatives, such as industry leadership programs or best-practice programs.

$\rightarrow$ What activities would they like to implement or expand upon in the future through the program? What resources would they need to do this? Who is expected to provide this? What is the timeframe for implementation?

$\rightarrow$ How will they raise awareness and understanding of reef issues and best practice? How will they promote their involvement in the program to their peers and community (e.g. newsletters, signage, face to face, information boards, community events, networking meetings)?

$\rightarrow$ What other people and organisations are they already partnering with to achieve similar aims and objectives of the program (internal and external to the organisation)? 


\section{Baseline assessment}

An initial site visit or property assessment can help you to recognise what participants have already achieved and their existing skills and resources relevant to stewardship objectives. This is a key ingredient for development of an initial action plan. This gives a baseline of activities to build from. An evaluation of the participants' property and activities already under way - whether on the farm, in a school or as part of a business - provides a good foundation to begin the stewardship journey. Assessments can help to establish best practice, and uncover issues that could affect or be influenced by their sector.

Site visits are also a good time to collect stories that illustrate the issues, views or experiences of each participant, and images to illustrate these in program promotion and reporting. This information may contribute to your program communication or outreach strategies. Participants may also be interested to share their stories with others within their sector and community, such as at a program launch event.

Mapping can assist with evaluations and action planning, especially for sectors such as farming. Even simple maps can help to visually represent the boundaries of a property and activities that are occurring. They can also be an effective way of engaging certain participants and drawing out valuable information about current activities and locations or issues that could be the focus of future activities.

Follow-up assessments can be a valuable way of evaluating progress. The program coordinator should decide in collaboration with participants on the frequency of site visits. The results of follow-up assessments can be used to revise and adjust the program if conditions or objectives have changed. Any conclusions or adjustments can be captured in assessment reports, or simply used to update the action plan. Based on existing Reef Guardians programs, action plan templates and evaluation tools will be most useful when they are specific; developed with and for the sector that you are engaging. Discuss this with your steering committee to find the best way forward.

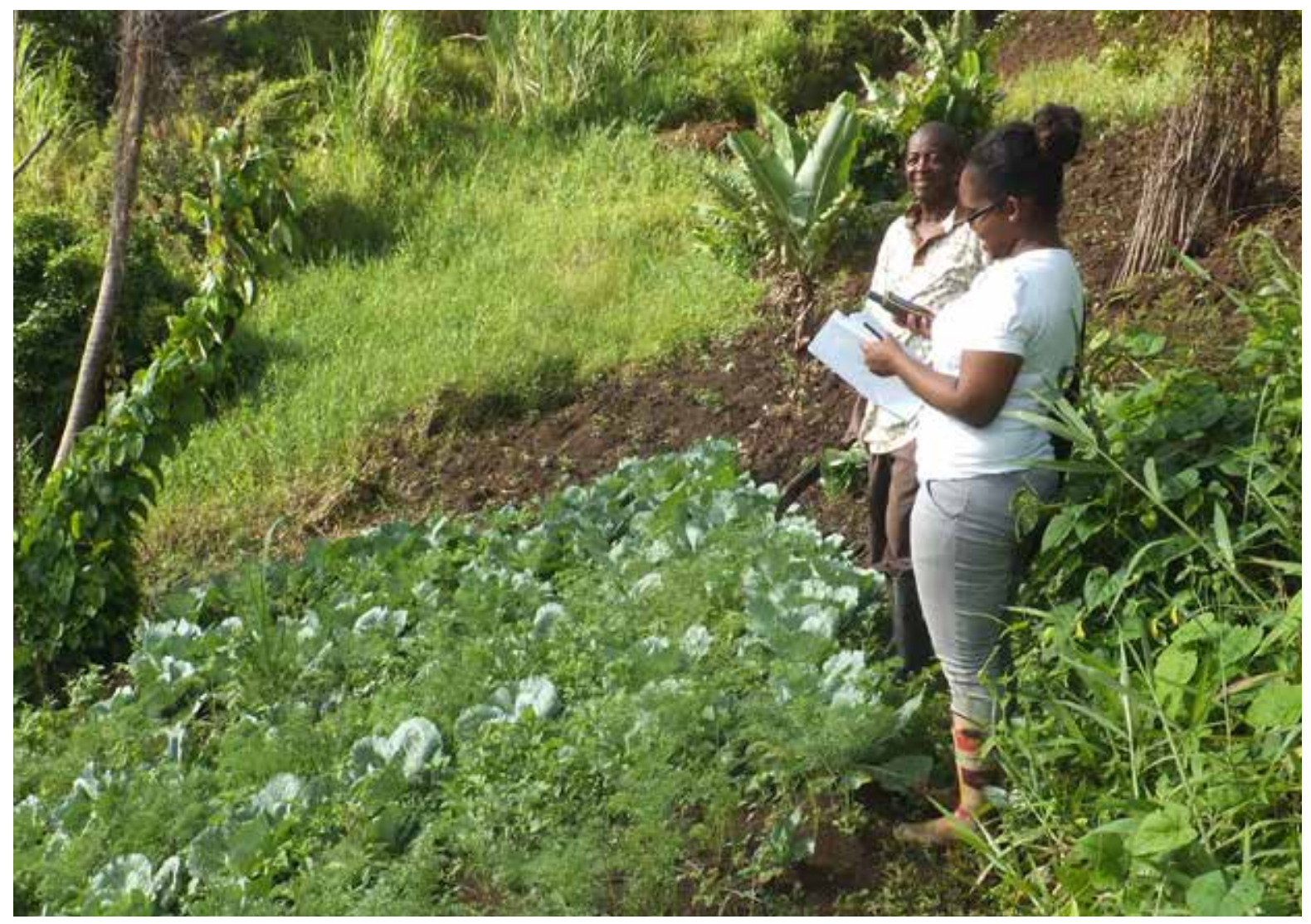




\subsection{Launch the program}

A program launch event can be an important way of raising community awareness of reef stewardship, building ownership and momentum amongst your participating sectors, and demonstrating the host's support for the program. Your communication and outreach strategy will help inform the scope and details of this event.

The program launch should be a celebration that attracts community attention, and recognises and promotes positive activities of the participants. It will also help to inform the community about the aims and objectives of the program. The launch will be most effective if it is a public event, which can help to get others interested in the program and potentially increase participation.

Key ingredients in a successful launch event include:

- Making the participants feel special

- Involving media - local, regional and/or national

- Helping participants, the host and other key stakeholders get to know one another

- Make it a community event (small or large scale) that creates a 'buzz'

- Highlight participants' reef-friendly behaviours by sharing stories of success. Perhaps participants can talk to the group about their experience and aspirations as reef stewards?

- Promote the key messages of the program and how others can get involved

- Focus on the positive actions people are doing rather than highlighting undesirable or negative behaviours

- Involve local, state and/or federal politicians

- Involve key stakeholders (e.g. from the steering group, host organisation, management authority, and other partner organisations).

By now you will have developed the branding (vision and title) of the program. The launch is the time to promote this. The launch may include a presentation of the program signage to participants to recognise their involvement in the initiative. The use of signage has proven successful for building a sense of identity and commitment to the program among participants. You may also like to use this opportunity to implement other forms of commitments such as public declarations or oaths. Reef Guardian Farmers in Grenada chose to read oaths that they had developed to the community as part of their commitment to joining the program.
次: Tip

When providing program signage to participants, include a guideline as to how you would like them to display this and follow up to make sure this has been actioned. Signage should be located close to where positive behaviours are occurring as well as be visible to participants and community.

-

Consider providing food and refreshments at the program launch or community gathering: sharing food can help bring people together and form supporting networks associated with your stewardship program.

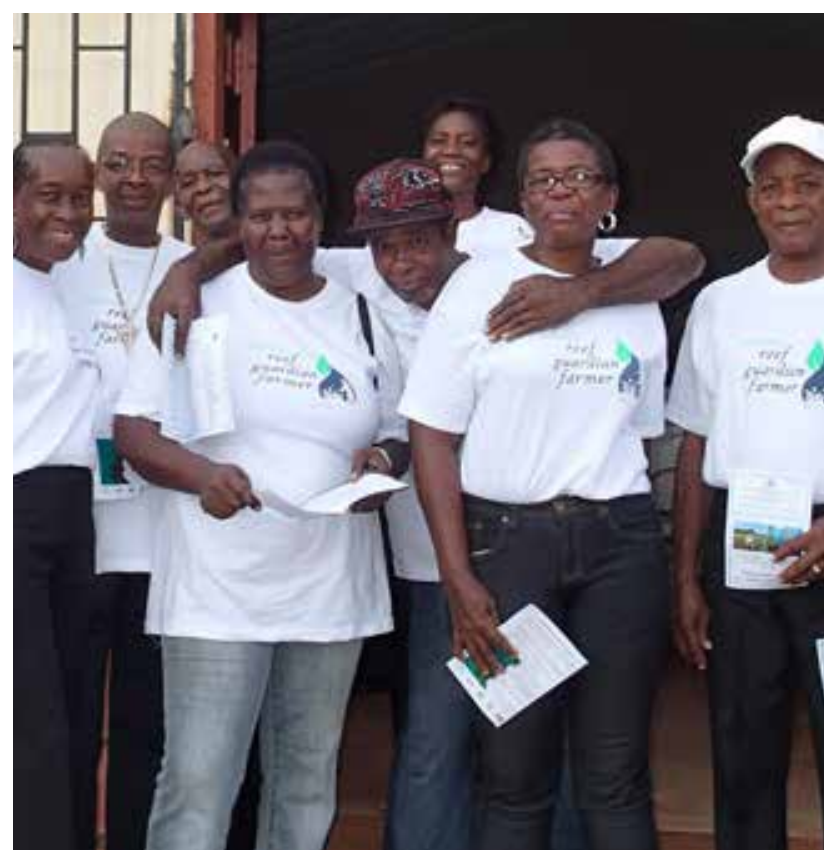


湿: 䖝

Make sure to manage expectations with

participants and stakeholders about

expansion of your stewardship program

beyond the pilot period. Explain to them

that you want to make sure you get it

right first before implementing on a

broader scale.

\subsection{Act, monitor and review}

After the program has been formally launched, the coordinator should continue to work through the strategies and activities in the program plan with participants, community and partners. The coordinator will be responsible for providing support to participants, direction on the program, and other resources as necessary. Maintaining contact with participants and building effective relationships is crucial to program success. The coordinator is also the contact point for participants to have ongoing input to program review and improvement.

Monitoring activities should be implemented in accord with the program plan. These create formal opportunities to review, reflect and realign program objectives and activities. Your steering group can help to assess, interpret and respond to monitoring results. A flexible approach to program implementation and providing regular opportunities for feedback will mean you can identify and address issues before they become too big or problematic.

Continue to evaluate how participants are progressing at intervals during the pilot and work to improve areas that need more attention. How often you review and evaluate participants' activities will depend on the length of your pilot.

Some questions that can help to structure your review, include:

- How are participants progressing against their action plans and the program plan?

- What targeted behaviours are they participating in?

- Are minimum standards being met? Has the benchmark increased?

- Have they got the resources and support to achieve what they proposed in their action plan?

- How are participants feeling about their involvement (self-reported outcomes)?

- What have been the initial benefits (environmental, social, cultural or economic)?

- Is there interest from more participants to join the initiative?

It will be important that you provide a final report to management, participants, the steering group and other key stakeholders and partners to share the outcomes of the pilot program. This will be a good opportunity to promote the level of participation and initial program successes with media. Taking the time to report on the pilot program can show management that you have adequately monitored, reviewed and assessed the effectiveness of the program. It can also give you the opportunity to propose continuation of the program in full, and to raise the possibility of expansion.

\subsection{Growing your program}

If your pilot program has been a success then you may be considering evolving it into a long-term initiative. Monitoring during the pilot program will help you collect data to assess the impact your program is having, and the ingredients required for program improvement and sustainability. The pilot program will help you decide:

- Whether the program met the aims and objectives it set out to achieve

- Opportunities for improvement

- How many participants and sectors you would like to engage with using the most relevant strategies

- Tactics for expansion, e.g. what resources and support will you need? 
- Where you will find support and resources to implement the next phase of your program beyond the pilot

- The duration of the next phase of the program.

It is likely that you will begin to think about continuation of the program before the pilot reaches its planned finish date. Regular monitoring, reviewing and assessing of the outcomes against the program aims will help assess success and prepare everyone involved for possible continuation of the program, and assist with a smooth transition from pilot to ongoing, sustainable program.

You may find that the guidance in this document — the framework (Part A) and step-by-step guide (Part B) will also help you plan for a continuation of the program beyond the pilot phase. A formal review of the program plan (involving participants and the steering group) and a proposal for continuation will help secure the support required for a transition to the next phase of the program.

Working with participants, partners and the steering group to identify and secure long-term support and resources for the program will show your commitment to the program and allow you to pursue increasingly substantive outcomes as part of a longer-term vision. Securing institutional and funding support for at least two years is recommended for program continuity.

\subsection{The road to resilience}

Coral reef management has entered a new era in which environmental and social changes are altering reef ecosystems at an unprecedented rate. In a world dominated by uncertainty and change, community stewardship has the potential to be a core strategy for building resilience in complex social-ecological systems like coral reefs. By fostering community stewardship, coral reef managers can harness the power of people who have a strong vested interest in the future of coral reefs. At the same time, involvement in stewardship activities builds social resilience through improved capacity and networks, greater involvement in decisionmaking processes, increased access to knowledge and heightened sense of control or agency ${ }^{1}$.

Fostering community stewardship is an ongoing journey, but helping people work together to improve the outlook for coral reefs and communities can be one of the most rewarding aspects of coral reef management. We hope this guide has given you the knowledge, confidence and tools to help you develop your own stewardship program.

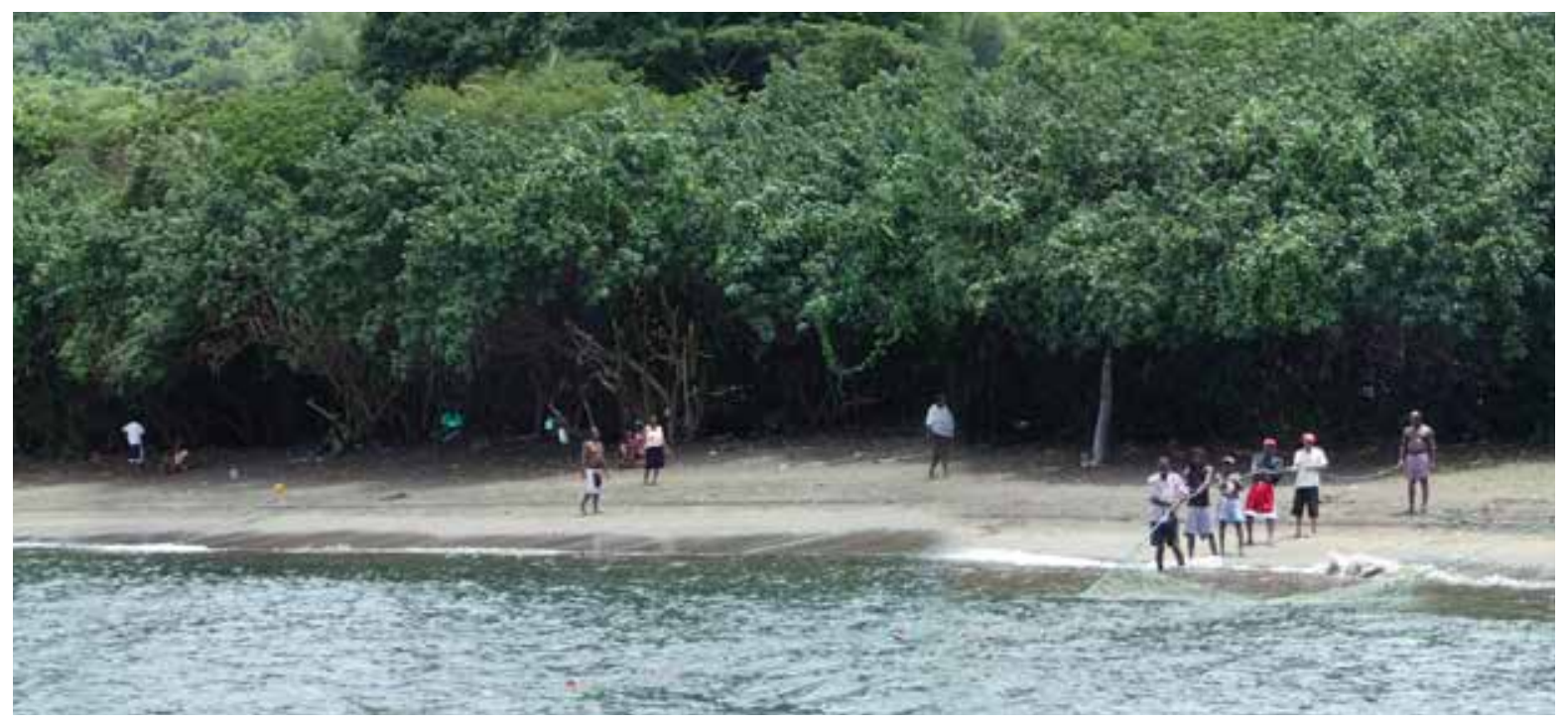

Marshall, N. A., and P. A. Marshall. 2007. Conceptualizing and operationalizing social resilience within commercial fisheries in northern Australia. Ecology and Society 12(1): 1. 


$$
=-5 \div-\infty
$$
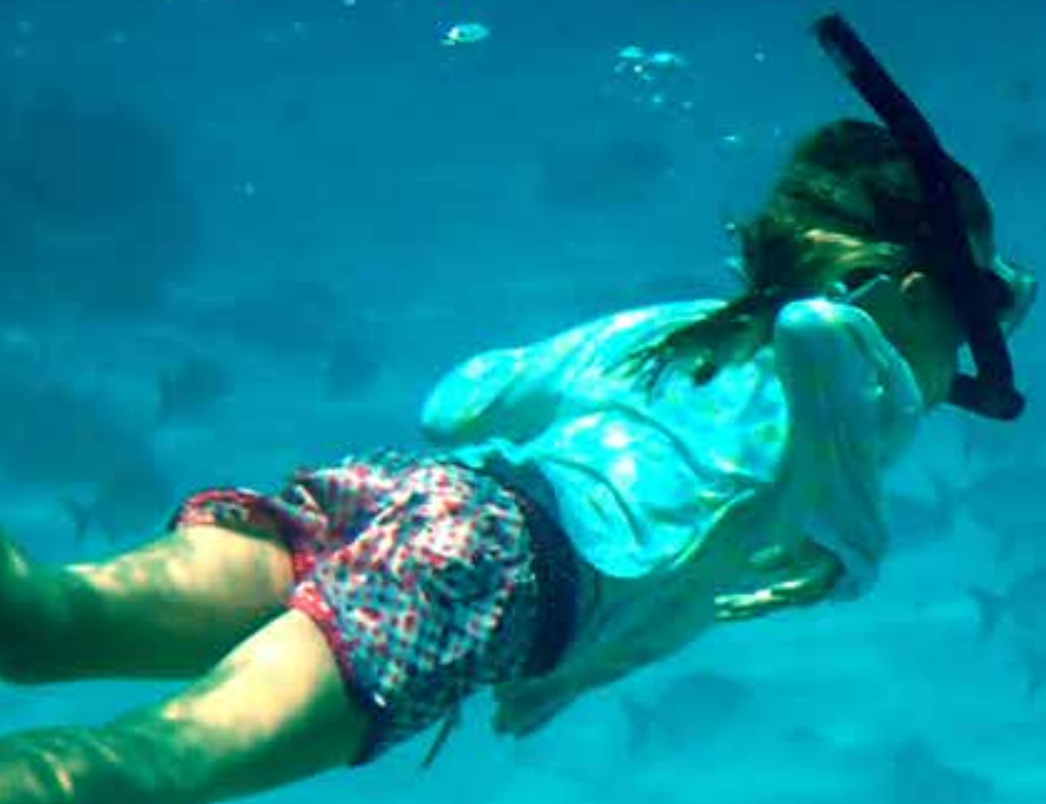

$\gamma$

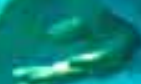

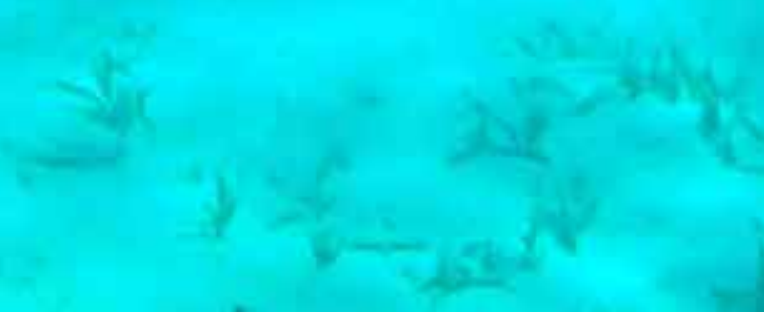




\section{Part C: \\ References \& Additional Resources}

\section{References}

Awjzen, I. 1991. The theory of planned behavior. Organizational behavior and human decision processes. 50, 2 (1991), 179-211.

http://dx.doi.org/10.1016/0749-5978(91)90020-T

Akerlof, K. and Kennedy, C. 2013. Nudging toward a healthy natural environment: How behavioural change research can inform conservation, George Mason University, 90 pp. http://climatechangecommunication.org/sites/default/files/ reports/NudgesforConservation_GMU_061013.pdf

Beeden, R. , J. Maynard, J. Johnson, J. Dryden, S. Kininmonth, and Marshall, P. 2014. No-anchoring areas reduce coral damage in an effort to build resilience in Keppel Bay, southern Great Barrier Reef. Australasian Journal of Environmental Management, 7, 1-9.

http://dx.doi.org/10.1080/14486563.2014.881307

Berkes, F., Mahon, R., McConney, P., Pollnac, R. and Pomeroy, R. 2001. Managing small-scale fisheries: Alternative directions and methods, International Development Research Centre (IDRC), Canada, 320 pp.

Link: http://www.idrc.ca/EN/Resources/Publications/openebooks/310-3/index.html

Borhan, M.T.B. 2011. Promoting environmental stewardship through project-based learning (PBL), Department of Planning, Aalborg University, Denmark Faculty of Education and Human Development, Sultan Idris Education University, Malaysia. Link: http://www.ijhssnet.com/journals/Vol._1_No._4;_April_2011/23.pdf

Brown, D.N. and Pomeroy, R.S. 1999. Co-management of CARICOM (Caribbean Community) fisheries, Marine Policy 23: 549-570.

http://dx.doi.org/10.1016/S0308-597X(98)00040-2

Chapin, F.S. III et al. 2009. Principles of ecosystem stewardship: Resilience based natural resource management in a changing world, pp. 149-170, Springer. Link: http://www.springer.com/environment/ environmental+management/book/978-0-387-73032-5

Chapin, F.S. III et al. 2010. Ecosystem stewardship: Sustainability strategies for a rapidly changing planet, Trends in Ecology and Evolution 25 (4). Link: https://dash.harvard.edu/bitstream/handle/1/9774650/Clark_ EcosystemStewardship.pdf

Commonwealth of Australia, 2015. Reef 2050 Long-Term Sustainability Plan, http://www.environment.gov.au/marine/gbr/long-term-sustainability-plan

Danielsen, $\mathrm{F}$ et al. 2007. Increasing conservation management action by involving local people in natural resource monitoring. AMBIO: 36: 566-570.

http://dx.doi.org/10.1579/0044-7447(2007)36[566:ICMABI]2.0.CO;2

Dobson, A. 2007. Environmental citizenship: Towards sustainable development, Wiley InterScience.

Dyer, CL.; McGoodwin, J.R., ed. 1994. Folk management in the world's fisheries. University Press of Colorado, Niwot, CO, USA.

Gifford, R., Kormos, C., and McIntyre, A. 2011. Behavioral dimensions of climate change: Drivers, responses, barriers, and interventions, Wiley Interdisciplinary Reviews: Climate Change 2 (6): 801-827.

Great Barrier Reef Marine Park Authority. 2012. Reef Guardians: Working together today for a healthier reef tomorrow. Link: http://elibrary.gbrmpa.gov.au/jspui/handle/11017/620

Great Barrier Reef Marine Park Authority. 2012. Reef Guardian Program Review FINAL. Clear Horizon Consulting. Link: http://www.gbrmpa.gov.au/_data/assets/pdf_file/0020/28406/GBRMPA-Annual-Report-2011-12.pdf 
Hernandez, M. 2007. Stewardship: Theoretical development and empirical test of its determinants, Doctoral dissertation, The Fuqua School of Business, Duke University, Durham, USA. Link: http://dukespace.lib.duke.edu/dspace/ bitstream/handle/10161/177/D_Hernandez_Morela_a_052007.pdf

Jentoft, S. and McCay, B.J. 1995. User participation in fisheries management. Lessons drawn from international experiences, Marine Policy 19: 227-246.

http://dx.doi.org/10.1016/0308-597X(94)00010-P

Johannes, R.E. 1978. Traditional marine conservation methods in Oceania and their demise, Annual Reviews of Ecology and Systematics 9: 349-364.

http://dx.doi.org/10.1146/annurev.es.09.110178.002025

Johannes, R.E., Lasserre, P., Nixon, S.W., Pliya, J. and Ruddle, K. 1983. Traditional knowledge and management of marine coastal systems, Biology International, Special issue 4.

Killam, D. 2004. Groupworks: Getting things done in groups. Vision, Missions, Goals and Objectives. Bulletin \#6107. University of Maine. Link: http://umaine.edu/publications/6107e/

Marshall, N. A., and Marshall, P. 2007. Conceptualizing and operationalizing social resilience within commercial fisheries in northern Australia. Ecology and Society 12(1): 1. http://www.ecologyandsociety.org/vol12/iss 1/art1/

Mathijs, E. 2002. Social capital and farmers' willingness to adopt countryside stewardship schemes, Centre for Sustainable Development in Agriculture (CENDO), Katholieke Universiteit Leuven, Leuven, Belgium.

Link: http://www.ifmaonline.org/pdf/congress/Mathijs\%202.pdf

Mickelson Consulting Inc. 2013 (March), Community engagement report: Communities adapting to climate change initiative, District of Sparwood, Port Moody, BC, Canada.

Link: http://adaptationresourcekit.squarespace.com/storage/SparwoodSummaryReport.pdf

Pinkerton, E., ed. 1989. Cooperative management of local fisheries: new directions for improved management and community development. University of British Columbia Press, Vancouver, BC, Canada.

Pregler, C. 2006. Building capacity for community stewardship into Bureau of Land Management training, The Partnership Series, Phoenix, AZ, USA.

Link: http://www.doi.gov/partnerships/tools/upload/Building-Capacity-into-BLM-Courses.pdf

Ross et al. 2009. Co-management and Indigenous protected areas in Australia: achievements and ways forward. Australasian Journal of Environmental Management. 16, 4 (2009).

http://dx.doi.org/10.1080/14486563.2009.9725211

Volker, G. 2011. Stewardship behavior and creativity, Management Revue 22 (3): 274-296.

Link: http://www.hampp-verlag.de/hampp_e-journals_mrev.htm 


\section{Additional resources}

Evaluation forms can help program managers engage with participants by assessing stewardship opportunities and recognising behaviours or actions already in place that are contributing to reef stewardship goals. The example below was developed for the Reef Guardian Farmers program in Grenada, based on similar approaches used in the GBRMPA program.
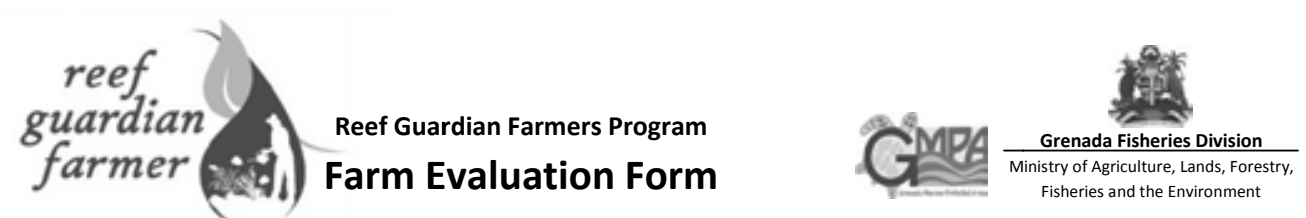

Farmer Information

First name

last name

$\square \mathrm{M} \quad \square \mathrm{F}$

Home address

Telephone

Mobile

Email

\section{Farm Information}

Type of farm

Location

GPS Coordinates

size of farm

Topography

Accompanying photo (Attach to this form)

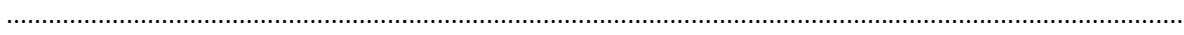

Crops cultivated $\square$

.

(n)

What is the main market for your produce?

$\square$ Farmers market $\square$ Supermarkets

$\square$ Industry (please describe)

Additional notes (are there additional workers?)

\section{Animals reared $\square$}
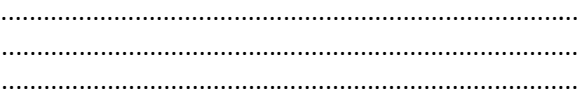

$\square$ Private stall

$\square$ Other (please describe)

...........

...................................

$\cdots$

Activities / practices

\section{Crop cultivation}

A Planting

Type of crop beds

Contour $\square$ Other

(describe slope)

Page 1 of 4 


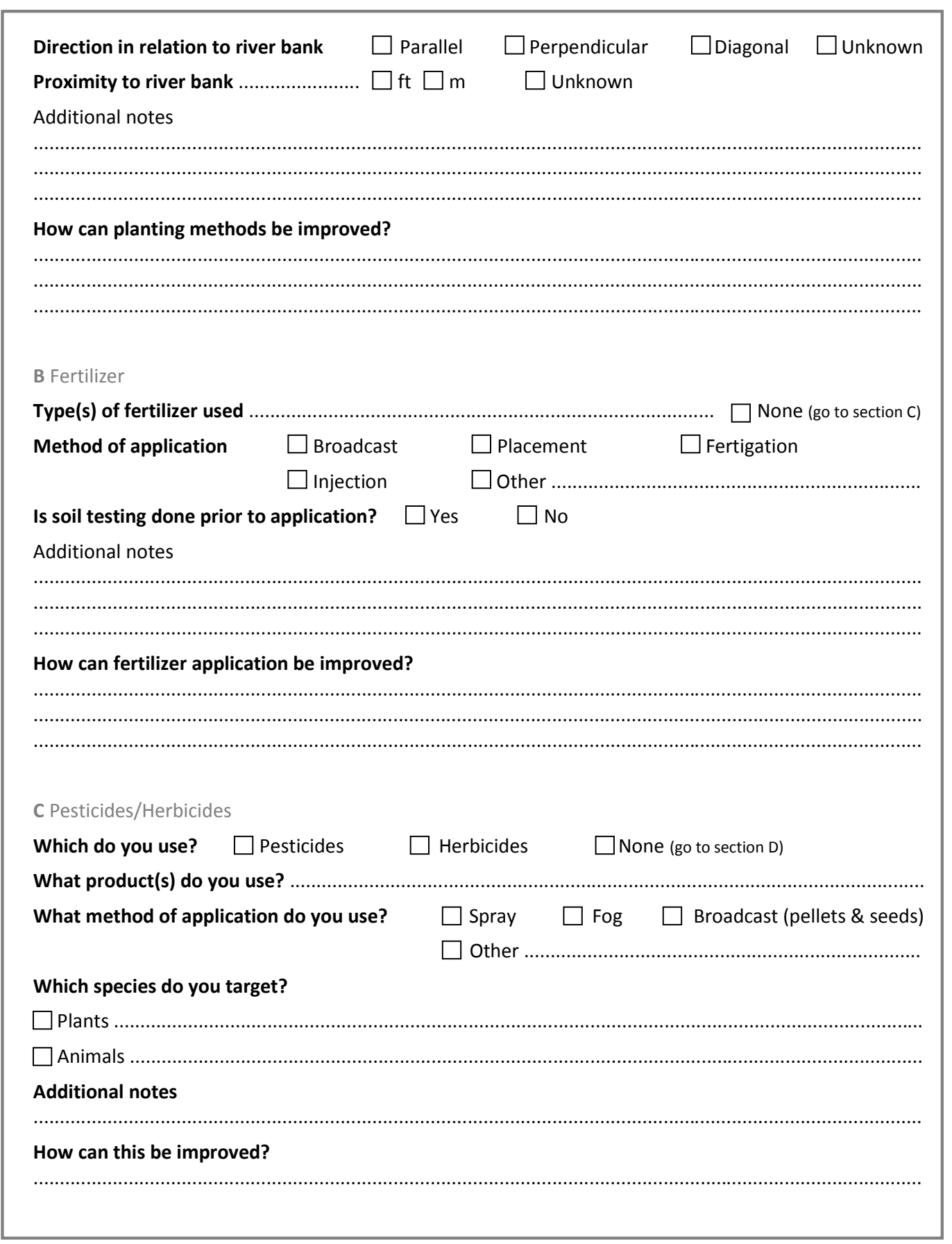

Page 2 of 4 
D Drainage

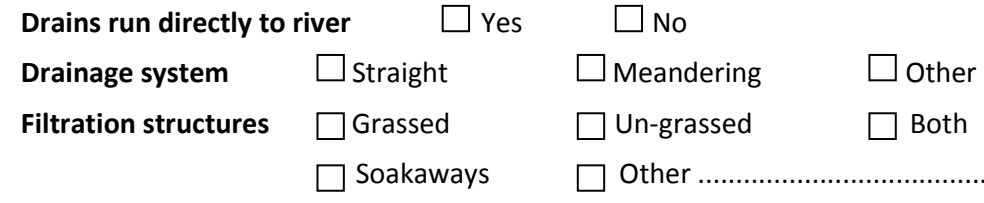

\section{Additional notes}

How can the drainage system be improved?

\section{Livestock rearing \\ A Housing \\ Housing type(s) used $\square$ Free range (tied) $\square$ Fenced area (pen) $\square$ Closed housing (coops, pens, stalls,etc) $\square$ Other .....}

Type of feed $\quad \square$ Commercial pellets $\quad \square$ Natural vegetation $\quad \square$ Kitchen waste

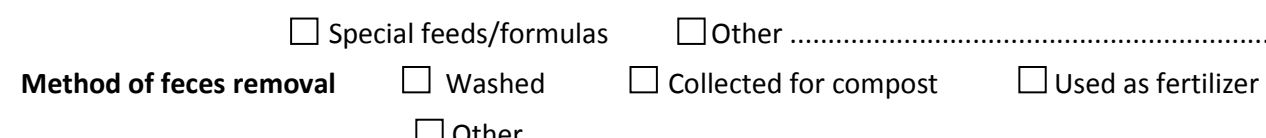

\begin{tabular}{|c|c|c|c|}
\hline Drains run directly to river & $\square$ Yes & \multicolumn{2}{|l|}{$\square$ No } \\
\hline Drainage system & $\square$ straight & $\square$ Meandering & $\square$ other. \\
\hline \multirow[t]{2}{*}{ Filtration structures } & $\square$ Grassed & $\square$ Un-grassed & $\square$ Both \\
\hline & $\square$ Soakaways & $\square$ Other ... & \\
\hline
\end{tabular}

\section{Additional notes}

How can the drainage system be improved?

Page 3 of 4 
(1)

1.

Other Information

Are there buffer zones close to the river banks?

Yes $\square \quad$ No $\square$

Do you compost waste material?

Yes $\square$

No

Additional environmentally friendly practices

I hereby acknowledge that the information stated above is true and is an accurate account of agricultural activities and practices carried out on my property. I also grant permissionto the Grenada Fisheries Division to use the above information for public awareness, education and other purposes.

$\mathrm{X} . . .$.

Signed
...........................

Page 4 of 4 

